\title{
OPTIMIZED SUPERCONDUCTING QUADRUPOLE ARRAYS \\ FOR MULTIPLE BEAM TRANSPORT
}

\section{DOE STTR Phase I Final Report \\ DE-FG02-04ER86205}

September 20, 2005

Advanced Magnet Lab, Inc 328 A West Hibiscus Blvd.

Melbourne, FL 32901

Authors:

Rainer B. Meinke (RBMeinke@dhmagnets.com)

Carl L. Goodzeit (carl@dhmagnets.com)

Millicent J. Ball (penny@dhmagnets.com)

Keywords: superconducting magnets, quadrupole arrays, multiple beam transport, inertial fusion

\begin{abstract}
This research project advanced the development of reliable, cost-effective arrays of superconducting quadrupole magnets for use in multi-beam inertial fusion accelerators. The field in each array cell must be identical and meet stringent requirements for field quality and strength. An optimized compact array design using flat double-layer pancake coils was developed.

Analytical studies of edge termination methods showed that it is feasible to meet the requirements for field uniformity in all cells and elimination of stray external field in several ways: active methods that involve placement of field compensating coils on the periphery of the array or a passive method that involves use of iron shielding.
\end{abstract}

Project period: 9/1/2004 to 4/12/2005 


\section{OPTIMIZED SUPERCONDUCTING QUADRUPOLE ARRAYS FOR MULTIPLE BEAM TRANSPORT}

\section{DOE STTR Phase I Final Report \\ Table of Contents}

Section

1.0 Significance and Background Information..................................... Page 2

1.1 Significance of the Problem and Technical Approach........................ Page 2

1.2 Anticipated Public Benefits............................................................. Page 3

2.0 Phase I Project Details ...................................................................... Page 3

2.1 Edge Termination Schemes ............................................................. Page 5

2.2 Field Quality …................................................................................. Page 9

2.3 Array Mechanical Structure and Cryostat........................................... Page 13

2.4 Phase I Study Conclusions.............................................................. Page 14

3.0 Personnel and Facilities............................................................... Page 15

3.1 Principal Investigator and Other Key Personnel .............................. Page 15

3.2 Facilities and Equipment.......................................................... Page 18

3.3 Consultants and Subcontractors …................................................ Page 18

Appendix Documents:

Parametric Study of Quadrupole Array Field Uniformity (11/26/04)

[MathCAD study results] . . . . . . . . . . . . . . . . Page 20

Optimization of Quadrupole Array Field Uniformity (1/24/05)

[description of the EXCEL-based computer procedure] . . . . . . Page 42

Quadrupole Array Design

[description of the array mechanical structure to study] . . . . . P Page 56

Optimization of Quadrupole Array Field Uniformity (1/24/05)

[EXCEL-based calculation for the array structure] . . . . . . . Page 83

Field Uniformity Optimization of a 3x3 Quadrupole Array (2/28/05)

[Results of further EXCEL-based calculations] . . . . . . . . . Page 95

Using an iron Shield in a 3x3 Array (pt.2) (3/25/05)

[Results of AMPERES analysis] . . . . . . . . . . . . Page 126 


\section{OPTIMIZED SUPERCONDUCTING QUADRUPOLE ARRAYS FOR \\ MULTIPLE BEAM TRANSPORT}

Topic 3. Paragraph a

\section{SIGNIFICANCE AND BACKGROUND INFORMATION}

\subsection{Significance of the Problem and Technical Approach}

The ultimate goal of the project research is to develop affordable, fully functional arrays of superconducting quadrupoles for multi-beam transport and focusing in heavy ion fusion (HIF) accelerators. Previous studies ${ }^{1}$ have shown that the multi-beam transport system, consisting of alternating gradient quadrupole magnets, a beam vacuum system, and the beam monitor and control system, will likely be one of the most expensive and critical parts of such an accelerator. This statement is true for near-term fusion research accelerators as well as accelerators for the ultimate goal of power production via inertial fusion. For this reason, research on superconducting quadrupole arrays is both timely and important for the inertial fusion energy (IFE) research program. Such research would also benefit near-term heavy ion fusion facilities such as the Integrated Research Experiment ${ }^{2}$ (IRE) and/or the Integrated Beam Experiment ${ }^{3}$ (IBX).

The superconducting quadrupole arrays needed for heavy ion fusion accelerators differ significantly from quadrupoles for single-beam focusing, commonly used in particle accelerators for high-energy physics experiments. While maximizing the field strength and field quality is a prime consideration for high-energy particle accelerators, minimizing the transverse dimensions of the quadrupole array is uniquely important for multi-beam fusion accelerators. Since heavy ion fusion accelerators have to compete with other technologies for energy generation, economy of the individual cells of the beam transport system, including the vacuum, is of utmost importance.

The field strength and uniformity of the quadrupole cells in an array are strongly affected by neighboring cells due to magnetic flux sharing. Cells located at the periphery of an array are not fully surrounded by other cells and their fields differ from the fields in center cells of the array. Furthermore, the stray magnetic field of the array needs to be highly suppressed to prevent coupling between the array and the magnetic material in the induction cores. Additional coils, referred to as the "edge termination scheme", are therefore required to correct the field in the array border cells and also reduce the external stray magnetic field by a sufficient amount.

1 Prev studies of multi-beam transport system cost, such as J.Schultz, "IRE Magnet System Calculation Spreadsheet”, March 2001, VNL (Virtual National Lab) collaboration online document HCX-MAG-01-0312-02 and W.Meyer et al, "Cost Considerations for IBX", October 2001, VNL collaboration online document HCX-MAG-011009-01.

2 J.Schultz, “IRE Magnet System”, Rev.2a, May 2001, VNL collaboration online document HCX-MAG-010504-01.

3 J.J. Barnard et al., "Integrated Experiments for Heavy Ion Fusion”, Laser \& Particle Beams (2002) V20; and G. Logan, "Next Step in Heavy Ion Fusion", presented at the "FY 2005 OFES Budget Planning Meeting", Gaithersburg, MD March 18, 2003. http://www.ofes.fusion.doe.gov/more_html/2003BPM/logan2.pdf 
In Phase I of this project we have addressed the development of suitable quadrupole arrays with an edge termination scheme that maintains the same field in the peripheral cells of an array as is produced in the center cells and suppresses the external field of the array. This array is based on the use of the currently developed flat coil (race track) magnets that have been used for HCX prototypes. Analytical studies were performed to optimize the coil design, including its dimensions, the cable configuration, the coil winding pattern, and the coil holder. Several feasible edge termination schemes were studied. Conceptual designs were prepared for the mechanical structure for a $3 \times 3$ array and its enclosing cryostat.

\subsection{Anticipated Public Benefits}

Research into efficient methods of multi-beam transport will develop key technologies needed for heavy-ion inertial fusion (HIF) accelerators. Fusion can be an environmentally acceptable, nearly limitless source of energy. HIF accelerators are a promising approach towards the realization of this goal. The research carried out in this Phase I project supports the Department of Energy in carrying out its Inertial Fusion Energy science program with strong emphasis on economics, and may benefit accelerator magnet technology for other applications.

The near-term market for the array magnets studied in this project will be the scientific research community, especially research programs in heavy ion inertial fusion. However, reliable low-cost superconducting quadrupole magnets are also important for other applications, such as magnetic separation. The number of cells and total aperture of a system of quadrupole arrays could be adjusted to individual requirements of a separation project. The proposed magnet design, based on the double pancake coils as used for the HCX magnets, has the necessary robustness for industrial applications.

The technology developed in this project, using a single coil to share flux with adjacent cells in a multiple quadrupole array, minimizes the size of the array and lowers it cost. A future demonstration of the $3 \times 3$ array model with edge termination would be needed to show that this array technology can meet the requirements for field uniformity and stray field for multiple beam focusing. Based on the work done in this Phase I project, the Advanced Magnet Lab is ready to work with industry or government programs to further the development of beam transport systems for heavy ion inertial fusion.

The long-term applications of the concepts developed in this R\&D project are most likely in the commercial energy market. Regarding the long-term developments, further advances in superconductor technology are expected and HTS materials might replace the currently used superconductors. Although the relatively mature superconductors such as niobium-titanium may continue to have advantages over advanced superconductors for this particular application, the proposed coil configuration could be easily adapted to $\mathrm{Nb}_{3} \mathrm{Sn}$ and HTS conductors.

\section{Phase I Project details}

The Phase I research addressed the needs of both the nearer and longer term requirements of the inertial fusion program. The quadrupole arrays for near term experiments require magnet designs with a small length-to-aperture ratio, with a typical length of $600 \mathrm{~mm}$ and an aperture of $60 \mathrm{~mm}$. We have developed an optimized design for a $3 \times 3$ array of such magnets with peripheral correction coils and possibly a rectangular iron shield. These magnets meet the field uniformity 
requirements as set forth by the Virtual National Laboratory (VNL) collaboration that is working on multiple beam systems. These requirements are summarized in Table I.

Table 1. Parameters for Quad Array

\begin{tabular}{|l|l|}
\hline Number of channels: & 9 \\
\hline Clear bore radius: & $30 \mathrm{~mm}$ \\
\hline Cell half-size: & $40 \mathrm{~mm}$ (or less) \\
\hline Physical coil length: & $600 \mathrm{~mm}$ \\
\hline Total physical length: & $700 \mathrm{~mm}$ (or less) \\
\hline Short sample gradient: & $85 \mathrm{~T} / \mathrm{m}$ (optimize) \\
\hline Operating current: & $0.7^{\star} I \mathrm{SS}$ \\
\hline Operating temperature: & $4.5 \mathrm{~K}$ \\
\hline Copper current density & $1.5 \mathrm{kA} / \mathrm{mm} 2 @$ Iss \\
\hline Magnetic length: & $570 \mathrm{~mm}$ (optimize) \\
\hline Harmonics Ref. Radius: & $20 \mathrm{~mm}$ \\
\hline Field quality: & $<50$ units @ Iop(optimize) \\
\hline Stray field - & was not strictly specified -say less than \\
& $10 \mathrm{G}$ in the "vicinity" of the array \\
\hline
\end{tabular}

The quadrupole magnets used in this scheme are based on flat double pancake windings which were developed by Lawrence Livermore National Laboratory and successfully tested for HCX prototype quadrupoles ${ }^{4}$. (See Figure 1) The HCX coils show excellent performance and enable quadrupoles with compact ends, as needed for the first part of an HIF accelerator. We have developed an arrangement that reduces the number of coils in an array to less than half the number in the previous HCX cell design. This is done by forming each cell wall of one double layer coil (rather than two) and having that one coil serve the two neighbor cells. The reduced total number of coils optimizes the cost of the array while using a proven magnet design. The manufacturing technology for these coils is fully developed and, based on its past experience building this magnet, AML has further optimized the design to reduce manufacturing cost.

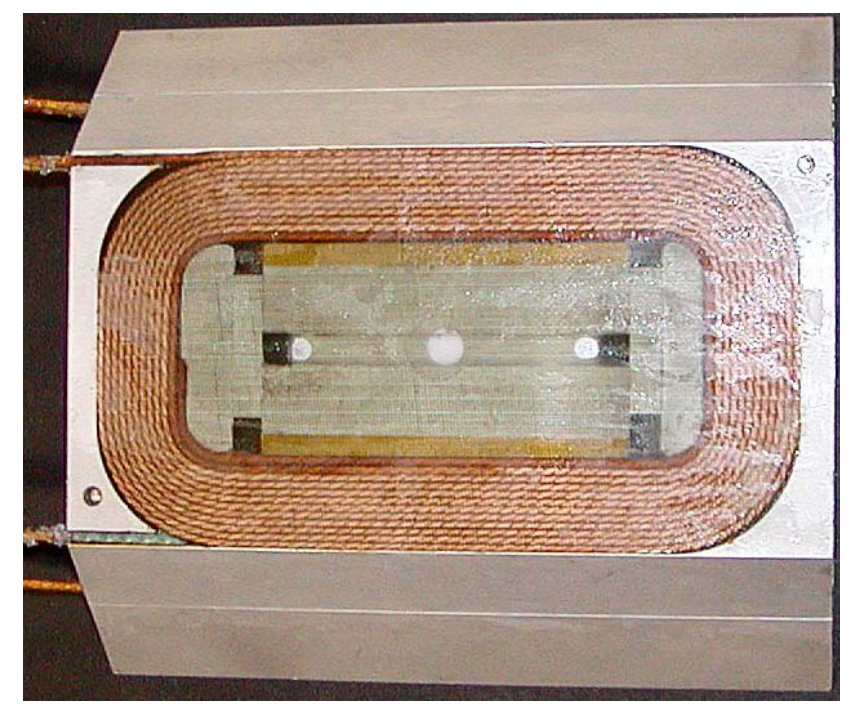

Figure 1. Flat double pancake coil in Al coil holder after vacuum impregnation. (Coil was manufactured at AML for LLNL). Four such coils are arranged in a square box to form an HCX magnet.

4 N. Martovetsky, B.Manahan, "Main parameters of the LLNL6r2 design (optimized HCX quad), January 2002, VNL collaboration online document HCX-MAG-02-0131-01 


\subsection{Edge Termination Schemes}

The main objective of Phase I was to investigate methods of edge termination for such a $3 \mathrm{x}$ 3 array that would (a) produce a uniform field in each of the nine cells of the array and (b) reduce the stray field outside of the array to an acceptable level. As illustrated in Figure 2, there are 3 types of cells in a 3x3 array: the center cell, the 4 corner cells, and the 4 side cells. If no edge termination scheme is employed, the gradient and harmonics in the 3 types of cells will be different.

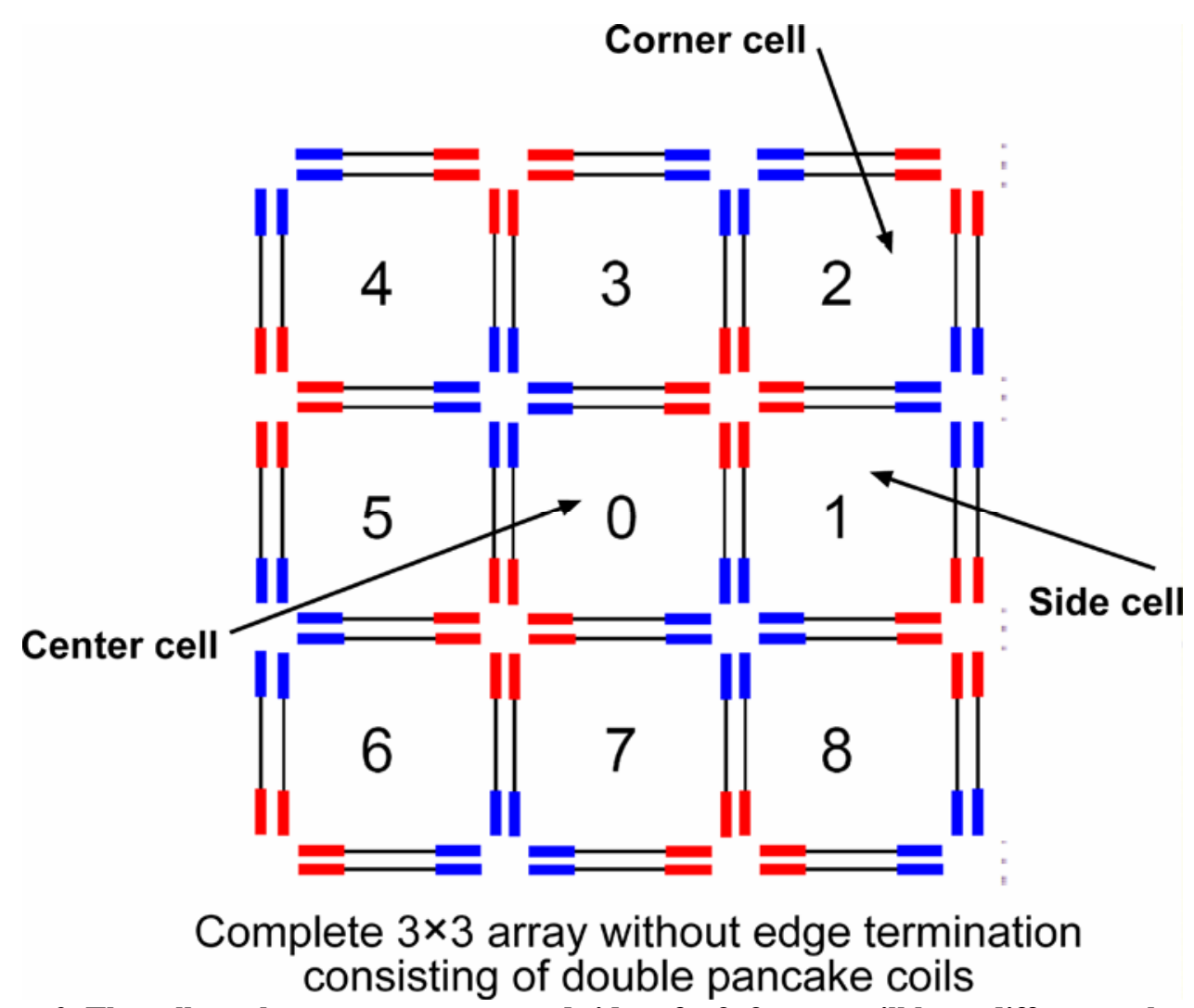

Figure 2. The cells at the center, corners, and sides of a 3x3 array will have different values of the gradient and harmonics.

From calculations of the arrays without edge termination, we know that even though the central cell may be optimized for field uniformity, characteristically the side cells will have a significant normal dipole component and its allowed harmonics, and the corner cells have both a significant normal and skew dipole component with associated allowed harmonics. Furthermore, the quadrupole gradient in the side cells is less than in the center cell, and the corner cells have an even lower gradient. It has been determined also that the allowed harmonics of quadrupole symmetry are not significantly affected by the position of the cell.

Consequently, the Phase I studies addressed the methods of edge termination that correct the presence of the dipole harmonic in the side and corner cells and make the gradient in each cell the same. Methods for optimization of the allowed harmonics by design of the current block were considered independently of the dipole component and gradient uniformity question. 
The use of compensating coils in the periphery of the array was studied by N. Martovetsky 5 . The preferred configuration, called Model 4, is shown in cross section in Figure 3. This is onequarter of a $3 \times 3$ array structure using compensating coils (indicated in green) on the periphery, with the current directions as shown.

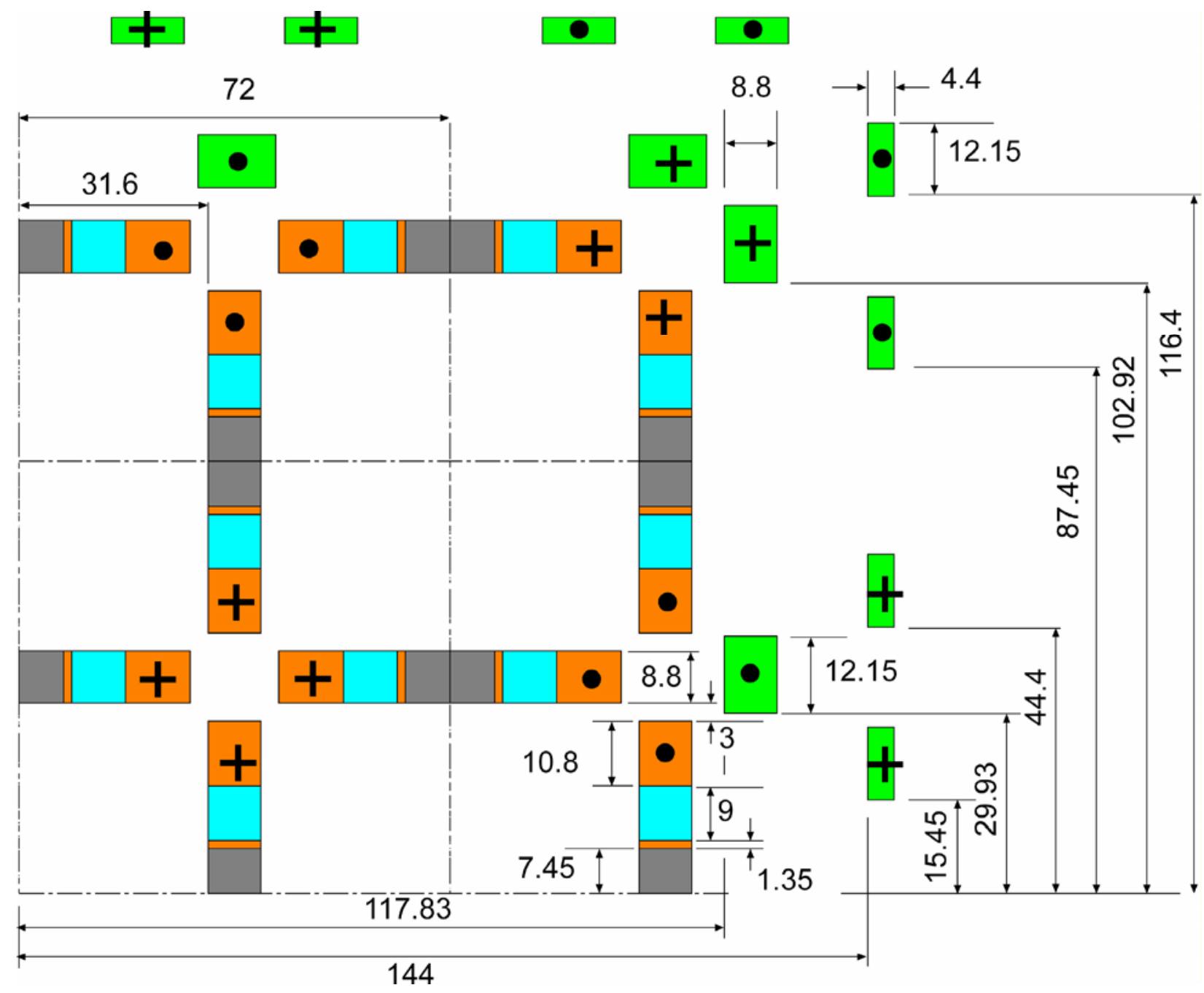

Figure 3. 3 x 3 Array termination Model 4, adapted from Martovetsky report.

The coil block configuration was optimized using a wedge after the first turn. The corner gap was $3 \mathrm{~mm}$, the minimum value determined to be sufficient for mechanical strength of the array. The compensating coils (shown in green) placed on the periphery are wound from the same $4.4 \mathrm{~mm}$ wide $\mathrm{x} 1.35 \mathrm{~mm}$ thick cable used for the main coils and operate at the same current. The compensating coils are wound in the same flat-ended racetrack configuration as the array coils, but are a different size. However, they can be wound using the same manufacturing technique that is used for the central cells of the array. 
A 3-D representation of the array with compensating coils is shown in Figure 4.

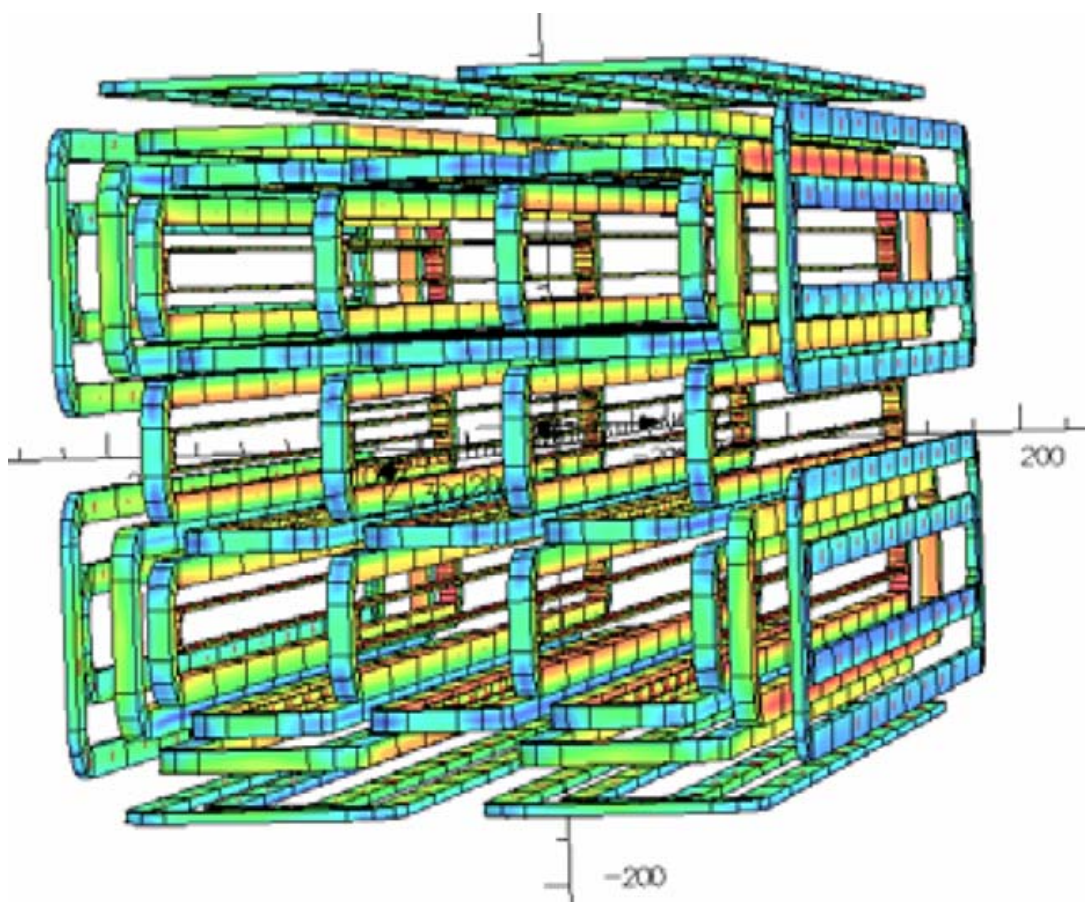

Figure 4. View showing the configuration of the $3 \times 3$ array with peripheral compensating coils, based on Martovetsky Model 4.

This configuration did a very good job of making the cell gradients equal. However, the side and corner cell dipole components were not completely eliminated, as will be seen in the next section. This configuration is a feasible method of constructing the array. The stray field can be made acceptably low by placing a. thin (i.e. $5 \mathrm{~mm}$ ) low carbon shield around the array.

An alternate method of using compensating coils around the periphery of the array was studied by Meinke ${ }^{6}$ The configuration is shown in Figure 5.

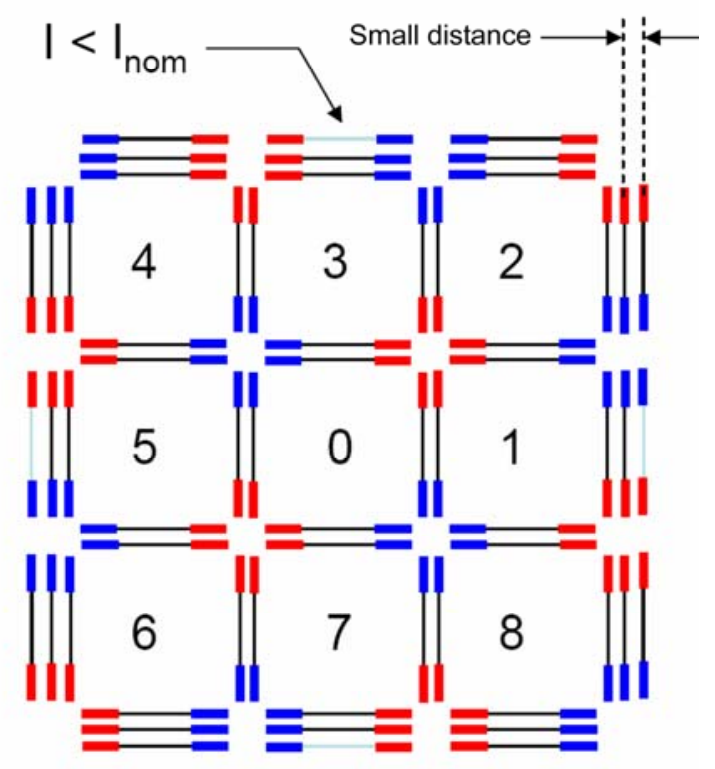

Figure 5. Edge termination with outer compensating coils with unequal currents (Meinke model). Current $I$ in coils by side cells is less than current $I_{\text {nom }}$ in all other coils.

6 R. Meinke, AML, “Field Uniformity Optimization of a 3x3 Quadrupole Array”, 2/28/05. 
Single-layer pancake coils, which are identical to the first layer of the double-layer array cell coils, are placed on the outside of the array, in close proximity to the array. The coils at the corners are operated at the nominal current of the array; the coils adjacent to the side cells are operated at an optimized current that is lower than the nominal current. In this scheme the side cell correction coils would be operated with an independent current supply. This configuration can be optimized to eliminate the dipole components in the side and corner cells and equalize the gradients in all of the cells. The stray field can be controlled by adding a thin iron shield to the outside of the array.

A passive edge termination scheme was investigated by C. Goodzeit. ${ }^{7}$ In this method, the $3 \times 3$ array is surrounded by a rectangular shield of low-carbon steel. The image current effect in the iron acts as compensating coils and produces the field pattern shown in Figure 6.

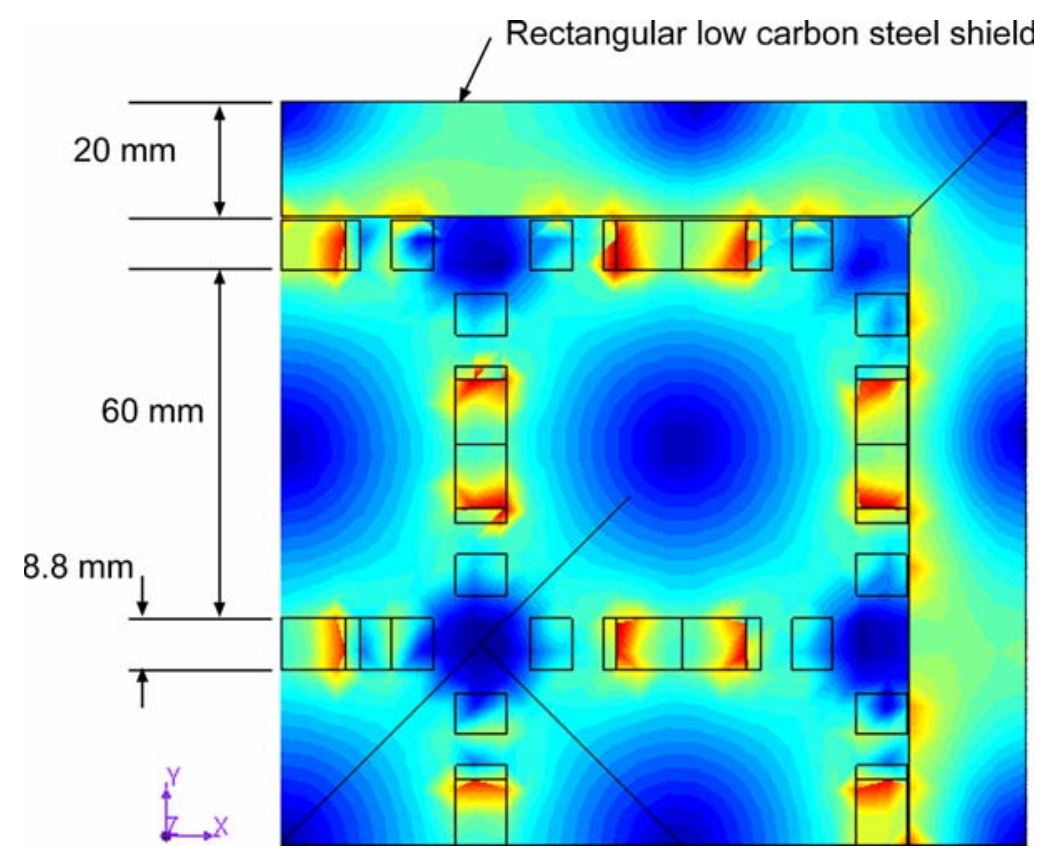

Figure 6. One quarter model of a $3 \times 3$ array with a rectangular shield. Iron pole pieces are also used in the coil winding packs. (Goodzeit model)

The potential for this development is illustrated in Figure 7 that shows how the dipole components in the side and corner cells of a 3 x 3 array vary with the thickness of the iron shield. When the thickness increases, the dipole component in the side cell decreases and that in the corner cell increases; thus, there is some thickness for which these components vanish; however, not at the same thickness. 


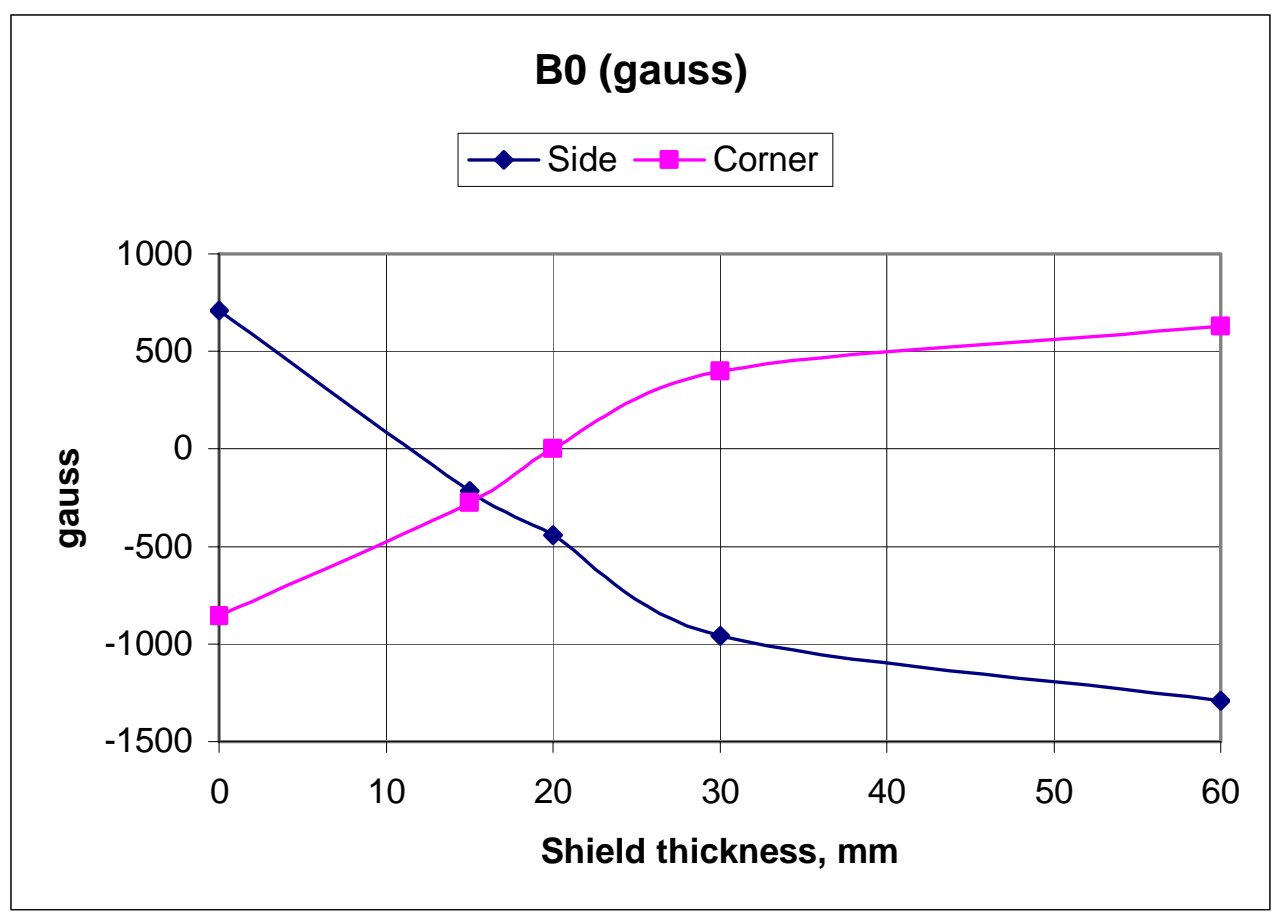

Figure 7. Effect of shield thickness on dipole components in a 3 x 3 array (Goodzeit model).

In the example shown, it is seen that the dipole component on the corner cell vanishes when the shield thickness is near $20 \mathrm{~mm}$. However, the side cell still has a dipole of about -400 gauss. Since the variation in dipole component with shield thickness has opposite signs for the side and corner cells, it may be feasible to tune both of them out simultaneously by using a shield that is thinner in the region of the side coil and thicker in the region of the corner coil, i. e. a stepped shield.

Thus, by suitably choosing the thickness (and shape, perhaps) of the iron, it may be possible to achieve the same results that can be obtained by using compensating coils. This may be a worthwhile method to investigate in detail, since the passive shielding approach would be simpler and less expensive than using compensating coils.

\subsection{Field Quality}

The following cases for 3 x 3 arrays are considered here for comparison:

Case 1: Array without edge termination (w/o iron poles)

Case 2: Edge termination using compensating coils (Martovetsky Model 4) (w/o iron poles)

Case 3: Edge termination using compensating coils (Meinke model) (w/o iron poles)

Case 4: Edge termination with $15 \mathrm{~mm}$ thick rectangular iron shield (Goodzeit model) (with iron poles)

\section{Gradient and Allowed Harmonics}

The ratio of the quadrupole gradient in the side and corner cells with respect to the gradient in the center cell for the four cases is shown in Figure 8. It is seen that the compensating coil approach and the rectangular shield are quite effective in equalizing the gradient in each of the cells. The allowed dodecapole (B5) harmonics are plotted in Figure 9 and all cases show a moderate increase from center to side to corner. However, as shown by Case 1, this effect also 
occurs without any of the edge termination schemes in place. Thus, it appears that the relative increase of the B5 component is not sensitive to the method used for edge termination. It should be noted here that the rather large B5 component for Case 4 is due to the use of iron pole pieces in this model. The coil design was optimized for low harmonics without an iron pole; thus, this offset represents the contribution of the iron pole to the harmonic content of the field.

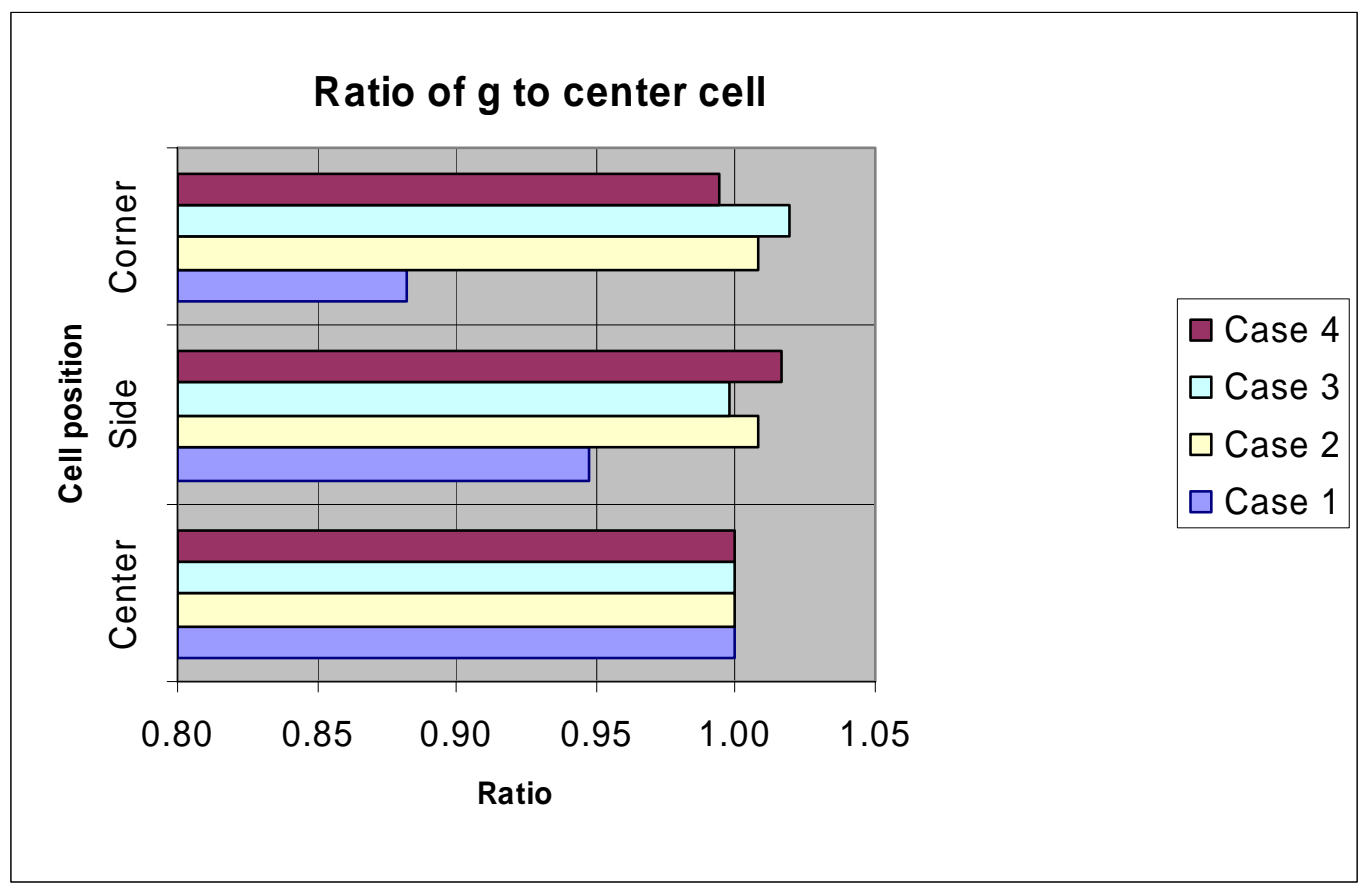

Figure 8. Quadrupole gradient in the cells

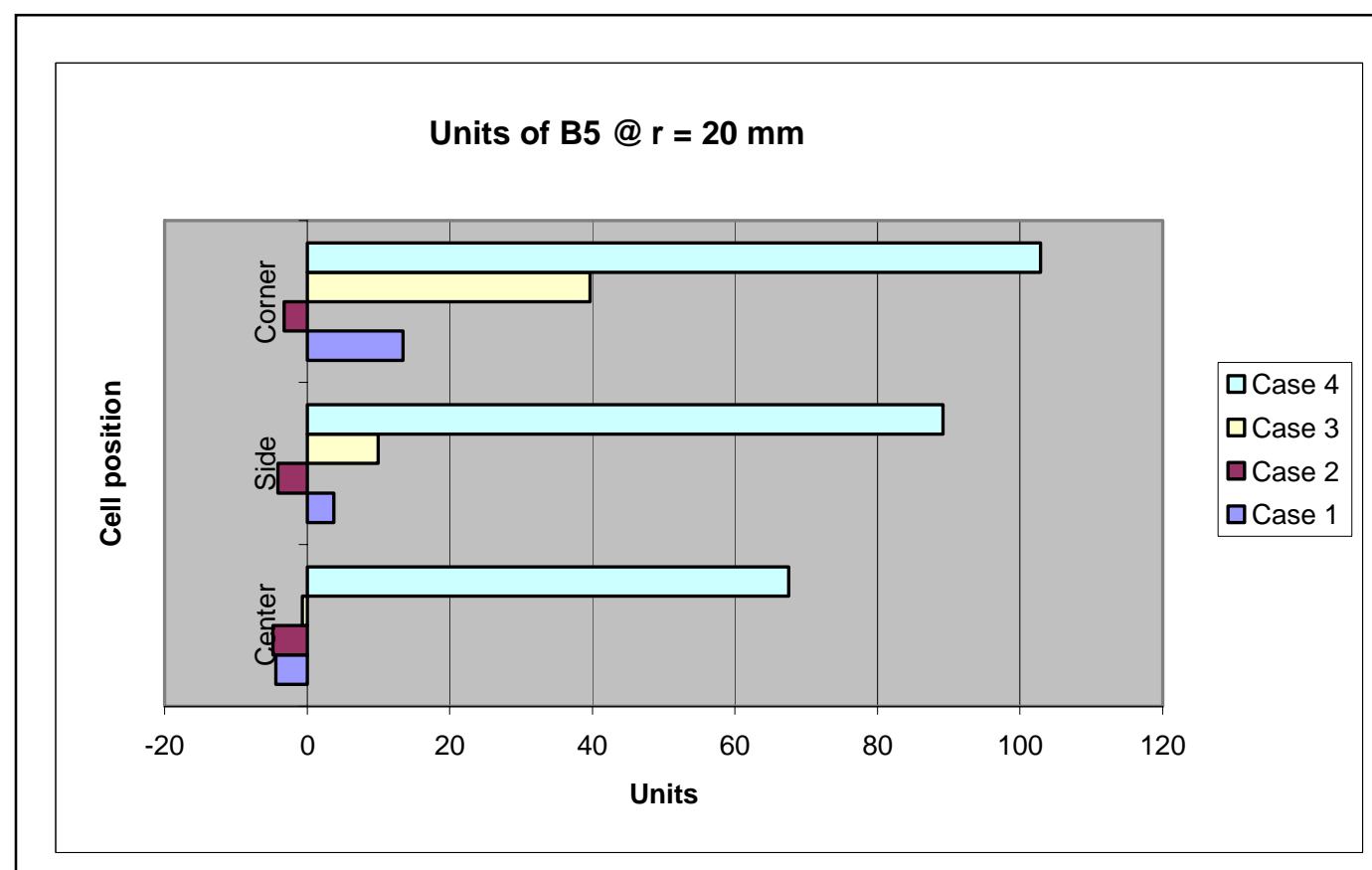

Figure 9. Units of $B 5$ in the cells. 


\section{Dipole field components}

Previous analysis has shown that the side cells in the 3 x 3 array have a rather large normal dipole component and the corner cells have rather large values for both normal and skew dipole components. In the corner cell, the normal and skew dipole are equal in magnitude. The effects of the edge termination schemes in the side and corner cells are shown in Figure 10. Case 3 (that uses separately powered compensating coils for the side cells) is an example of how this method can be optimized to eliminate the dipole components. Case 2 shows a significant decrease in the dipole components and may be capable of further optimization. The example studied for Case 4 used a fixed width $(15 \mathrm{~mm})$ rectangular shield. As explained in the discussion of the edge termination schemes, it should be possible to optimize the shape of the shield (i.e. vary its thickness) to eliminate the dipole components.

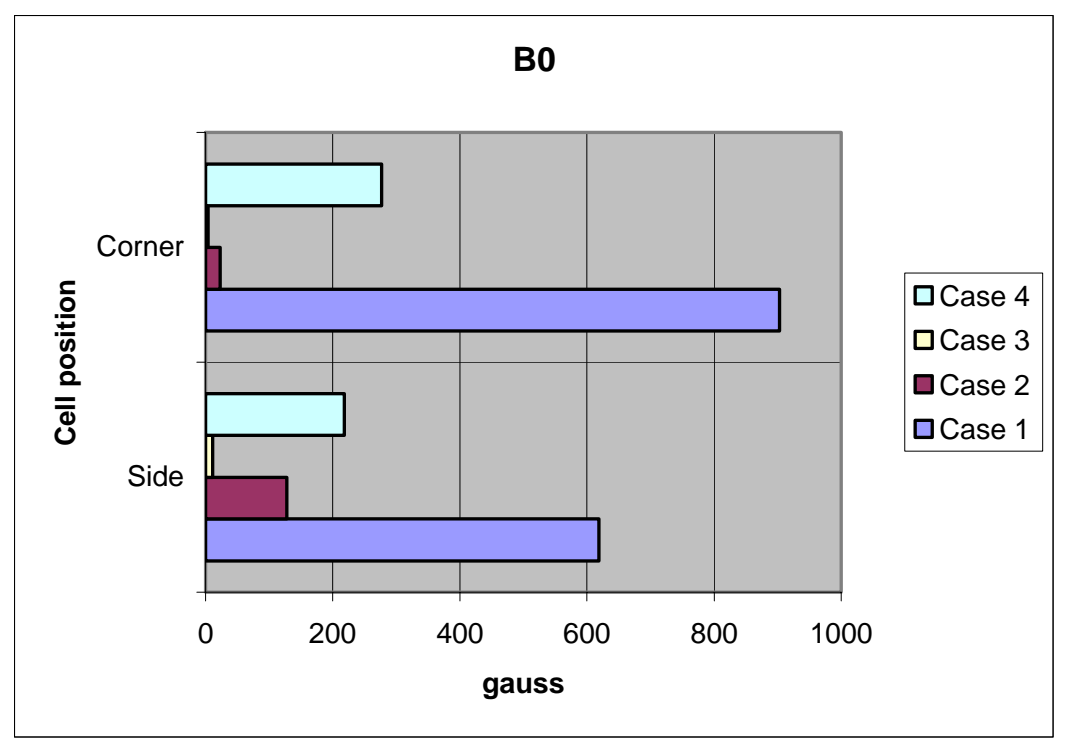

Figure 10. Dipole component in side and corner cells

\subsection{Array Mechanical Structure and Cryostat}

A scheme for the array mechanical structure was developed in Phase I. It is illustrated in Figure 11. Aluminum extrusions are used to form the array coil holders, in a manner similar to that used for the HCX coils. The holders are interlocked in a way that provides an efficient and reliable method for stacking the components of an array of any size. The compensating coils are assembled in a similar manner, using extrusions that serve as coil holders and spacers. The entire array is keyed using aluminum filler laminations at the corners of the array. An iron shield to reduce the stray field can be used over the array. This complete array structure is then enclosed by the helium containment shell. This cold mass is penetrated by nine cold bore tubes that form the inner helium containment boundary and serve as access to the individual cells for insertion of magnetic measurement probes or other types of instrumentation. 


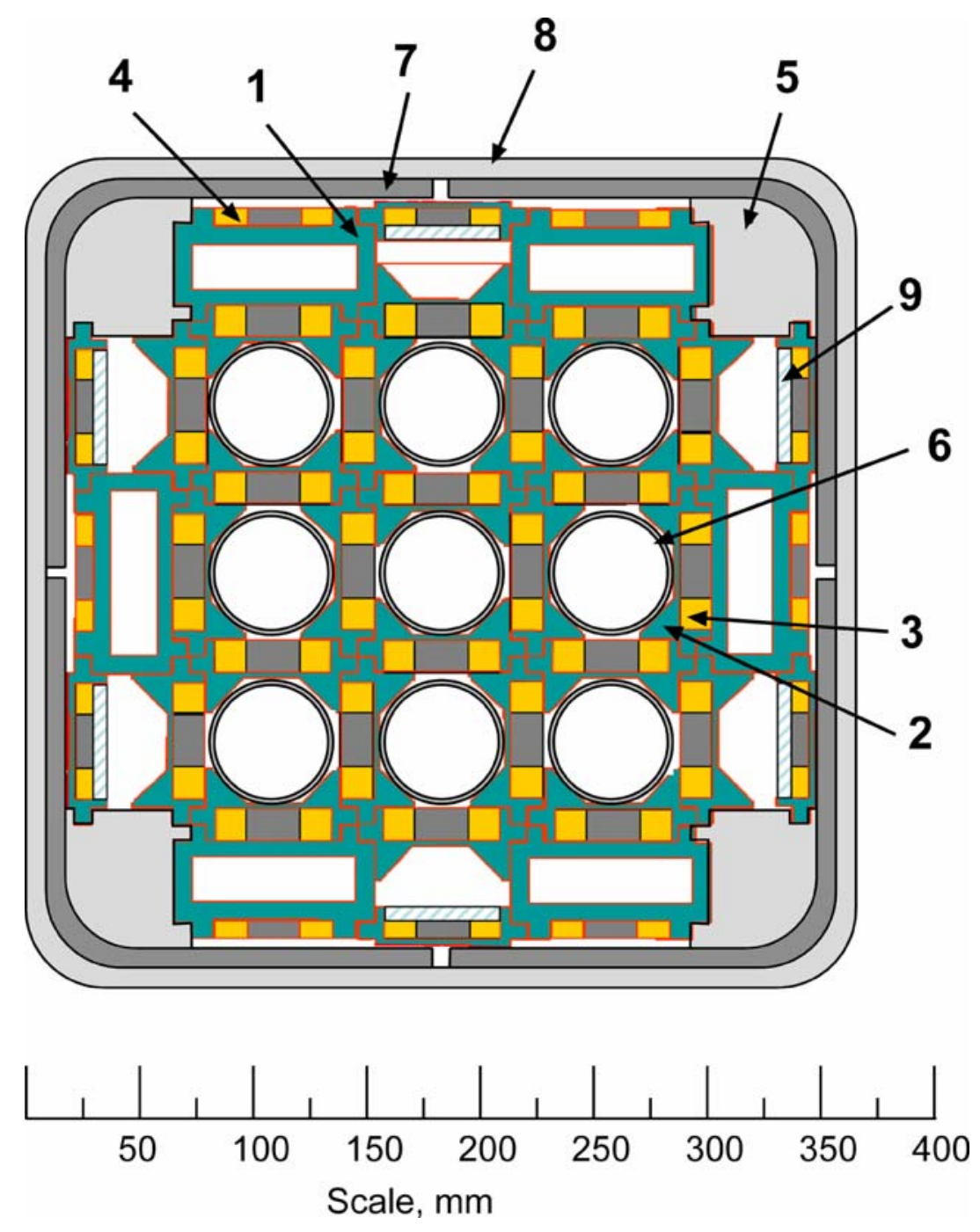

Figure 11. Cross section of cold mass for the $3 \times 3$ demonstration array. 1 . Al extrusion for holding compensating coil,

2 . Interlocking coil supports made from Al extrusions,

3. 2-layer Flat coil packs forming cells,

4. Single layer flat coil packs for compensating coils,

5. Spacer extrusions (Al),

6. Cold bore tube,

7. Iron shield (as required),

8. Helium containment shell,

9. Lead support for compensating coil

The cold mass will be supported by a single low heat leak support post and housed in a compact cryostat as shown in Figure 12. Nine access ports with thin walled tubes extending into the cold bores will be provided from one end of the vacuum vessel for magnetic measurements and other tests. 


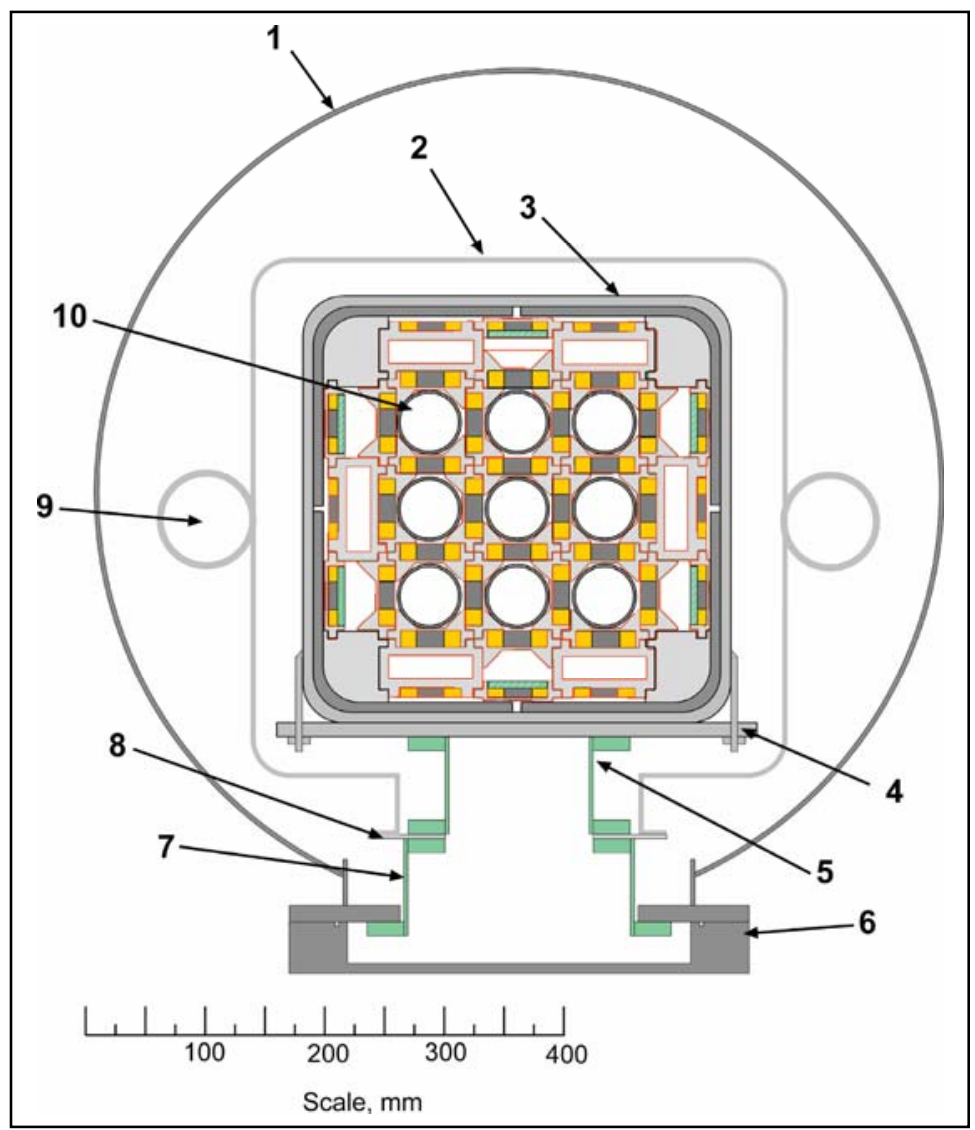

Figure 12. Cross section of cold mass and cryostat at support post. (Multi-layer insulation and other details not shown.)

1. Vacuum tank assembly,

2. Liquid nitrogen shield,

3. Helium containment shell,

4. Cold mass support plate,

5. Upper support post,

6. Vacuum tank closure,

7. Lower support post,

8. Nitrogen shield intercept,

9. Liquid nitrogen reservoir,

10. Cold bore tube (external access holes will be provided at one end of the vacuum tank for insertion of nine thin walled tubes into the cold bore tubes for magnetic measurement)

The assembly procedure is to first assemble the cold mass to the mounting plate (4) and the upper support post (5). Then the liquid nitrogen shield is attached to the intercept (8), and insulation blankets added to the assembly. This subassembly is positioned in the vacuum vessel and the lower part of the support post (7) is assembled through the bottom port and the vacuum tank closure (6) added. All cryogenic and electrical connections are made at this time. The vacuum tank is sealed at one end using a demountable end plate with provisions for inserting and sealing the nine access tubes.

A compact post will be used to support the cold mass in the cryostat as shown in the cross section in Figure 12. The cryostat's vacuum tank is designed to provide access to the nine cells of the $3 \times 3$ array in order to accommodate a magnetic measurement probe for field measurements. Figure 13 shows the features of the vacuum tank assembly for the proposed cryostat. The cryostat will be floor mounted and will contain all features required for tests, such as feed-throughs for voltage taps and temperature sensors, flanges for the safety valves, and top hat connections for cryogenic and vapor cooled power leads. 


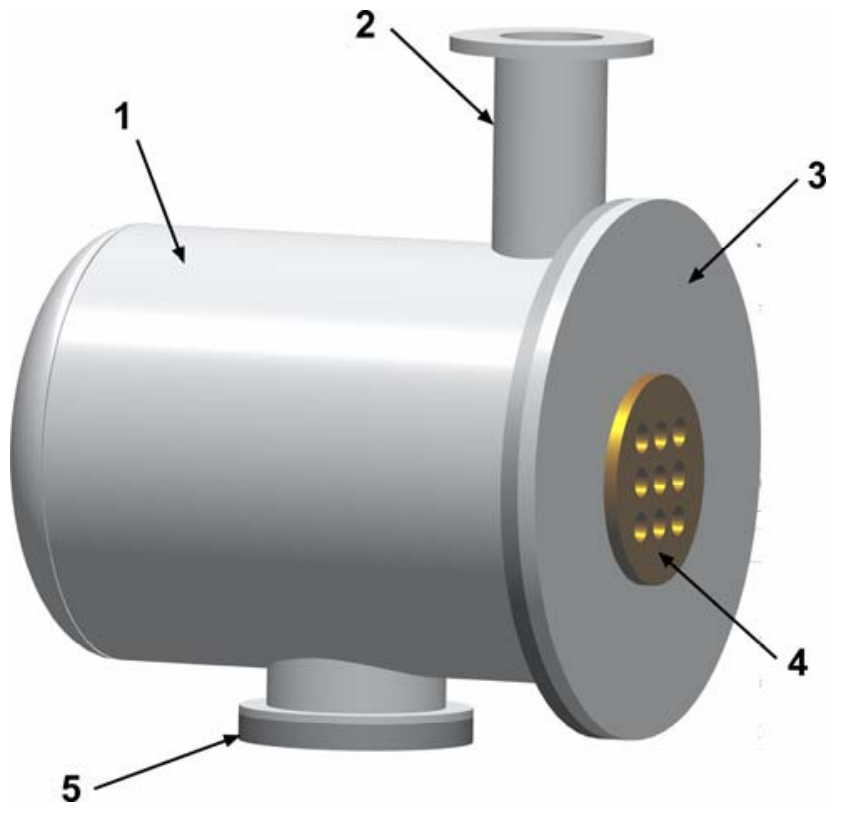

Figure 13. View of proposed cryostat assembly.

1. Vacuum tank shell, 2. Top hat for cryogenic and electrical lead-throughs,

3. Demountable closure plate, 4. Adjustable cover plate for access tubes to the $3 \times 3$ array, 5. Cryostat support and vacuum closure.

\subsection{Phase I Study Conclusions}

The work done thus far clearly indicates that it is possible to build a $3 \times 3$ array with edge termination that will meet design requirements. This conclusion is mainly based on the results of the various two dimensional analyses performed in Phase I.

Martovetsky [see previous reference] has done some three dimensional analysis on the scheme represented as Case 2 (his Model 4) and has shown that the end effects can be dealt with. In particular, the gradients in the end region are practically equal for each cell position. The end harmonics differ in each cell location; however, it was pointed out that the integrals of the harmonics along the length of the end are within specifications, primarily due to the fact that the sign of the harmonic reverses in the end region. This analysis has also shown that the external fields at the ends can be reduced to an acceptable level by placement of an iron shield at the end with access holes for the bores of the magnets.

The primary objective for the next phase of research is to develop a cost-effective design for a $3 \times 3$ array with edge termination that satisfies the field requirements in each of the array cells. The first step to meeting this objective will be further studies of the edge termination schemes that were developed in Phase I. For each scheme, the array coil and termination designs will be optimized to provide the required field uniformity in each cell and keep the stray field outside of the array within prescribed limits. One edge termination scheme will be selected, based on cost and performance considerations.

At a later stage, a model array would be built, housed in a suitable cryostat, and its performance verified by cryogenic testing with magnetic measurements in each of the cells. Such an array would demonstrate the feasibility of building much larger arrays for future applications. The array would be assembled from individual flat pancake coils wound in a double-layer configuration i.e., a 2-layer flat coil wound from a single un-spliced length of cable by the 
method similar to that used to construct the HCX prototype. The coils would be mounted in interlocking coil holders that can be assembled into an array configuration with edge termination, as shown in Figure 11. This figure shows a peripheral compensating coil edge termination configuration; however, the use of a passive iron shield is also possible.

\section{Personnel and Facilities}

\subsection{Principal Investigator and Other Key Personnel}

\section{$\underline{\text { Rainer Meinke, Ph.D.: } \quad \text { Principal Investigator }}$}

Dr. Rainer Meinke has more than 25 years of experience in physics and engineering, including all major accelerator systems, detector development for HEP experiments, and software development for experiment simulations and data analysis. This includes 15 years of experience in development, manufacturing and testing of superconducting magnets.

As a cofounder of the AML, he has devoted a major effort to the development of advanced magnet manufacturing technology. He designed, manufactured and successfully tested several state-of-the-art superconducting magnets including complex helical magnet for the Relativistic Heavy Ion Collider and sextupole accelerator magnets for the Large Hadron Collider. Recently, Dr. Meinke completed conceptual design of a unique superconducting quadrupole array magnet system for next generation fusion at Lawrence Berkley Laboratory. Dr. Meinke is also a coinventor of the Direct Conductor Placement System and related advanced magnet assembly/material processes as well as a co-inventor of the double-helix magnet concept for use in accelerator magnets and electrical machinery.

From 1991 to 1995 Dr. Meinke was a Senior Scientist at the Superconducting Super Collider Laboratory (SSCL), in Dallas, Texas. As the Collider Machine Leader, he was responsible for technical design, budget and schedule of the $20 \mathrm{TeV}$ proton-proton Collider. He significantly improved the formerly existing conceptual design of the Collider to a technically mature and cost effective design.

From 1985 to 1991 Dr. Meinke participated in the HERA Construction at DESY, in Hamburg, Germany. He was in charge of development, build-up and operation of a test facility for superconducting magnets at HERA; the first accelerator to employ industrially produced magnets of this kind. He headed a group of 70 scientists, engineers and technicians from ten different countries. Major advances in test equipment led to several new discoveries on the behavior of superconducting magnets.

Dr. Meinke received his Ph.D. in high-energy physics from Technical University Munich, Germany. His work in physics included development of phenomenological models for elementary particle interactions, and participation in hardware development and experimental data analysis for high-energy physics experiments at different accelerators and laboratories, including construction of the world's largest streamer chamber detector at the European Center for Nuclear Research (CERN).

Dr. Meinke has published well over 100 papers on physics, accelerator technology, and magnet topics.

Bibliography of Related Topics 
R.B. Meinke, M.J. Ball, C.L. Goodzeit, "Superconducting Double-Helix Accelerator Magnets”, IEEE Proceedings of the 2003 Particle Accelerator Conference, 2003, Vol.3, pages 1996-1998.

R. B. Meinke, C. L. Goodzeit, and M. J. Ball, "Modulated Double-Helix Quadrupole Magnets”, Paper 4LC08, ASC2002, Houston, TX, August 2002; IEEE Transactions on Superconductivity, June 2003, Vol.13, Issue 2, pages 1369-1372.

C. L. Goodzeit, R. B. Meinke, and M. J. Ball, "The Double-Helix Dipole - A Novel Approach to Accelerator Magnet Design”, Paper 4LC07, ASC2002, Houston, TX, August 2002; IEEE Transactions on Superconductivity, June 2003, Vol.13, Issue 2, pages 1365-1368.

C.L. Goodzeit, M.J. Ball, R.B. Meinke, "Interactive Procedure for Rapid Performance Estimates of Magnet Designs", IEEE Proceedings of the 1999 Particle Accelerator Conference, 1999, Vol.5, pages 3245-3247.

Rainer B. Meinke, Andris Faltens, Roger O. Bangerter, "Conceptual Design of Superconducting Quadrupole Arrays for Heavy-Ion Fusion”, IEEE Proceedings of the 1999 Particle Accelerator Conference, 1999, Vol 5, pages 3215-3217.

Rainer B. Meinke, Yuping Zhao, “A Novel Approach to Magnet Design and Optimization”, IEEE Proceedings of the 1999 Particle Accelerator Conference, 1999, Vol.5, pages 3212-3214.

R. Meinke and M. Senti, “3D Complex Coil Winding Using Advanced Robotics”, Florida Conference on Recent Advances in Robotics, March 1998

R. Meinke and M. Senti, “Automated Design \& Manufacturing of 3D Coils” Electrical Mfg. \& Coil Winding Expo ‘97, Sept. 1997

\section{Carl L. Goodzeit, P. E.: $\quad$ Engineering, analysis}

Mr. Goodzeit received his Sc. M. in Engineering Mechanics from Brown University and his B. S. in Mechanical Engineering from Rutgers University. He is a Registered Professional Engineer in the State of New York.

He has had a long involvement in the development of superconducting accelerator magnets that includes work at BNL (1981-1990) and the SSC Lab (1990-1994). In February 2001, Mr. Goodzeit became a part time employee of AML, participating in its superconducting magnet development programs.

Mr. Goodzeit is the principal inventor of the double-helix dipole concept for accelerator magnets and for use in electrical machinery. He plays a major role in AML's design and analysis of magnets involving the double-helix and other configurations.

While at BNL Mr. Goodzeit was responsible for the mechanical design of the cold masses for the dipole magnets for the Colliding Beam Accelerator (CBA) and RHIC, and also was a participant in the early design collaboration for SSC dipoles. He led the effort to design, build, calibrate, and implement coil stress transducers that were used to measure the change in coil stress in superconducting accelerator magnets. 
In 1990, Mr. Goodzeit joined the staff at the SSC Laboratory and was responsible for managing the team that was developing the cold masses for the in-house built magnets for the SSC intersection and utility regions.

In January 2001 Mr. Goodzeit participated in the US Particle Accelerator School at Rice University where he presented a segment of the Superconducting Accelerator Magnets course entitled: "An Introduction to Mechanical Design and Construction Methods".

Bibliography of Related Topics

(See first 4 items in list under R. B. Meinke)

Millicent ("Penny") Ball, Ph.D.: Magnetic and Structural Analysis, documentation

Dr. Ball received her B.S. in mathematics from Antioch College and her Ph.D. in High Energy Physics from the University of Maryland. Her experience includes over 13 years involvement with programming and database development for superconducting magnet R\&D work at national laboratories and 4 years leading the development of a CD-ROM tutorial on superconducting accelerator magnets. Her earlier work experience includes 10 years of high energy physics research and programming support activities.

In February 2001, Dr. Ball became a part-time employee of AML, to work on magnetic analysis of superconducting magnet systems and technical report writing. Dr. Ball is a coinventor of the novel coil configuration called the double helix dipole that is being developed for accelerator magnets and is the basis of a design for high power density, compact superconducting motors and generators. She has participated in the analysis effort for previous AML SBIR projects on double helix dipoles and arrays of quadrupole magnets for fusion applications.

From 1994 to 1998, Dr. Ball was principal investigator/content developer for a CD-ROM tutorial on the design and construction of superconducting accelerator magnets which was developed by MJB Consulting (now MJB Plus Inc.) under a DOE SBIR award.

As a computer analyst in the Magnet Division of Brookhaven National Laboratory, from June 1980 to June 1990, Dr. Ball was responsible for the design and implementation of a relational database to track measurements of key parameters for the superconductor and coils in magnets that were designed for use in Isabelle, CBA, SSC, and RHIC accelerators. In 1988 she began collaborating with the Superconducting Super Collider (SSC) project and in 1990 joined the SSC Laboratory as leader of the Data Management Group for the Magnet Systems Division/ Test Department.

Prior to 1980, her work in high energy physics research included analysis of bubble chamber experiments (at the University of Maryland and the Institute fuer Hochenergiephysik in Heidelberg, Germany) and development of computer programs for automatic bubble chamber track measurement (at Imperial College in London, England and Purdue University).

Bibliography of Related Topics

(See first 4 items in list under R. B. Meinke) 


\subsection{Facilities and Equipment}

The Advanced Magnet Laboratory (AML) is located in Melbourne, Florida. In spring 2005 it moved to the Advanced Research Laboratory on the campus of Florida Technical Institute. The AML facility has a fully equipped machine and welding shop for manufacturing short magnets, and has all necessary computer equipment for mechanical design and software development.

AML's technology portfolio includes CoilCAD ${ }^{\mathrm{TM}}$, RoboWire ${ }^{\mathrm{TM}}$, and patented processes for the manufacturing and design of 3D wire/coil forms. The specialized magnet design software CoilCAD $^{\mathrm{TM}}$ and winding machine control software RoboWire ${ }^{\mathrm{TM}}$ have been developed over several years and have been used in design and production of magnets for research and industrial applications. AML has Algor software for 3D structural analysis and AMPERES for 3D magnetic field calculations with non-linear iron effects.

\subsection{Consultants and Subcontractors: Primary investigator at the RI}

\section{Nicolai N. Martovetsky, Ph.D.}

Dr. Nicolai Martovetsky has 26 years of the experience in applied superconductivity, cryogenics, design of magnets and superconductors, thermal, electromagnetic and structural analyses, project management, system engineering, system integration, construction of superconducting, and resistive magnets, instrumentation, data acquisition, testing and post test analyses. He has an extensive experience in technology transfer, collaboration with industry and international partners.

Since March 1994, Dr. Martovetsky has been with Lawrence Livermore National Laboratory, where he participated in many projects on magnet technology for fusion and energy storage as an engineer, program leader, group leader and deputy project manager. His activity for this period includes the Tokamak Physics eXperiment magnets development, International Thermonuclear Engineering Reactor CS Model coil design, construction and testing, reconstruction of the LLNL facility and testing of a 32 MJ SMES coil, development, construction and testing focusing magnets for heavy ion fusion.

In the period of March 1992- March 1994 Dr. Martovetsky worked at the SSC Laboratory, responsible for System Engineering of the GEM Detector Magnet System, \$127M, 20m dia x30 $\mathrm{m}$ long detector magnet.

In October 1977 - March 1992 he worked at Kurchatov Institute for Atomic Energy, Moscow, Russia, on analyses, design and testing of magnets and superconductors for variety of applications, including first Nb3Sn tokamak T-15 and UNK accelerator magnets conductor.

Dr. Martovetsky has over 100 publications in refereed journals. He presented invited talks on Applied Superconductivity Conferences- San Francisco (1988), Virginia Beach (2000), Houston (2002), Magnet Technology Conferences - St. Petersburg, (1991), Geneva (2001), IEEE Power Engineering Society Summer Meeting, Portland, Oregon, (1996), ANS Topical meetings in Nashville (1998), Park City (2000) and Washington, DC (2002), International Cryogenic Engineering Topical Conference 03, Enschede, Netherlands (2003).

Invited expert for five project design reviews for NSF and DoE. 
Bibliography of Related Topics

N.N. Martovetsky and R.R. Manahan Focusing Magnets for HIF based on Racetracks, IEEE Transactions on Applied Superconductivity v.11, N1, March 2001, p.2030-2033.I

N. Martovetsky, R. Manahan, A. Lietzke, Development of Superconducting Focusing Quadrupoles for Heavy Ion Drivers, IEEE Transactions on Applied Superconductivity v.12, N 1 March 2002, p. 157-160

A.Lietzke, G. Sabbi, P. Seidl et.al, R. Manahan, N. Martovetsky, Development of Superconducting quadrupoles for heavy ion fusion Proceedings of the 2001 Particle Accelerator Conference, Chicago, June 18-22, 2001, p. 3436-3439, IEEE \#01CH37268C. Piscataway, NJ 08855

A. Faltens, A.Lietzke, G. Sabbi, P. Seidl, S. Lund, B. Manahan, N. Martovetsky, et al, Progress in the development of superconducting quadrupoles for heavy ion fusion, LASER AND PARTICLE BEAMS 20 (4), 2002, p.617-620 


\section{Parametric Study of Quadrupole Array Field Uniformity}

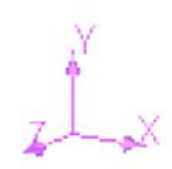

C. Goodzeit, R. Meinke, M. Ball AML

\section{$11 / 26 / 2004$}

DoE Award No. DE-FG02-04ER86205 


\section{Field Uniformity Optimization}

\section{Executive Summary:}

Optimization of the quadrupole array and the related edge termination scheme requires a mathematical description of the system, which can easily be changed. A MathCAD program has been developed, which enables a rapid analysis and optimization of coil configurations for the $3 \times 3$ array.

In this 2-D model the array cells consist of 8 rectangular current blocks. The individual current blocks are modeled by groups of current filaments, which carry the ampere turns of the block. With the help of this program the best aspect ration for the current blocks has be determined. A systematic study has been performed for two different values of the corner gap ( $3 \mathrm{~mm}$ and $1.5 \mathrm{~mm}$ ). Carl's case of 3.75-mm corner gap, done with AMPERE has been analyzed for comparison.

The analysis performed shows that the one-degree of freedom in this coil configuration is insufficient to reduce both of the two major higher-order multipole fields (twelve and twenty-pole) simultaneously to the required level of a few times $10^{-4}$. 


\section{MP Fields of Rectangular Current Blocks}

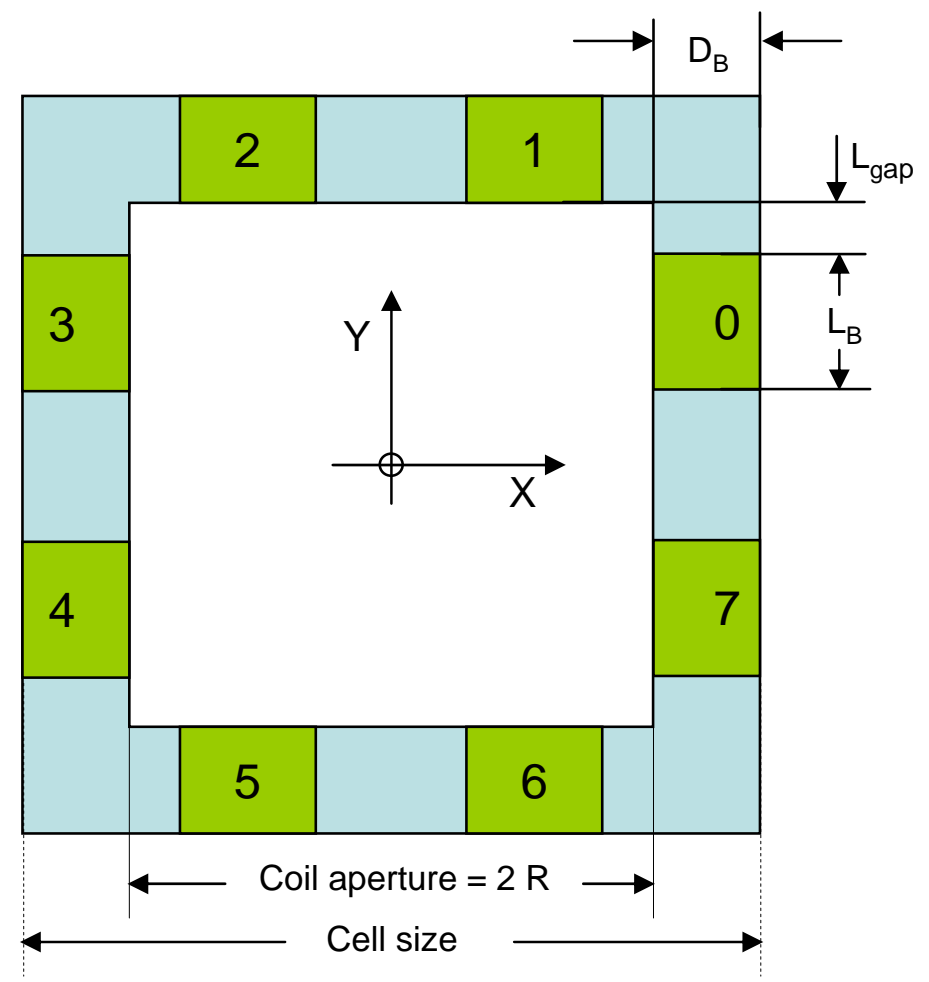

a We assume that the individual quadrupole cells are built up with 4 identical single pancake coils.

a In 2-D, each coil consists of 2 current blocks as shown in the sketch. The current blocks 1-2, 3-4, 5-6 and 7-0 form the 4 coils.

a The coils are described by 4 parameters:

$>L_{B}: \quad$ Block length

> $\mathrm{D}_{\mathrm{B}}$ : Block width (cable width)

$>\mathrm{L}_{\text {gap }}: \quad$ Gap in the corner

$>\mathrm{R}$ : $\quad$ Aperture radius

ㄱe cell size in this model is given by:

$$
\text { cell size }=2 R+2 D_{B}
$$




\section{MP Calculation}
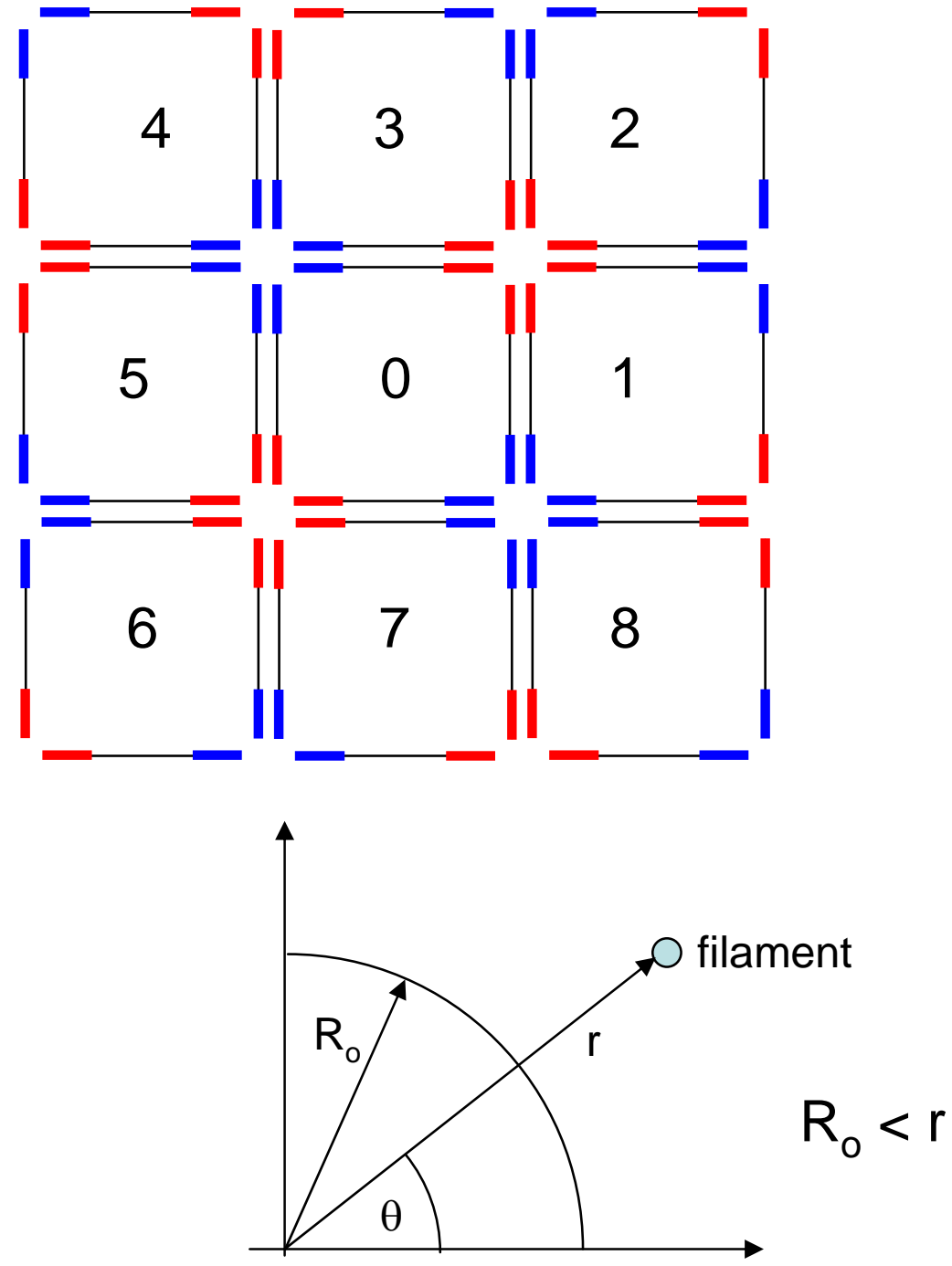

a A $3 \times 3$ array is built up as indicated in the sketch.

- We assume that each current block consists of $\mathrm{nx} \times$ ny infinitely thin current filaments, which carry the total ampere-turns "I" of the block.

a The MP field components $A_{n}, B_{n}$ in tesla of each filament relative to a defined origin and a reference radius $R_{0}$ are given by:

$$
\begin{aligned}
& B n=\frac{\mu_{0}}{2 \cdot \pi} \cdot I \cdot\left[\frac{R_{0}{ }^{n}}{r^{n+1}} \cdot \cos [(n+1) \cdot \theta]\right] \\
& \text { An }=\frac{\mu_{0}}{2 \cdot \pi} \cdot I \cdot\left[\frac{R_{0}{ }^{n}}{n+1} \cdot \sin [(n+1) \cdot \theta]\right]
\end{aligned}
$$

Summation over all filaments gives the MP fields for any combination of current blocks inside of the array $\left(R_{o}<r\right)$. 


\section{Flux Sharing}

- The manufactured coils are double pancakes, which means they consist of two layers of a Rutherford type cable. In the field calculation it is assumed that each cell of the array has one layer of the double pancakes.

a If the field is calculated for a single cell, only one layer of cable is therefore considered. When the fields are calculated for an array assembly, the second layer of the double pancake contributes.

a Considering the second layer of the double pancake as belonging to the neighboring cell, the flux sharing becomes very strong.

a As shown later, the field of the center cell is increased by more than a factor of two in respect to the center cell consisting of single layer pancakes.

- If the field in the center cell is calculated using the surrounding double pancakes and comparing with the field in the array, yields a field enhancement of $27.9 \%$ for a cell size of $77.6 \mathrm{~mm}$. 


\section{Single Cell: Carl's Case}

\section{Cell Parameters:}

\begin{tabular}{|c|c|}
\hline Aperture & $\mathrm{R}_{\mathrm{ap}}=30 \mathrm{~mm}$ \\
\hline Current blocks/cell & iblock $=8$ \\
\hline Contributing quad cells & mcell $=1$ \\
\hline Cell size & dcell $=68.8 \mathrm{~mm}$ \\
\hline $\begin{array}{l}\text { Block width } \\
\text { Cable width: }\end{array}$ & $\mathrm{D}_{\mathrm{B}}=4.4 \mathrm{~mm}$ \\
\hline Block lenght: & $\mathrm{L}_{\mathrm{B}}=17.55 \mathrm{~mm}$ \\
\hline Block aspect ratio: & $\frac{\mathrm{L}_{\mathrm{B}}}{\mathrm{D}_{\mathrm{B}}}=3.99$ \\
\hline Corner gap: & $\mathrm{L}_{\mathrm{gap}}=3.75 \mathrm{~mm}$ \\
\hline Reference radius & $\mathrm{R}_{\mathrm{O}}=20 \mathrm{~mm}$ \\
\hline Block ampere-turns: & Iblock $=5.85 \times 10^{4} \mathrm{amp}$ \\
\hline
\end{tabular}

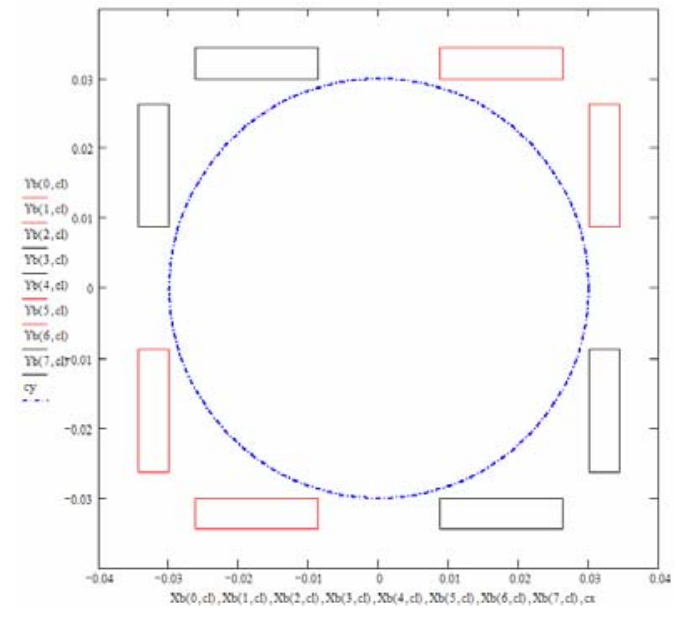

Cable insulated:

$4.4 \times 1.35 \mathrm{~mm}^{2}$
The circle shows the 60$\mathrm{mm}$ aperture

\section{Field Uniformity}

$$
\begin{aligned}
& \frac{\mathrm{B}_{\text {total }}(5)_{1}}{\mathrm{~B}_{\text {total }}(1)_{1}}=4.22 \times 10^{-2} \\
& \frac{\mathrm{B}_{\text {total }}(9)_{1}}{\mathrm{~B}_{\text {total }}(1)_{1}}=-5 \times 10^{-3}
\end{aligned}
$$$$
\begin{aligned}
& \frac{\mathrm{B}_{\text {total }}(13)_{1}}{\mathrm{~B}_{\text {total }}(1)_{1}}=-4.83 \times 10^{-4} \\
& \frac{\mathrm{B}_{\text {total }}(17)_{1}}{\mathrm{~B}_{\text {total }}(1)_{1}}=-7.49 \times 10^{-6}
\end{aligned}
$$

The fields are calculated for a single cell as shown. The current is assumed to be 4500 amps (see next slide). The pancake coil has 13 turns yielding a block length of $17.55 \mathrm{~mm}$. The quadrupole field at a reference radius of $20 \mathrm{~mm}$ is 1.10 tesla, with an equivalent gradient of $55.1 \mathrm{tes} / \mathrm{a} / \mathrm{m}$. 


\section{Carl's Case (Double Pancake in Center Cell)}

\section{Cell Parameters:}

Aperture

Current blocks/cell

Contributing quad cells

Cell size

Block width

Cable width:

Block lenght:

Block aspect ratio:

Corner gap:

Reference radius

Block ampere-turns:
$\mathrm{R}_{\mathrm{ap}}=30 \mathrm{~mm}$

iblock $=8$

mcell $=1$

dcell $=77.6 \mathrm{~mm}$

$\mathrm{D}_{\mathrm{B}}=8.8 \mathrm{~mm}$

$\mathrm{L}_{\mathrm{B}}=17.55 \mathrm{~mm}$

$\frac{L_{B}}{D_{B}}=1.99$

$\mathrm{L}_{\text {gap }}=3.75 \mathrm{~mm}$

$\mathrm{R}_{\mathrm{O}}=20 \mathrm{~mm}$

Iblock $=1.17 \times 10^{5} \mathrm{amp}$

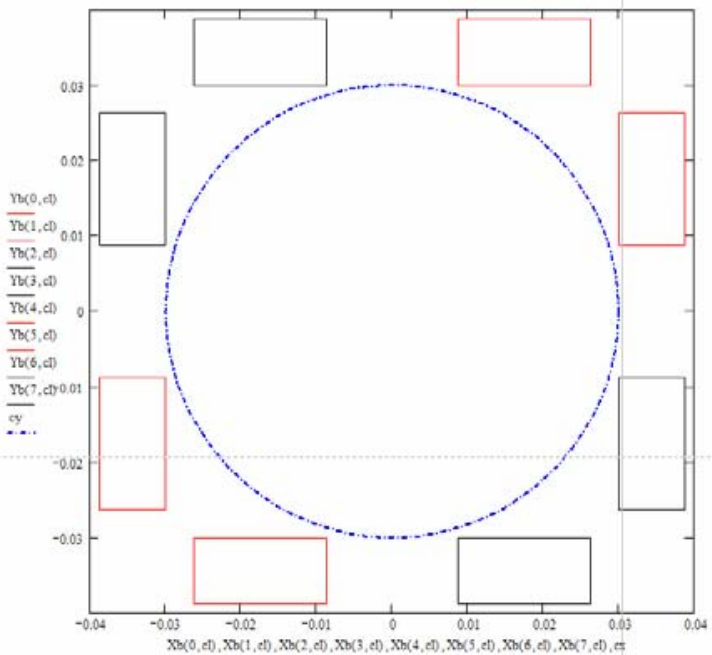

Double pancake coil.

$$
\begin{aligned}
& \frac{\mathrm{B}_{\text {total }}(5)_{1}}{\mathrm{~B}_{\text {total }}(1)_{1}}=4.27 \times 10^{-2} \\
& \frac{\mathrm{B}_{\text {total }}(9)_{1}}{\mathrm{~B}_{\text {total }}(1)_{1}}=-3.57 \times 10^{-3} \\
& \frac{\mathrm{B}_{\text {total }}(13)_{1}}{\mathrm{~B}_{\text {total }}(1)_{1}}=-3.35 \times 10^{-4} \\
& \frac{\mathrm{B}_{\text {total }}(17)_{1}}{\mathrm{~B}_{\text {total }}(1)_{1}}=-6.84 \times 10^{-6}
\end{aligned}
$$

Cable insulated: $4.4 \times 1.35 \mathrm{~mm}^{2}$

\section{Quadrupole field on $\mathbf{R}_{\mathbf{o}}: \quad \mathrm{B}_{\mathrm{total}}(1)_{1}=1.939 \mathrm{tesla}$}

Gradient: $\quad \operatorname{grad}:=\frac{\mathrm{B}_{\text {total }}(1)_{1}}{0.02 \cdot \mathrm{m}} \quad \operatorname{grad}=96.93 \frac{\text { tesla }}{\mathrm{m}}$

The fields are calculated for a single cell as shown. The current is assumed to be 4500 amps. The double pancake coil has a total of 26 turns with a block length of $17.55 \mathrm{~mm}$. The quadrupole field at a reference radius of $20 \mathrm{~mm}$ is 1.94 tesla, with an equivalent gradient of $96.9 \mathrm{tes} \mathrm{la} / \mathrm{m}$. 


\section{Nominal Current and Superconductor}

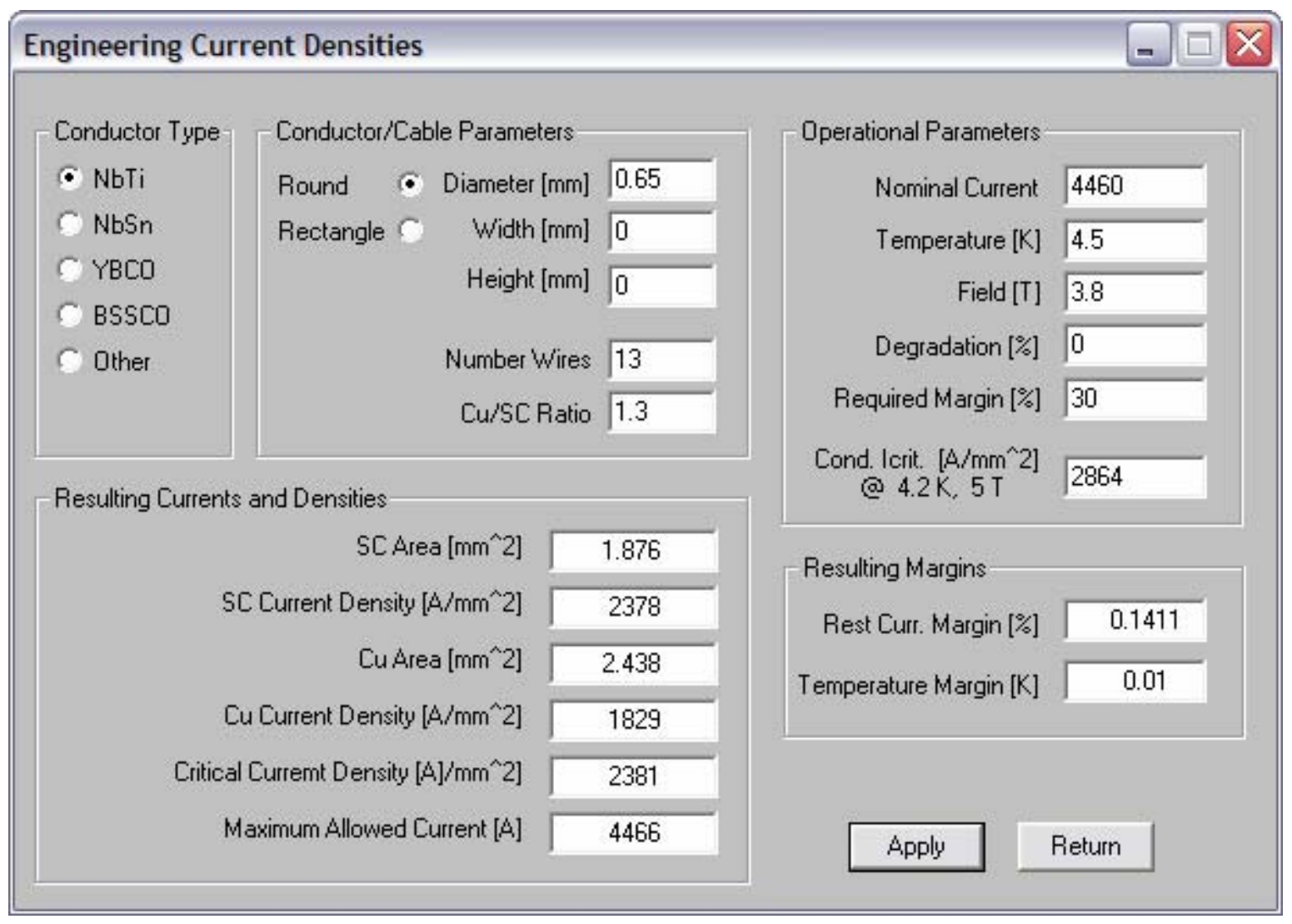

We assume a 13 strand cable with a strand diameter of 0.65 $\mathrm{mm}$ and a copper to SC ratio of 1.3 .

The insulated cable dimensions are $4.4 \times 1.35 \mathrm{~mm}$.

The required margin is set to $30 \%$, the "Resulting Margins" are remaining rest margins on top of the $30 \%$ at the given temperature of $4.5 \mathrm{~K}$.

With the requested margin of $30 \%$ and a nominal temperature of $4.5 \mathrm{~K}$, which seems reasonable for an array, we can operate at about $4500 \mathrm{~A}$. 


\section{3×3 Array: Carl's Case}

\section{Cell Parameters:}

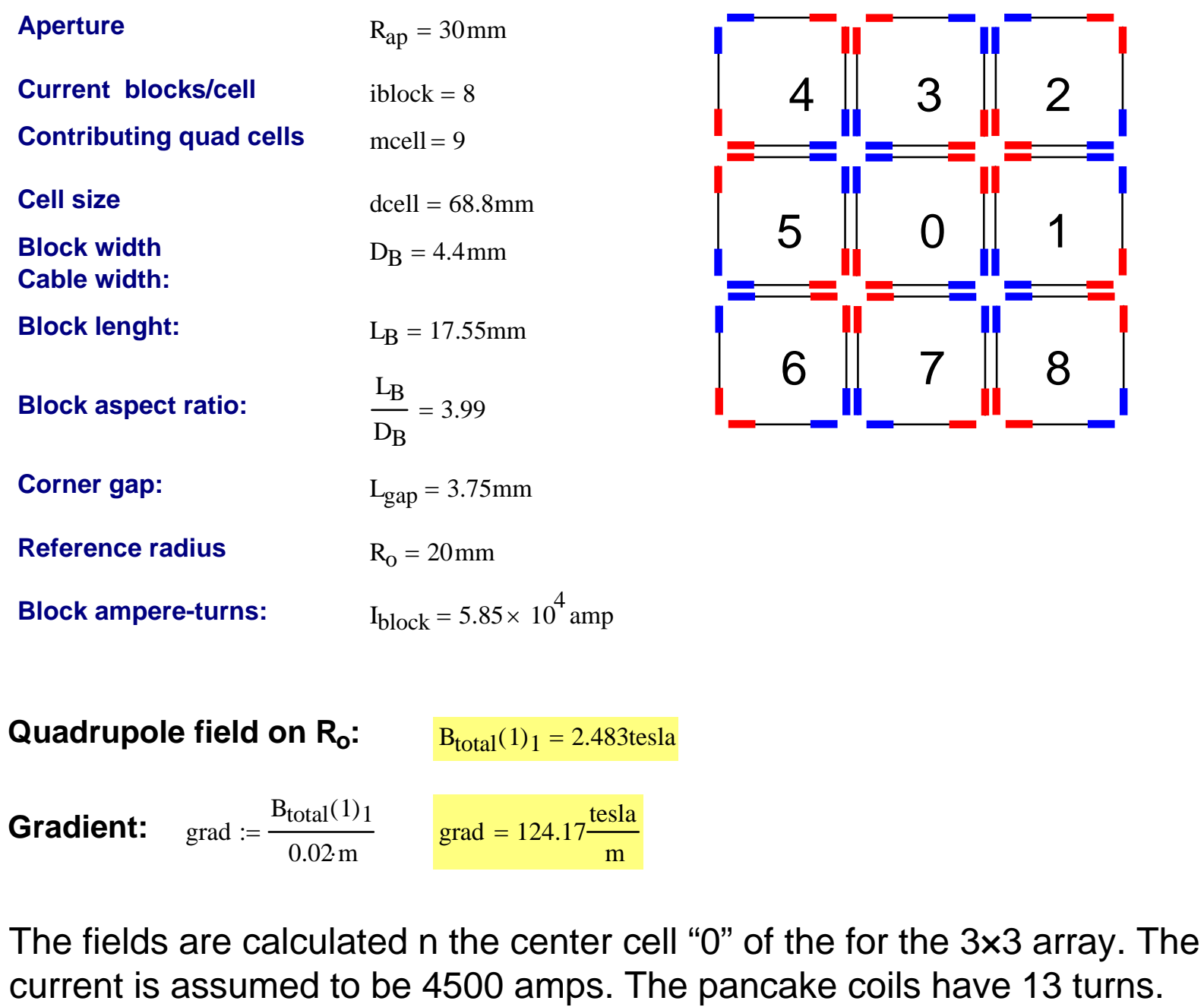

\section{Field Uniformity}

$$
\begin{aligned}
& \frac{\mathrm{B}_{\text {total }}(5)_{1}}{\mathrm{~B}_{\text {total }}(1)_{1}}=3.08 \times 10^{-2} \\
& \frac{\mathrm{B}_{\text {total }}(9)_{1}}{\mathrm{~B}_{\text {total }}(1)_{1}}=-2.79 \times 10^{-3} \\
& \frac{\mathrm{B}_{\text {total }}(13)_{1}}{\mathrm{~B}_{\text {total }}(1)_{1}}=-2.61 \times 10^{-4} \\
& \frac{\mathrm{B}_{\text {total }}(17)_{1}}{\mathrm{~B}_{\text {total }}(1)_{1}}=-5.36 \times 10^{-6}
\end{aligned}
$$

current is assumed to be 4500 amps. The pancake coils have 13 turns. 


\section{Carl's Case}

- Since half of the double pancake coils belong to the neighboring cells, the flux sharing is very strong. The quadrupole field increases by a factor: 124/55 $\sim 2.25$, when the neighboring cells are "switched on".

a Comparing Carl's case, where the field in the center cell is calculated for double pancakes, gives a field enhancement in the $3 \times 3$ array of $124 / 96.9 \sim 1.28$

- As a cross check of the quadrupole field strength, the 8 current blocks per cell have been replaced by individual wires (thin filaments), which carry the full block current.

- The field quality in the center cell of an array is almost a factor of 2 better than for a single cell. This is can be contributed to the fact that higher-order MP fields fall off very rapidly and therefore have little effect on neighboring cells.

- As pointed out by Carl, the field uniformity of such an array is very poor.

a The MathCAD program will be used to make a systematic parametric search for coil geometries with better field quality. The goal is to make all MP fields smaller than $10^{-4}$ of the quadrupole field. 


\section{Variation of Block Shape (single cell)}

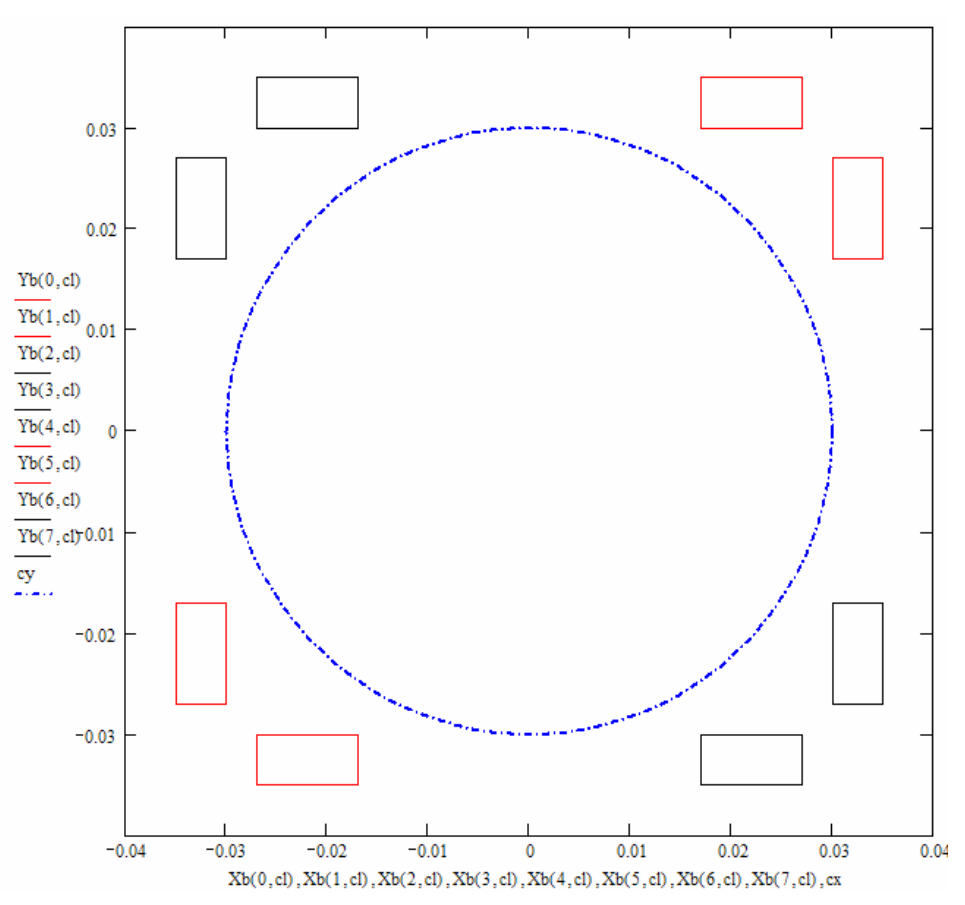

MathCad plot showing the calculated current blocks. The circle shows the $60-\mathrm{mm}$ aperture.

\section{Cell Parameters:}

\begin{tabular}{|c|c|}
\hline Aperture & $\mathrm{R}_{\mathrm{ap}}=30 \mathrm{~mm}$ \\
\hline Current blocks/cell & iblock $=8$ \\
\hline Contributing quad cells & mcell $=1$ \\
\hline Cell size & dcell $=70 \mathrm{~mm} \quad$ Vari \\
\hline $\begin{array}{l}\text { Block width } \\
\text { Cable width: }\end{array}$ & $\mathrm{D}_{\mathrm{B}}=5 \mathrm{~mm}$ \\
\hline Block lenght: & $\mathrm{L}_{\mathrm{B}}=10 \mathrm{~mm}$ \\
\hline Corner gap: & $\mathrm{L}_{\mathrm{gap}}=3 \mathrm{~mm}$ \\
\hline Reference radius & $\mathrm{R}_{\mathrm{O}}=20 \mathrm{~mm}$ \\
\hline Block ampere-turns: & $\mathrm{I}_{\mathrm{block}}=5 \times 10^{4} \mathrm{amp}$ \\
\hline \multirow[t]{4}{*}{ Field Uniformity: } & $\frac{\mathrm{B}_{\text {total }}(5)_{1}}{\mathrm{~B}_{\text {total }}(1)_{1}}=-2.43 \times 10^{-2}$ \\
\hline & $\frac{\mathrm{B}_{\text {total }}(9)_{1}}{\mathrm{~B}_{\text {total }}(1)_{1}}=-2.41 \times 10^{-3}$ \\
\hline & $\frac{\mathrm{B}_{\text {total }}(13)_{1}}{\mathrm{~B}_{\text {total }}(1)_{1}}=3 \times 10^{-4}$ \\
\hline & $\frac{\mathrm{B}_{\text {total }}(17)_{1}}{\mathrm{~B}_{\text {total }}(1)_{1}}=-1.08 \times 10^{-5}$ \\
\hline
\end{tabular}




\section{Field Uniformity versus Block Length (single cell)}

\section{Corner gap $=3.0 \mathrm{~mm}, \mathrm{I}_{\text {block }}=50,000 \mathrm{amp}$}

\begin{tabular}{|l|r|r|r|r|r|r|r|r|r|}
\hline \multicolumn{1}{|c|}{ Single Cell } \\
\hline Parameter & & & & & & & & & \\
\hline Block length [mm] & 5.0 & 10.0 & 12.5 & 13.80 & 15.0 & 17.5 & 20.0 & 22.5 & 25.0 \\
\hline Block width [mm] & 5.0 & 5.0 & 5.0 & 5.0 & 5.0 & 5.0 & 5.0 & 5.0 & 5.0 \\
\hline Corner gap [mm] & 3.0 & 3.0 & 3.0 & 3.0 & 3.0 & 3.0 & 3.0 & 3.0 & 3.0 \\
\hline Quad Field on Ro (B1) & 0.929 & 0.956 & 0.958 & 0.955 & 0.951 & 0.932 & 0.901 & 0.857 & 0.802 \\
\hline B5/B1 & $-4.06 \mathrm{E}-02$ & $-2.43 \mathrm{E}-02$ & $-9.55 \mathrm{E}-03$ & $-1.12 \mathrm{E}-04$ & $9.54 \mathrm{E}-03$ & $3.17 \mathrm{E}-02$ & $5.43 \mathrm{E}-02$ & $7.38 \mathrm{E}-02$ & $8.65 \mathrm{E}-02$ \\
\hline B9/B1 & $6.17 \mathrm{E}-04$ & $-2.41 \mathrm{E}-03$ & $-4.26 \mathrm{E}-03$ & $-5.02 \mathrm{E}-03$ & $-5.45 \mathrm{E}-03$ & $-5.06 \mathrm{E}-03$ & $-2.61 \mathrm{E}-03$ & $1.22 \mathrm{E}-03$ & $4.58 \mathrm{E}-03$ \\
\hline B13/B1 & $7.83 \mathrm{E}-05$ & $3.00 \mathrm{E}-04$ & $2.69 \mathrm{E}-04$ & $1.67 \mathrm{E}-04$ & $2.06 \mathrm{E}-05$ & $-3.48 \mathrm{E}-04$ & $-4.96 \mathrm{E}-04$ & $-1.42 \mathrm{E}-04$ & $4.64 \mathrm{E}-04$ \\
\hline B17/B1 & $-9.98 \mathrm{E}-06$ & $1.08 \mathrm{E}-05$ & $1.23 \mathrm{E}-05$ & $2.66 \mathrm{E}-05$ & $3.45 \mathrm{E}-05$ & $1.18 \mathrm{E}-05$ & $-5.11 \mathrm{E}-05$ & $-5.48 \mathrm{E}-05$ & $3.72 \mathrm{E}-05$ \\
\hline
\end{tabular}

The MP fields shown in the table are for a reference radius of $20 \mathrm{~mm}$, i.e. $2 / 3$ of the coil aperture. The block width is $5 \mathrm{~mm}$, which is the width of a realistic cable.

B5 and B9 are the only MP fields of relevance. The higher MP fields are for all block lengths in the order of $10^{-4}$ or significantly below. 


\section{2-pole (B5) versus Block Length (gap $=3 \mathrm{~mm}$ )}

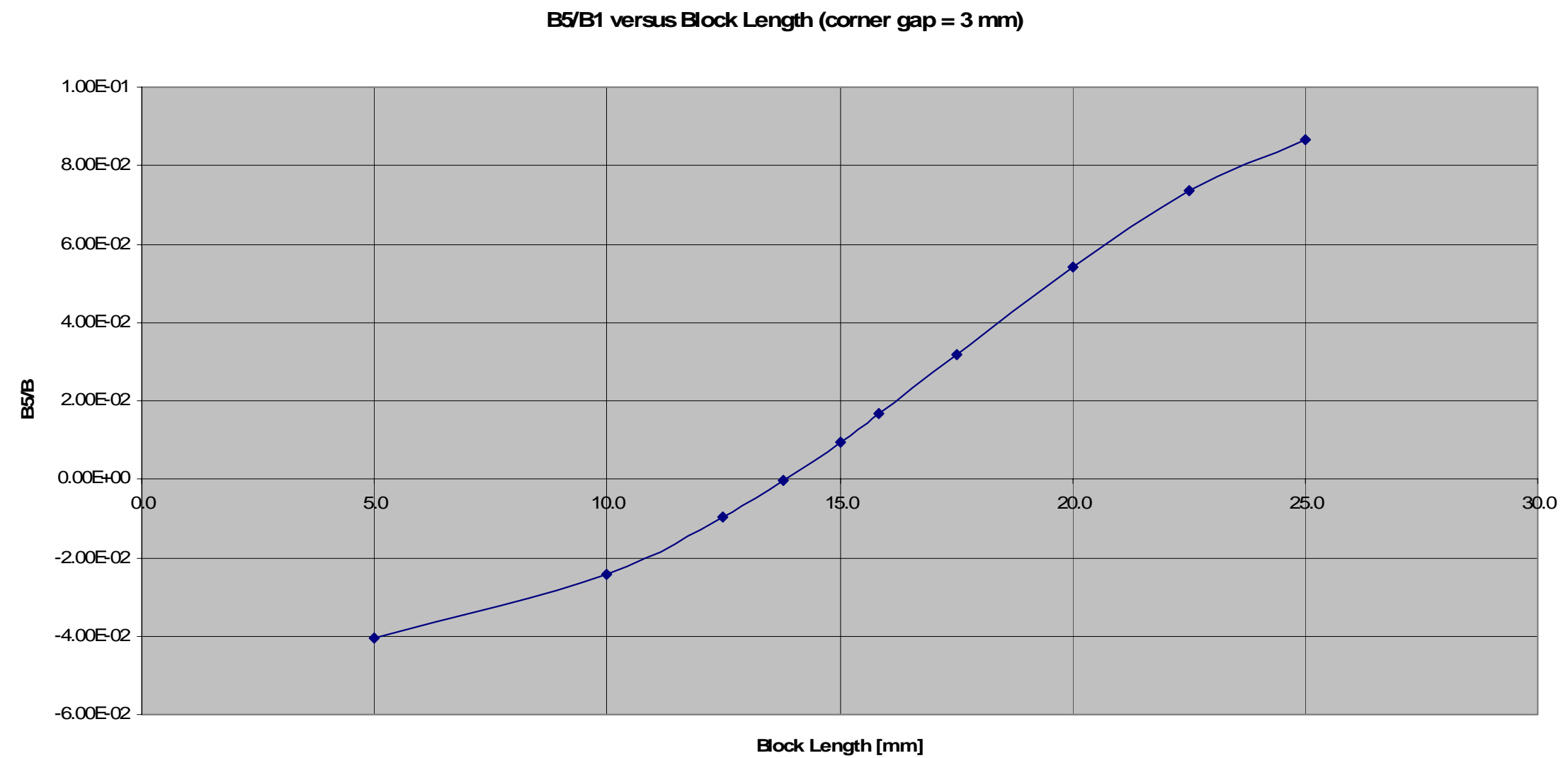

The 12-pole crosses zero at a block length of $\sim 13.80 \mathrm{~mm}$ 


\section{B9/B1 versus Block Length $($ gap $=3 \mathrm{~mm})$}

\section{B9/B1 versus Block Length (corner gap $=\mathbf{3} \mathbf{~ m m}$ )}

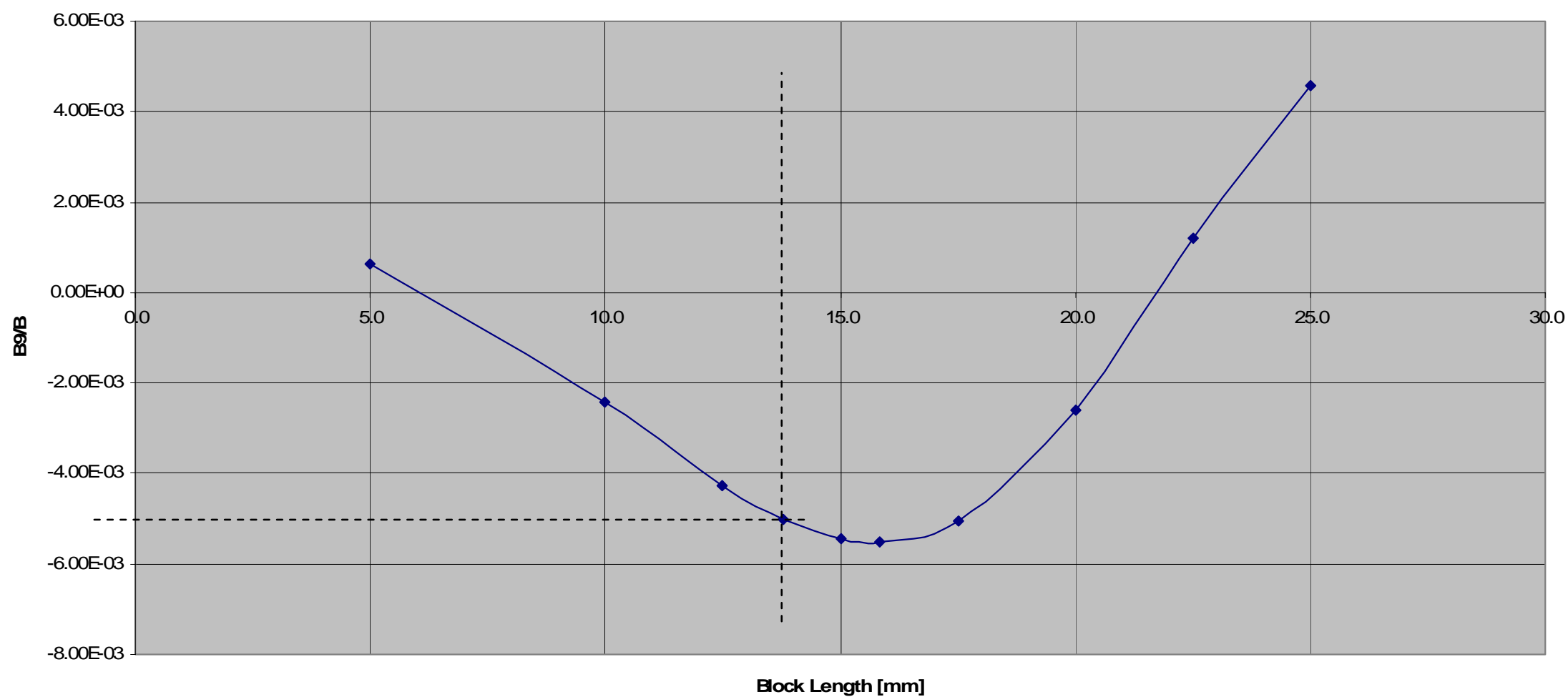

Using a block length of $13.80 \mathrm{~mm}$, which minimizes B5, leads to a B9/B1 of about 5 E-3. A comparison of the B5 and B9 curves shows that the 2 MP fields cannot be minimized simultaneously by changing the aspect ratio of the current blocks.

This result is of course obvious. A MP field is minimized for a well defined angular coverage of the current block and therefore cannot minimize the next higher MP field simultaneously. 


\section{Variation of Block Shape $(3 \times 3$ array, gap $=3 \mathrm{~mm})$}

\section{Cell Parameters:}

Aperture

Current blocks/cell

Contributing quad cells

Cell size

Block width

Cable width:

Block lenght:

Block aspect ratio:

Corner gap:

Reference radius

Block ampere-turns:

$$
\mathrm{R}_{\mathrm{ap}}=30 \mathrm{~mm}
$$

iblock $=8$

mcell $=9$

dcell $=70 \mathrm{~mm}$

$\mathrm{D}_{\mathrm{B}}=5 \mathrm{~mm}$

$\mathrm{L}_{\mathrm{B}}=13.2 \mathrm{~mm}$

$\frac{L_{B}}{D_{B}}=2.64$

$\mathrm{L}_{\text {gap }}=3 \mathrm{~mm}$

$\mathrm{R}_{\mathrm{O}}=20 \mathrm{~mm}$

Iblock $=5 \times 10^{4} \mathrm{amp}$

\section{Quadrupole field on $\mathbf{R}_{\mathbf{0}}: \quad \mathrm{B}_{\text {total }}(1)_{1}=2.201$ tesla}

Gradient: $\quad \operatorname{grad}:=\frac{\mathrm{B}_{\mathrm{total}}(1) 1}{0.02 \cdot \mathrm{m}} \quad \operatorname{grad}=110.07 \frac{\text { tesla }}{\mathrm{m}}$

Field Uniformity: $\quad \frac{\mathrm{B}_{\text {total }}(5)_{1}}{\mathrm{~B}_{\mathrm{total}}(1)_{1}}=-9.3 \times 10^{-5}$

$$
\begin{aligned}
& \frac{\mathrm{B}_{\text {total }}(9)_{1}}{\mathrm{~B}_{\text {total }}(1)_{1}}=-2.81 \times 10^{-3} \\
& \frac{\mathrm{B}_{\text {total }}(13)_{1}}{\mathrm{~B}_{\text {total }}(1)_{1}}=9.69 \times 10^{-5} \\
& \frac{\mathrm{B}_{\text {total }}(1)_{1}}{\mathrm{~B}_{\text {total }}(1)_{1}}=1.03 \times 10^{-5}
\end{aligned}
$$

For the full $3 \times 3$ array the field in the center cell requires a slightly different block length $(13.2 \mathrm{~mm})$ for the smallest B5. The other MP fields are smaller than for an individual cell. The B9 has decreased by a factor of about 2, but is still too large. 


\section{Variation of Block Shape (single cell, gap $=1.5 \mathrm{~mm}$ )}

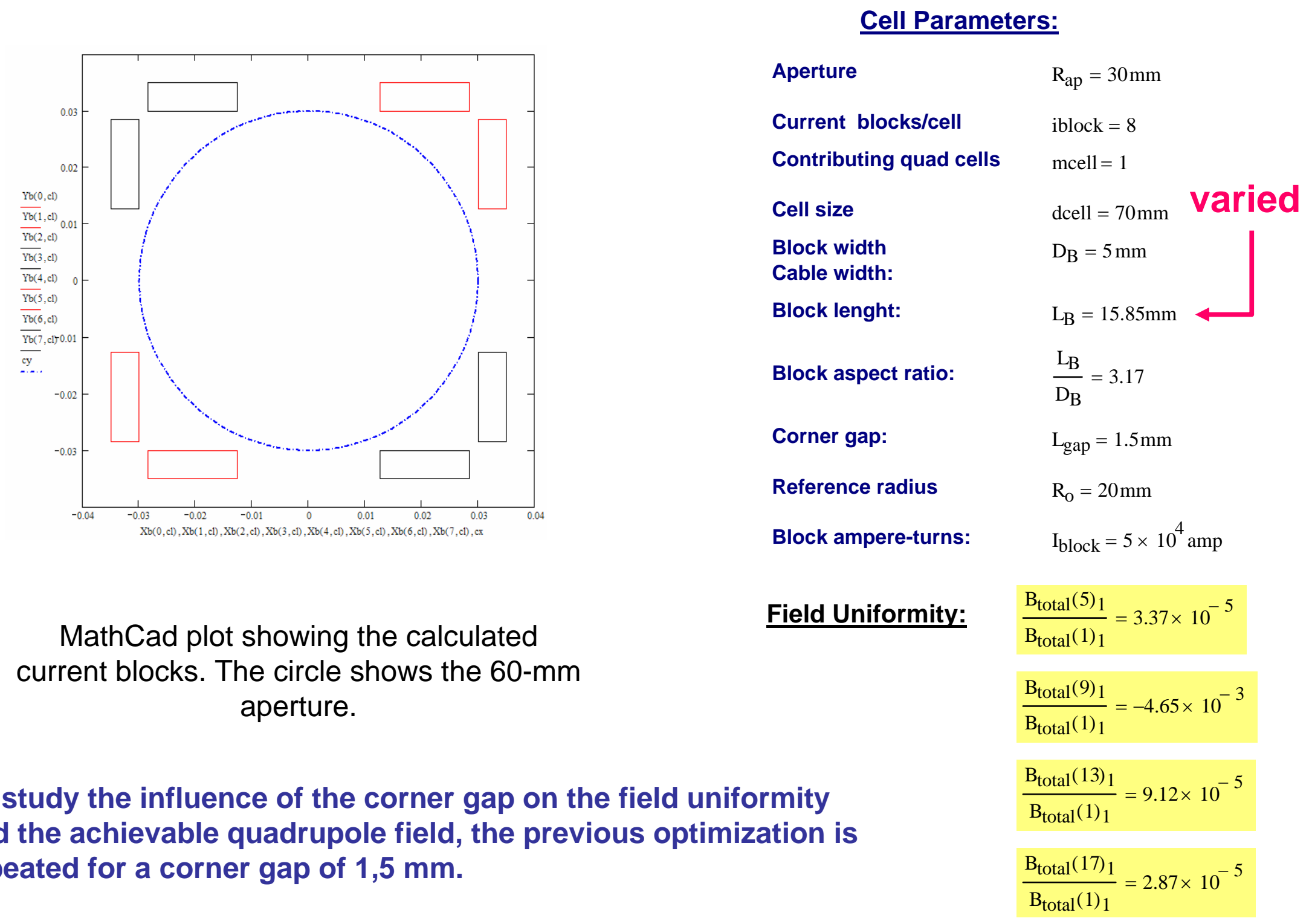




\section{Field Uniformity versus Block Length (single cell)}

Corner gap $=1.5 \mathrm{~mm}, \mathrm{I}_{\text {block }}=50,000$

\begin{tabular}{|l|r|r|r|r|r|r|r|r|r|r|}
\hline \multicolumn{10}{|c|}{ Single Cell } \\
\hline Block length [mm] & 5.0 & 10.0 & 12.5 & 13.8 & 15.0 & 15.85 & 17.5 & 20.0 & 22.5 & 25.0 \\
\hline Block width [mm] & 5.0 & 5.0 & 5.0 & 5.0 & 5.0 & 5.0 & 5.0 & 5.0 & 5.0 & 5.0 \\
\hline Corner gap [mm] & 1.5 & 1.5 & 1.5 & 1.5 & 1.5 & 1.5 & 1.5 & 1.5 & 1.5 & 1.5 \\
\hline Quad Field on Ro (B1) & 0.901 & 0.938 & 0.947 & 0.948 & 0.947 & 0.945 & 0.938 & 0.917 & 0.884 & 0.838 \\
\hline B5/B1 & $-4.31 \mathrm{E}-02$ & $-3.27 \mathrm{E}-02$ & $-2.17 \mathrm{E}-02$ & $-1.42 \mathrm{E}-02$ & $-6.19 \mathrm{E}-03$ & $3.37 \mathrm{E}-05$ & $1.32 \mathrm{E}-02$ & $3.48 \mathrm{E}-02$ & $5.57 \mathrm{E}-02$ & $7.22 \mathrm{E}-02$ \\
\hline B9/B1 & $1.30 \mathrm{E}-03$ & $-8.89 \mathrm{E}-04$ & $-2.63 \mathrm{E}-03$ & $-3.54 \mathrm{E}-03$ & $-4.26 \mathrm{E}-03$ & $-4.65 \mathrm{E}-03$ & $-4.95 \mathrm{E}-03$ & $-3.89 \mathrm{E}-03$ & $-9.74 \mathrm{E}-04$ & $2.68 \mathrm{E}-03$ \\
\hline B13/B1 & $-2.83 \mathrm{E}-06$ & $2.04 \mathrm{E}-04$ & $2.69 \mathrm{E}-04$ & $2.45 \mathrm{E}-04$ & $1.73 \mathrm{E}-04$ & $9.12 \mathrm{E}-05$ & $-1.22 \mathrm{E}-04$ & $-4.29 \mathrm{E}-04$ & $-3.93 \mathrm{E}-04$ & $9.43 \mathrm{E}-05$ \\
\hline B17/B1 & $-3.52 \mathrm{E}-06$ & $-1.33 \mathrm{E}-05$ & $-2.94 \mathrm{E}-06$ & $9.14 \mathrm{E}-06$ & $2.16 \mathrm{E}-05$ & $2.87 \mathrm{E}-05$ & $3.04 \mathrm{E}-05$ & $-1.16 \mathrm{E}-05$ & $-6.16 \mathrm{E}-05$ & $2.28 \mathrm{E}-05$ \\
\hline
\end{tabular}

The MP fields shown in the table are for a reference radius of $20 \mathrm{~mm}$, i.e. $2 / 3$ of the coil aperture. The block width is $5 \mathrm{~mm}$, which is the width of a realistic cable.

B5 and B9 are the only MP fields of relevance. The higher MP fields are for all block lengths in the order of $10^{-4}$ or $10^{-5}$. 


\section{2 -pole versus Block Length (gap $=1.5 \mathrm{~mm}$, single cell)}

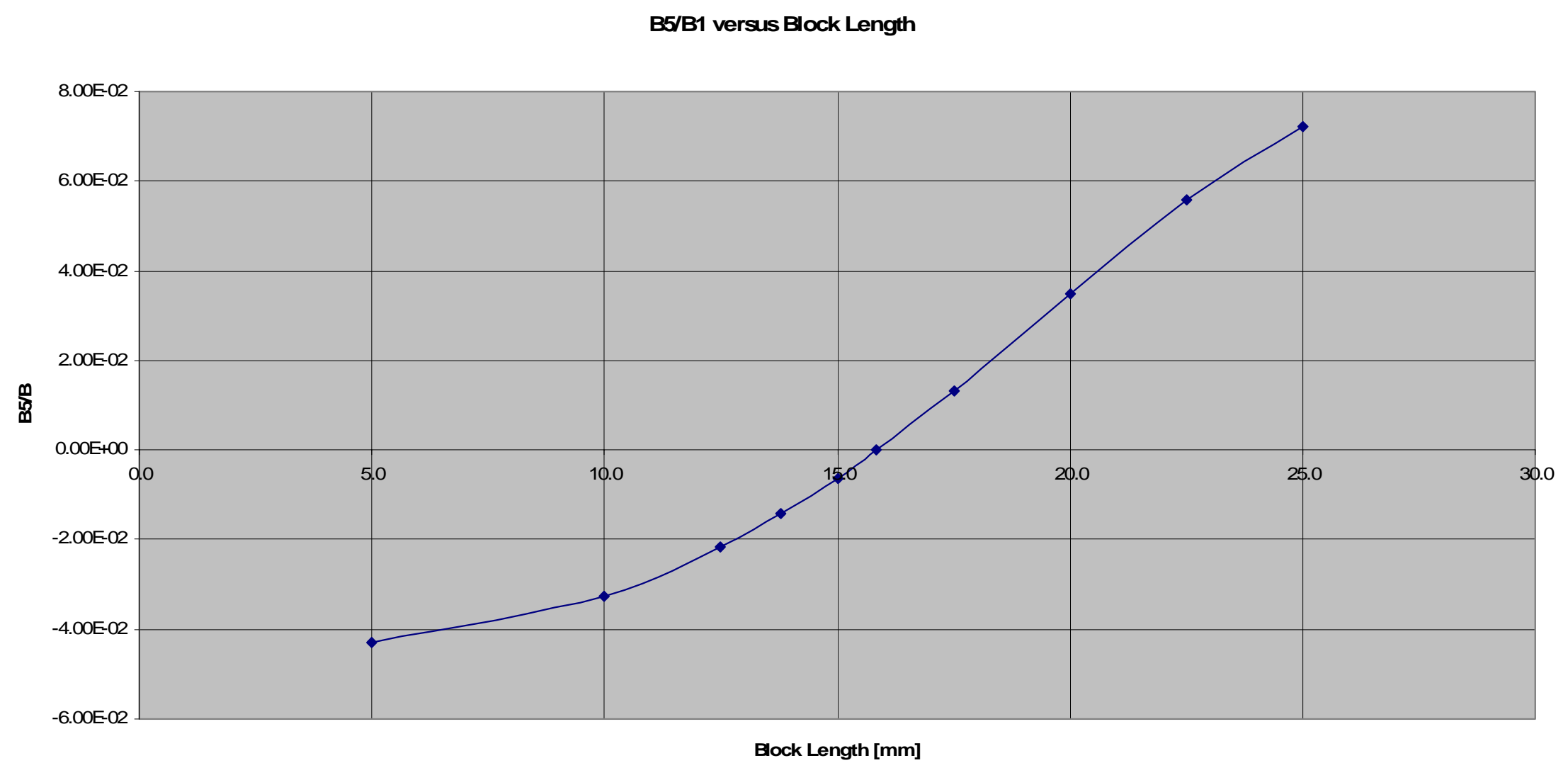

The 12-pole crosses zero at a block length of $\sim 15.85 \mathrm{~mm}$ for a single cell, which is significantly larger than for the $3 \mathrm{~mm}$ corner gap. 


\section{B9/B1 versus Block Length (gap $=1.5 \mathrm{~mm}$, single cell)}

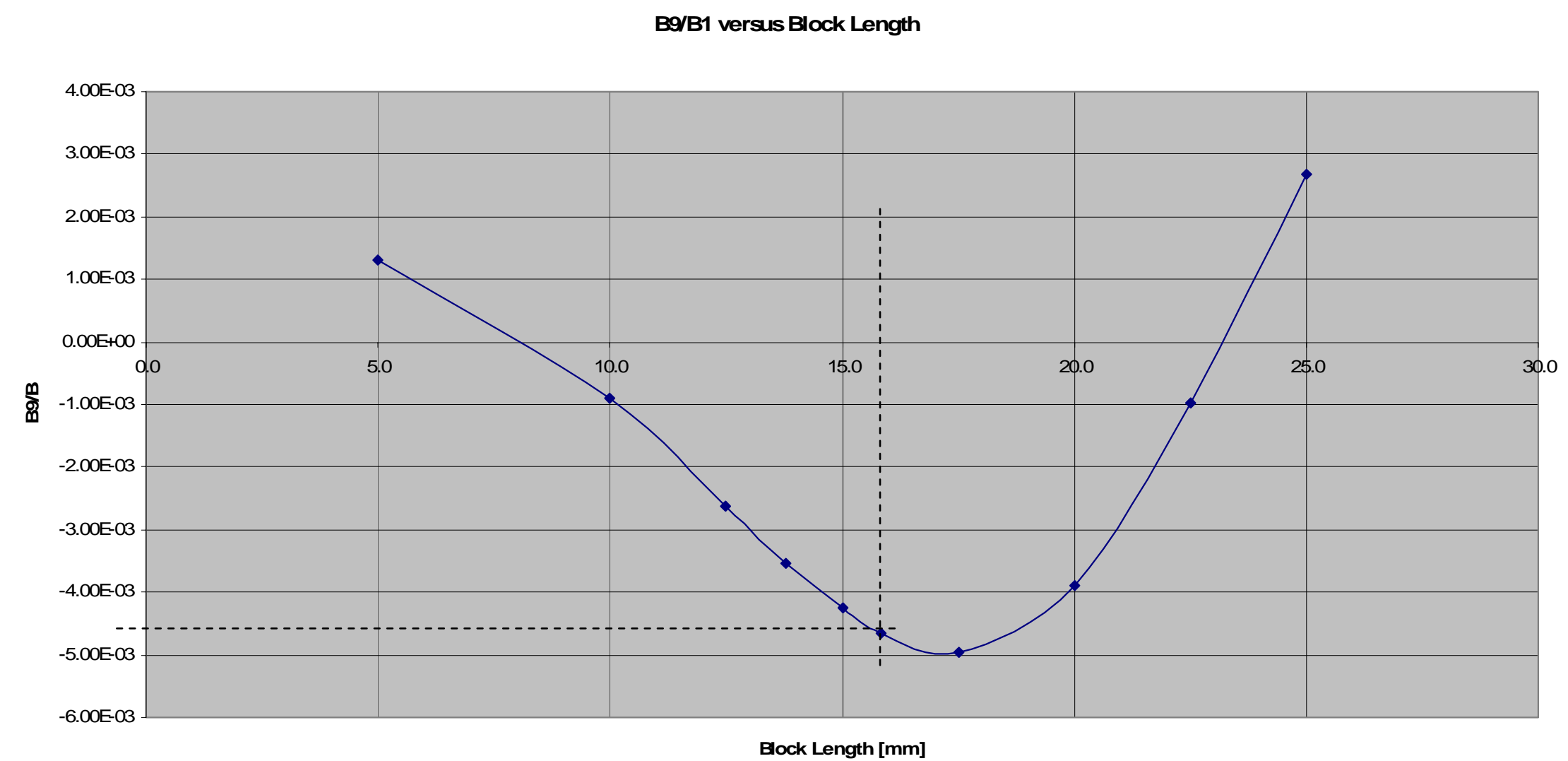

Using a block length of $15.85 \mathrm{~mm}$, which minimizes B5 leads to a B9/B1 of about 4.6 E-3. As for the 3-mm corner gap B5 and B9 cannot be minimized simultaneously. 


\section{Variation of Block Shape ( $3 \times 3$ array, gap $=1.5 \mathrm{~mm}$ )}

Cell Parameters:

Aperture

Current blocks/cell

Contributing quad cells

Cell size

Block width

Cable width:

Block lenght:

Block aspect ratio:

Corner gap:

Reference radius

Block ampere-turns:

$$
\mathrm{R}_{\mathrm{ap}}=30 \mathrm{~mm}
$$

iblock $=8$

mcell $=9$

dcell $=70 \mathrm{~mm}$

$\mathrm{D}_{\mathrm{B}}=5 \mathrm{~mm}$

$\mathrm{L}_{\mathrm{B}}=15.4 \mathrm{~mm}$

$\frac{L_{B}}{D_{B}}=3.08$

$L_{\text {gap }}=1.5 \mathrm{~mm}$

$\mathrm{R}_{\mathrm{O}}=20 \mathrm{~mm}$

Iblock $=5 \times 10^{4} \mathrm{amp}$
Field Uniformity: $\quad \frac{\mathrm{B}_{\text {total }}(5)_{1}}{\mathrm{~B}_{\text {total }}(1)_{1}}=-4.04 \times 10^{-5}$

$\frac{\mathrm{B}_{\text {total }}(9)_{1}}{\mathrm{~B}_{\text {total }}(1)_{1}}=-2.59 \times 10^{-3}$

$\frac{\mathrm{B}_{\text {total }}(13)_{1}}{\mathrm{~B}_{\text {total }}(1)_{1}}=5.37 \times 10^{-5}$

$\frac{\mathrm{B}_{\text {total }}(17)_{1}}{\mathrm{~B}_{\text {total }}(1)_{1}}=1.21 \times 10^{-5}$

Quadrupole field on $\mathbf{R}_{\mathbf{o}}: \quad \mathrm{B}_{\mathrm{total}}(1)_{1}=2.201$ tesla

Gradient: $\quad \operatorname{grad}:=\frac{\mathrm{B}_{\text {total }}(1) 1}{0.02 \cdot \mathrm{m}} \quad \operatorname{grad}=110.03 \frac{\text { tesla }}{\mathrm{m}}$

For the full $3 \times 3$ array the field in the center cell requires a slightly different block length $(15.4 \mathrm{~mm})$ for smallest B5. All higher-order MP fields are smaller than for the single cell. B9 has decreased by a factor of about 2, but is still too large. 


\section{Comparison of $1.5 \mathrm{~mm}$ and $3 \mathrm{~mm}$ Gap}

\begin{tabular}{|l|r|r|}
\hline \multicolumn{3}{|c|}{ Array } \\
\hline Block length [mm] & 13.20 & 15.40 \\
\hline Block width [mm] & 5.0 & 5.0 \\
\hline Corner gap [mm] & 3.0 & 1.5 \\
\hline Quad Field on Ro (B1) & $\mathbf{2 . 2 0}$ & $\mathbf{2 . 2 0}$ \\
\hline Aspect Ratio & 2.64 & 3.08 \\
\hline Block Area & 66.00 & 77.00 \\
\hline Block Area Ratio & & $\mathbf{1 . 1 7}$ \\
\hline B5/B1 & $-9.30 \mathrm{E}-05$ & $-4.04 \mathrm{E}-05$ \\
\hline B9/B1 & $-2.81 \mathrm{E}-03$ & $-2.59 \mathrm{E}-03$ \\
\hline B13/B1 & $9.69 \mathrm{E}-05$ & $5.37 \mathrm{E}-05$ \\
\hline B17/B1 & $1.03 \mathrm{E}-05$ & $1.21 \mathrm{E}-05$ \\
\hline
\end{tabular}

In both cases the same total ampere turns (current) were used for the blocks. The quadrupole fields and the field uniformity for both cases is the same. However, the block area for the smaller corner gap is $17 \%$ larger, which means that a larger quadrupole field and gradient is possible for a given margin (assuming that the peak fields are about the same) for the smaller corner gap. 


\section{Minimizing B5 and B9 Simultaneously}

- It needs to be analyzed if B9 and B5 can be minimized simultaneously by placing an iron pole into the coil.

- Such a pole should have the geometry shown below:

> By optimizing depth and width of the two pockets, the iron should have a similar effect as two conductor layers with different extensions, as needed for simultaneously optimizing B5 and B9.

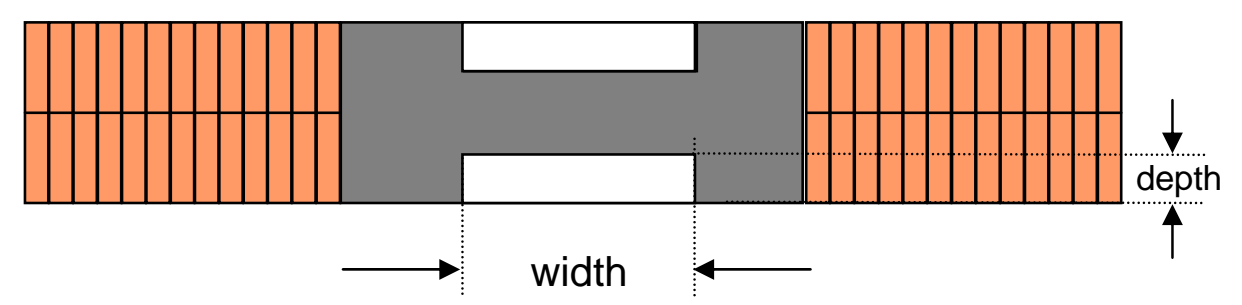




\section{Optimzation of \\ Quadrupole Array Field Uniformity}

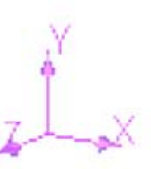

C. Goodzeit, R. Meinke, M. Ball AML

$1 / 24 / 2005$

DoE Award No. DE-FG02-04ER86205 


\section{Field Uniformity Optimization}

\section{Executive Summary:}

Previous analysis has shown that the twelve and twenty pole of an individual cell and of the array center cell cannot be simultaneously reduced to the required level of a few times $10^{-4}$ by only changing the aspect ratio of the current blocks.

The required extra degree of freedom can be introduced by placing a spacer into the pancake winding. A non-conducting material with the width of the cable can be wrapped around the coil after the appropriate number of turns to generate the required gap in the pancake winding.

Introducing the spacer in the winding gives a total of 3 degrees of freedom, i.e., the block aspect ratio, the start location and the width of the spacer. Of these parameters, the start location is quantized, since the spacer has to start after an integer number of turns.

It is almost impossible to perform a function optimization with more than 2 parameters by a try and error method. (I tried without success.) A flexible and reliable optimization code is therefore needed.

After comparing the various options for such an optimization, Excel was chosen. The somewhat surprising choice for this optimization approach are justified below.

Using the Excel program, all higher-order MP fields for a single cell are simultaneously reduced to less than $5 \times 10^{-5}$. 


\section{MP Fields of Rectangular Current Blocks}

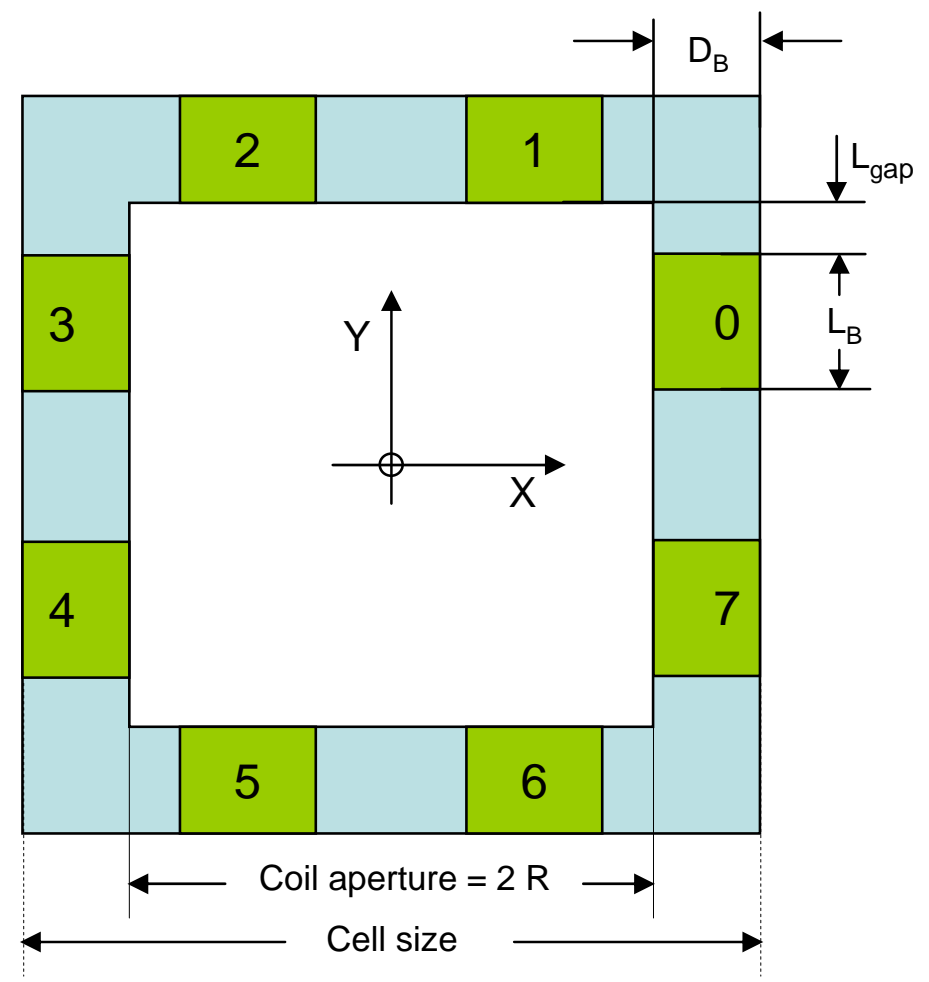

- As in the previous analysis the quadrupole cells are built up with 4 identical single pancake coils.

a In 2-D, each coil consists of 2 current blocks as shown in the sketch. The current blocks 1-2, 3-4, 5-6 and 7-0 form the 4 coils.

a The coils are described by 4 parameters:

$>L_{B}: \quad$ Block length

> $\mathrm{D}_{\mathrm{B}}$ : Block width (cable width)

$>\mathrm{L}_{\text {gap }}: \quad$ Gap in the corner

$>\mathrm{R}$ : $\quad$ Aperture radius

ㄱe cell size in this model is given by:

$$
\text { cell size }=2 R+2 D_{B}
$$




\section{Spacer Description}

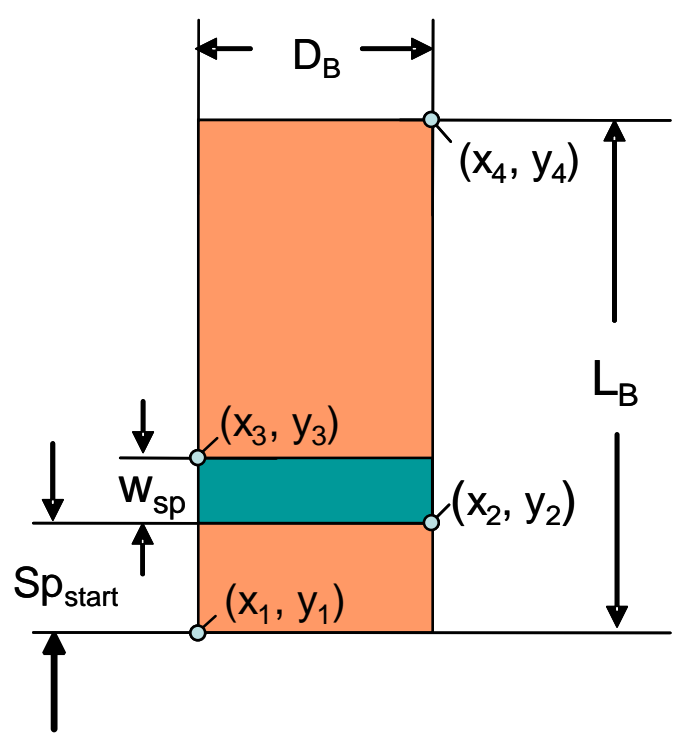

A spacer is introduced into each current block as indicated in the sketch.

The spacer is described by two parameters, i.e., the start location $\mathrm{SP}_{\text {start }}$, measured from the pole face and the width of the spacer, $\mathrm{W}_{\mathrm{sp}}$.

Such a spacer is introduced into the pancake winding as follows. After a certain number of turns a nonconducting, sufficiently solid material with the width of the cable is wrapped around the existing winding pattern as shown in the sketch below.

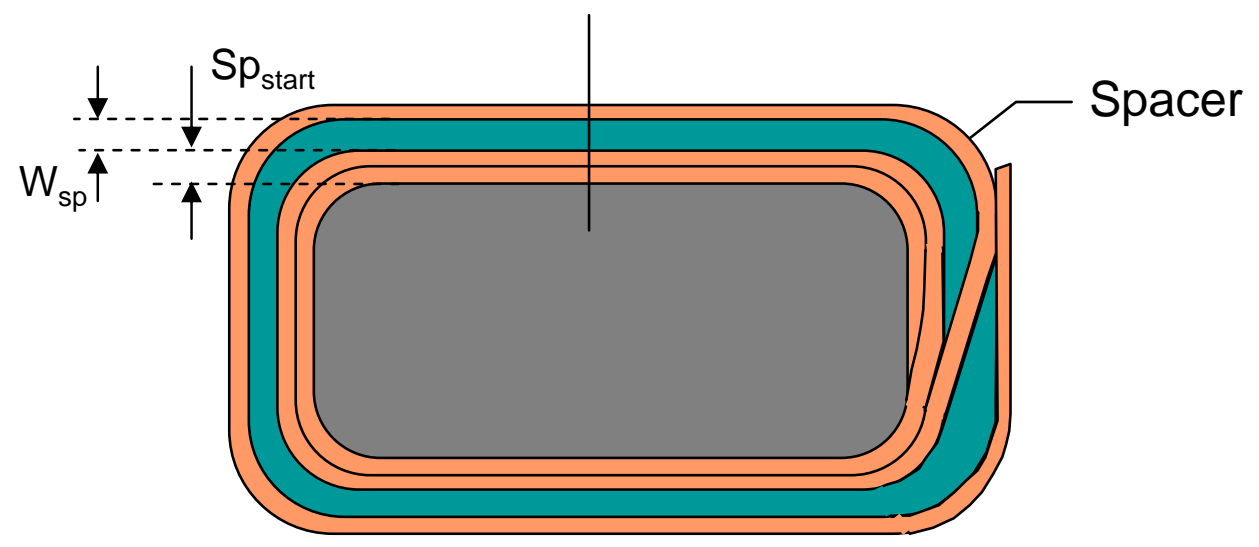




\section{Optimization Requirements}

- The optimizer for the required field uniformity optimization should allow for a wide spectrum of constraints. Most of the dimensions in the optimization have to be greater than zero and greater or smaller than other parameters to yield meaningful solutions.

- After considering several possibilities like MathCAD, a Fortran- or C-program, it was decided to use Excel. Excel includes a very powerful optimizer for complex models and allows for almost arbitrary constraints on parameters.

- Excel allows for User-Defined functions, which can be called like the build-in functions. The large function library of Excel and Visual Basic are directly accessible for these user-defined functions. As for build-in functions, the user-defined functions are automatically updated whenever a function argument changes.

- Optimization is simply performed by specifying the optimization target cell and the cells which should be modified for this optimization. 


\section{Excel Array Input}

\begin{tabular}{|l|c|c|r|}
\hline \multicolumn{4}{|c|}{ Block Defining Parameters } \\
\hline Parameter & Name & Unit & Value \\
\hline Number of cells per block & & & \\
\hline Aperture radius & Iblock & - & \\
\hline Corner gap & Rap & $\mathrm{m}$ & 0.03000 \\
\hline Block width (cable width) & Lgap & $\mathrm{m}$ & 0.00150 \\
\hline Block length & DB & $\mathrm{m}$ & 0.00500 \\
\hline Spacer distance from pole & LB & $\mathrm{m}$ & 0.01600 \\
\hline Spacer width & SPstart & $\mathrm{m}$ & 0.00300 \\
\hline
\end{tabular}

Block parameters for optimization, Start Values

\begin{tabular}{|l|c|c|r|}
\hline \multicolumn{4}{|c|}{ General Parameters } \\
\hline Reference Radius & Ro & $\mathrm{m}$ & 0.02000 \\
\hline Size of Block sub-division & SubDiv & $\mathrm{m}$ & 0.00100 \\
\hline Engineering current density & EngCD & $1 / \mathrm{mm} 2$ & 690 \\
\hline
\end{tabular}

\begin{tabular}{|l|c|c|r|}
\hline \multicolumn{4}{|c|}{ Derived Cell Parameters } \\
\hline Cell size & Dcell & $\mathrm{m}$ & 0.07000 \\
\hline Pole width & Wpole & $\mathrm{m}$ & 0.01565 \\
\hline
\end{tabular}




\section{Excel Array Input}

\begin{tabular}{|c|c|c|c|c|c|c|c|c|c|c|c|}
\hline \multicolumn{12}{|c|}{ Define Center Cell of Array } \\
\hline & X1 & $X 2$ & Y1 & Y2 & $\begin{array}{c}\text { Amp- } \\
\text { Turns 12 }\end{array}$ & sign & X3 & X4 & Y3 & Y4 & $\begin{array}{c}\text { Amp- } \\
\text { Turns } 34\end{array}$ \\
\hline \multicolumn{12}{|c|}{ Block } \\
\hline 0 & 0.030 & 0.035 & \begin{tabular}{l|l|}
0.013 \\
\end{tabular} & 0.016 & 10,350 & 1 & 0.030 & 0.035 & 0.019 & 0.029 & 34,500 \\
\hline 1 & -0.035 & -0.030 & \begin{tabular}{l|l|}
0.013 \\
\end{tabular} & 0.016 & $-10,350$ & -1 & -0.035 & -0.030 & 0.019 & 0.029 & $-34,500$ \\
\hline 2 & -0.035 & -0.030 & \begin{tabular}{|c|}
-0.016 \\
\end{tabular} & -0.013 & 10,350 & 1 & -0.035 & -0.030 & -0.029 & -0.019 & 34,500 \\
\hline 3 & 0.030 & 0.035 & -0.016 & -0.013 & $-10,350$ & -1 & 0.030 & 0.035 & -0.029 & -0.019 & $-34,500$ \\
\hline 4 & 0.013 & 0.016 & 0.030 & 0.035 & 10,350 & 1 & 0.019 & 0.029 & 0.030 & 0.035 & 34,500 \\
\hline 5 & -0.016 & -0.013 & \begin{tabular}{l|l|}
0.030 \\
\end{tabular} & 0.035 & $-10,350$ & -1 & -0.029 & -0.019 & 0.030 & 0.035 & $-34,500$ \\
\hline 6 & -0.016 & -0.013 & -0.035 & -0.030 & 10,350 & 1 & -0.029 & -0.019 & -0.035 & -0.030 & 34,500 \\
\hline 7 & 0.013 & 0.016 & \begin{tabular}{l|}
-0.035 \\
\end{tabular} & -0.030 & $-10,350$ & -1 & 0.019 & 0.029 & -0.035 & -0.030 & $-34,500$ \\
\hline
\end{tabular}

Cell corner coordinates calculated for the given start value parameters.

Only one Block of the cell needs to be defined, all others follow simply from the symmetry of the system.

For an individual cell without neighbors one block is sufficient for the field calculations. For the array calculations the symmetry is broken for the edge cells and all blocks are needed. 


\section{MP Field Calculation}

\section{=B_block(MP1,I35:M35)+ B_block(MP1,035:S35)}

\begin{tabular}{|c|c|c|c|c|c|c|c|c|}
\hline \multicolumn{9}{|c|}{ Calculate MP Fields } \\
\hline & A1 Block & B1 Block & $\begin{array}{c}\text { A5 } \\
\text { Block }\end{array}$ & B5 Block & A9 Block & B9 Block & $\begin{array}{c}\text { A13 } \\
\text { Block }\end{array}$ & $\begin{array}{c}\text { B13 } \\
\text { Block }\end{array}$ \\
\hline MP-Order & 1 & 1 & & 5 & 9 & 9 & 13 & 13 \\
\hline Block 0 & & 0.105 & 2 & $-4.8 \mathrm{E}-04$ & & $-3.7 \mathrm{E}-04$ & & $-2.1 E-06$ \\
\hline Block 1 & & 0.105 & & $-4.8 \mathrm{E}-04$ & & $-3.7 \mathrm{E}-04$ & & $-2.1 \mathrm{E}-06$ \\
\hline Block 2 & & 0.105 & & $-4.8 \mathrm{E}-04$ & & $-3.7 \mathrm{E}-04$ & & $-2.1 E-06$ \\
\hline Block 3 & & 0.105 & & $-4.8 \mathrm{E}-04$ & & $-3.7 \mathrm{E}-04$ & & $-2.1 \mathrm{E}-06$ \\
\hline Block 4 & & 0.105 & & $-4.8 \mathrm{E}-04$ & & $-3.7 E-04$ & & $-2.1 E-06$ \\
\hline Block 5 & & 0.105 & & $-4.8 \mathrm{E}-04$ & & $-3.7 E-04$ & & $-2.1 E-06$ \\
\hline Block 6 & & 0.105 & & $-4.8 E-04$ & & $-3.7 E-04$ & & $-2.1 E-06$ \\
\hline \multirow[t]{3}{*}{ Block 7} & & 0.105 & & $-4.8 \mathrm{E}-04$ & & $-3.7 E-04$ & & $-2.1 E-06$ \\
\hline & & & & & & & & \\
\hline & $\begin{array}{c}\text { A1 } \\
\text { Total }\end{array}$ & $\begin{array}{c}\text { B1 } \\
\text { Total }\end{array}$ & A5 Total & $\begin{array}{c}\text { B5 } \\
\text { Total }\end{array}$ & $\begin{array}{c}\text { A9 } \\
\text { Total }\end{array}$ & $\begin{array}{c}\text { B9 } \\
\text { Total }\end{array}$ & $\begin{array}{c}\text { A13 } \\
\text { Total }\end{array}$ & $\begin{array}{l}\text { B13 } \\
\text { Total }\end{array}$ \\
\hline Norm. Fields & 0.000 & 0.840 & $0.000 \mathrm{E}+00$ & 4.550E-03 & $0.000 \mathrm{E}+00$ & 3.494E-03 & $0.000 \mathrm{E}+00$ & 2.032E-05 \\
\hline Units & & & $0.000 \mathrm{E}+00$ & 4.550E+01 & $0.000 \mathrm{E}+00$ & 3.494E+01 & $0.000 \mathrm{E}+00$ & 2.032E-01 \\
\hline
\end{tabular}

B_block is the user-defined function for the MP calculation. Argument MP1 is the MP order, 135:M35 is the cell range defining the corner coordinates. Each wdg. pack consists of 2 blocks due to the spacer. 


\section{Solver (Optimization) Call}

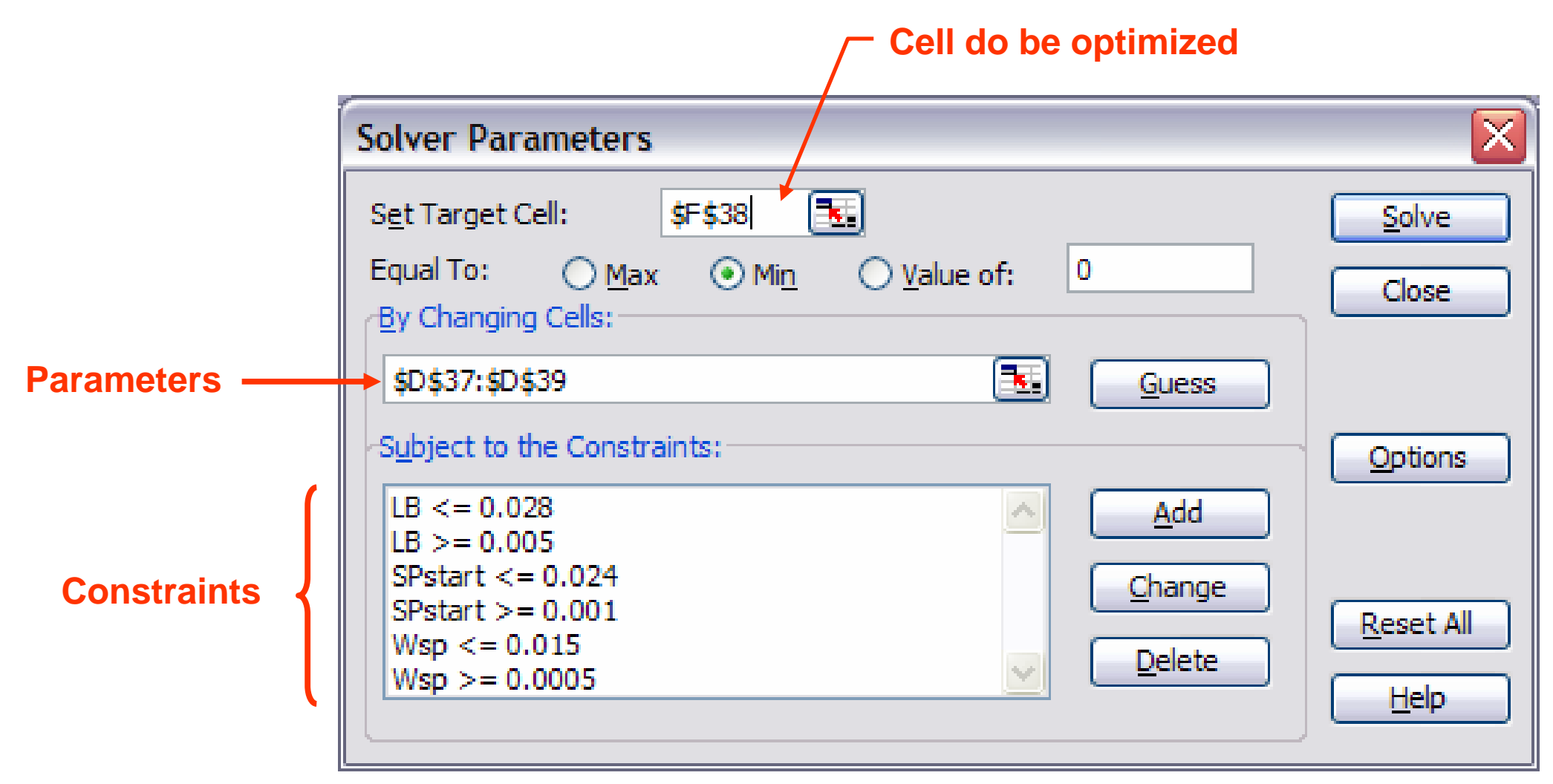

The Cell to be minimized contains |B5/B1| + 2*|B9/B1|. The weight "2" on B9 was necessary to reduce it sufficiently. 


\section{Solution for "Realistic" Spacer Start}

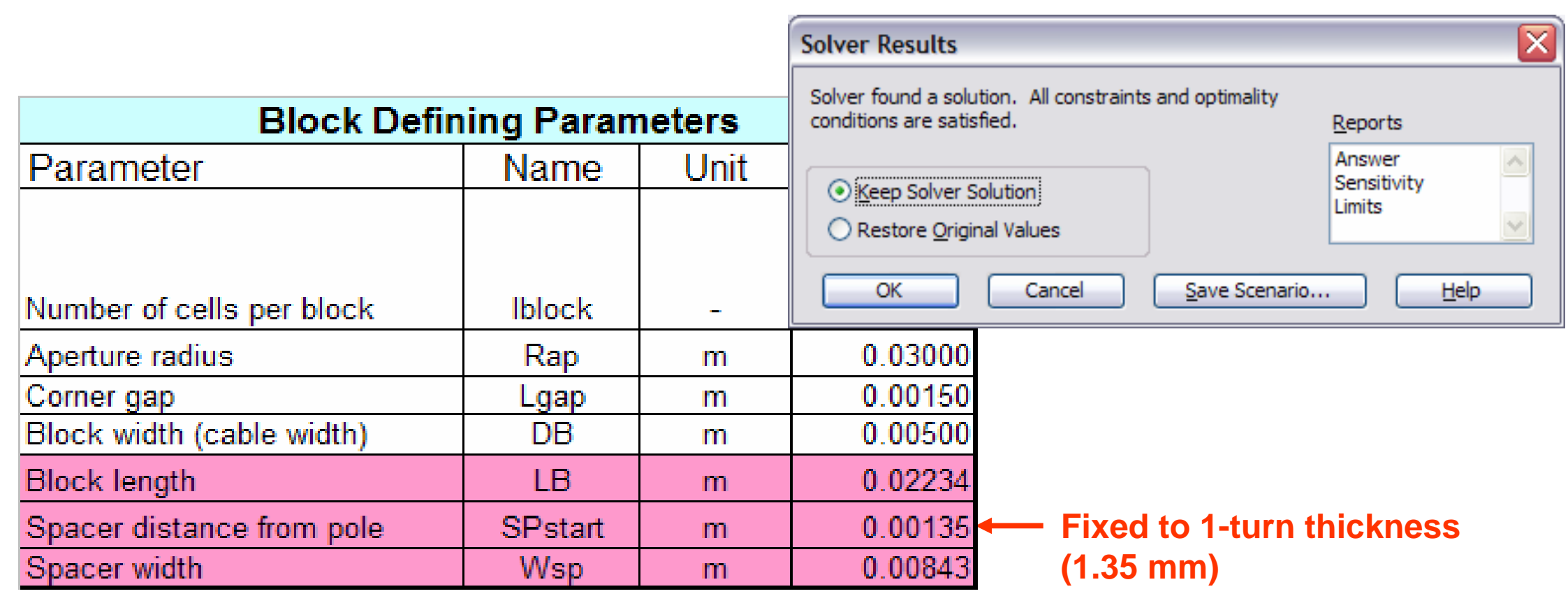

\begin{tabular}{|c|c|c|c|c|c|c|c|c|}
\hline & $\begin{array}{c}\text { A1 } \\
\text { Total }\end{array}$ & $\begin{array}{c}\text { B1 } \\
\text { Total }\end{array}$ & $\begin{array}{c}\text { A5 } \\
\text { Total }\end{array}$ & $\begin{array}{c}\text { B5 } \\
\text { Total }\end{array}$ & $\begin{array}{c}\text { A9 } \\
\text { Total }\end{array}$ & $\begin{array}{c}\text { B9 } \\
\text { Total }\end{array}$ & $\begin{array}{c}\text { A13 } \\
\text { Total }\end{array}$ & $\begin{array}{c}\text { B13 } \\
\text { Total }\end{array}$ \\
\hline Norm. Fields & 0.000 & 0.875 & $0.000 \mathrm{E}+00$ & $7.465 \mathrm{E}-09$ & $0.000 \mathrm{E}+00$ & $4.949 \mathrm{E}-09$ & $0.000 \mathrm{E}+00$ & $3.209 \mathrm{E}-04$ \\
\hline Units & & & $0.000 \mathrm{E}+00$ & $7.465 \mathrm{E}-05$ & $0.000 \mathrm{E}+00$ & $4.949 \mathrm{E}-05$ & $0.000 \mathrm{E}+00$ & $3.209 \mathrm{E}+00$ \\
\hline
\end{tabular}

All MP below $5 \times 10^{-4}$ 


\section{Optimizing Cable Width}

In the optimization shown on the previous pages the spacer start is fixed to one cable thickness, i.e., $1.35 \mathrm{~mm}$. I have tried various other solutions with 2, 3,... cable width, but no solution can be found, where all higher-order MP are below 10 units. This result is also confirmed by leaving this parameter also free. In this case the optimum start of the spacer is at $1.63 \mathrm{~mm}$, which could be accommodated with a cable of that width.

\begin{tabular}{|l|c|c|r|}
\hline \multicolumn{4}{|c|}{ Block Defining Parameters } \\
\hline Parameter & Name & Unit & Value \\
\hline Number of blocks per cell & lblock & - & 8 \\
\hline Aperture radius & Rap & m & 0.03000 \\
\hline Corner gap & Lgap & m & 0.00150 \\
\hline Block width (cable width) & DB & m & 0.00440 \\
\hline Block length & LB & m & 0.02079 \\
\hline Spacer distance from pole & SPstart & m & 0.00163 \\
\hline Spacer width & Wsp & m & 0.00766 \\
\hline
\end{tabular}

\begin{tabular}{|c|c|c|c|c|c|c|c|c|} 
& A1 & B1 & A5 & B5 & A9 & B9 & A13 & B13 \\
\hline Norm. Fields & 0.000 & 0.740 & $0.000 \mathrm{E}+00$ & $2.117 \mathrm{E}-07$ & $0.000 \mathrm{E}+00$ & $5.485 \mathrm{E}-07$ & $0.000 \mathrm{E}+00$ & $1.917 \mathrm{E}-06$ \\
\hline Units & & & $0.000 \mathrm{E}+00$ & 0.00211684 & $0.000 \mathrm{E}+00$ & $5.485 \mathrm{E}-03$ & $0.000 \mathrm{E}+00$ & $1.917 \mathrm{E}-02$ \\
\hline
\end{tabular}

In this case the target cell $=\mathrm{B} 5^{2}+\mathrm{B}^{2}+\mathrm{B} 13^{2}$ was minimized. All MPs are well below 1 unit. 


\section{Optimization for 4-mm Corner Gap}

\begin{tabular}{|l|c|c|r|}
\hline \multicolumn{4}{|c|}{ Block Defining Parameters } \\
\hline Parameter & Name & Unit & Value \\
\hline Number of blocks per cell & Iblock & - & 8 \\
\hline Aperture radius & Rap & m & 0.03000 \\
\hline Corner gap & Lgap & $\mathrm{m}$ & 0.00400 \\
\hline Block width (cable width) & DB & $\mathrm{m}$ & 0.00440 \\
\hline Block length & LB & $\mathrm{m}$ & 0.01795 \\
\hline Spacer distance from pole & SPstart & $\mathrm{m}$ & 0.00119 \\
\hline Spacer width & Wsp & $\mathrm{m}$ & 0.00896 \\
\hline
\end{tabular}

\begin{tabular}{|c|c|c|c|c|c|c|c|c|} 
& A1 & B1 & A5 & B5 & A9 & B9 & A13 & B13 \\
\hline Norm. Fields & 0.000 & 0.514 & $0.000 \mathrm{E}+00$ & $1.193 \mathrm{E}-08$ & $0.000 \mathrm{E}+00$ & $1.211 \mathrm{E}-08$ & $0.000 \mathrm{E}+00$ & $1.314 \mathrm{E}-08$ \\
\hline Units & & & $0.000 \mathrm{E}+00$ & 0.00011928 & $0.000 \mathrm{E}+00$ & $1.211 \mathrm{E}-04$ & $0.000 \mathrm{E}+00$ & $1.314 \mathrm{E}-04$ \\
\hline
\end{tabular}

All MPs are vanishing for a cable width and spacer start of $1.19 \mathrm{~mm}$, which is actually a very "attractive" value for the cable width. However, since 17.95 cannot be exactly made with a 1.19-mm cable, I recalculate the MP content for $15^{\star} 1.19 \mathrm{~mm}=17.8 \mathrm{~mm}$. It still gives a very good field quality without any reoptimization. The larges MP (B5) is 2.5 units.

\begin{tabular}{|c|c|c|c|c|c|c|c|c|} 
& A1 & B1 & A5 & B5 & A9 & B9 & A13 & B13 \\
\hline Norm. Fields & 0.000 & 0.505 & $0.000 \mathrm{E}+00$ & $2.536 \mathrm{E}-04$ & $0.000 \mathrm{E}+00$ & $2.495 \mathrm{E}-05$ & $0.000 \mathrm{E}+00$ & $3.120 \mathrm{E}-05$ \\
\hline Units & & & $0.000 \mathrm{E}+00$ & 2.53631555 & $0.000 \mathrm{E}+00$ & $2.495 \mathrm{E}-01$ & $0.000 \mathrm{E}+00$ & $3.120 \mathrm{E}-01$ \\
\hline
\end{tabular}




\section{Effect of Corner Gap Size}

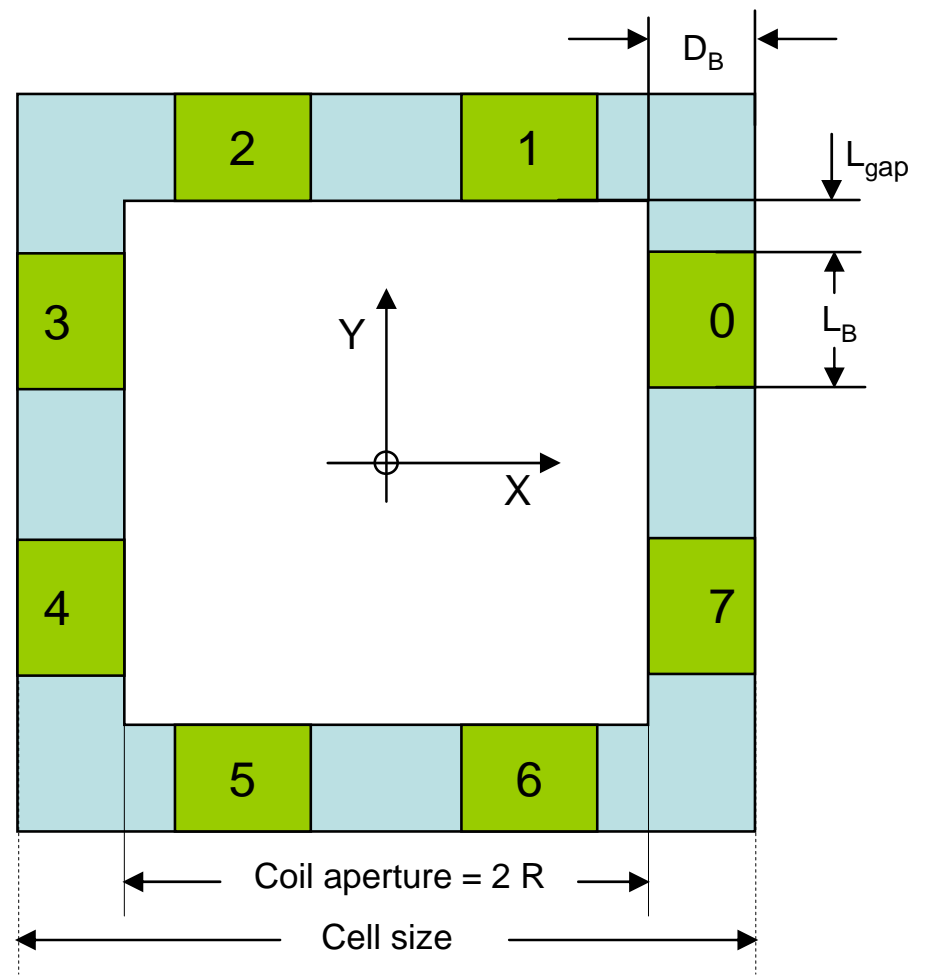

The size of the corner gap has been varied and the $3 \times 3$ array MP content in the center cell optimized for each case:

\begin{tabular}{|r|r|r|r|r|}
\hline Lgap & Grad. & \multicolumn{1}{c|}{ B5 } & \multicolumn{1}{c|}{ B9 } & \multicolumn{1}{c|}{ B13 } \\
\hline mm & \multicolumn{1}{c|}{ T/m } & units & units & \multicolumn{1}{c|}{ units } \\
\hline 1.00 & 103.7 & -1.3 & -5.5 & 2.3 \\
\hline 2.00 & 91.7 & 2.4 & -4.2 & 2.2 \\
\hline 3.00 & 77.6 & 4.6 & -3.3 & 1.3 \\
\hline 3.50 & 68.8 & 4.6 & -2.9 & 0.6 \\
\hline
\end{tabular}

Increasing the corner gap by $1 \mathrm{~mm}$ reduces the gradient for an array with optimized MP content by more than 10 tesla/m.

The calculated gradients shown above are for an engineering current density of $690 \mathrm{~A} / \mathrm{mm}^{2}$ 


\section{Work In Progress}

The developed optimization procedure will be applied to the array and the edge termination.

- The coil lay-out used for this process is described in "Mechanical Quad Array Design" 


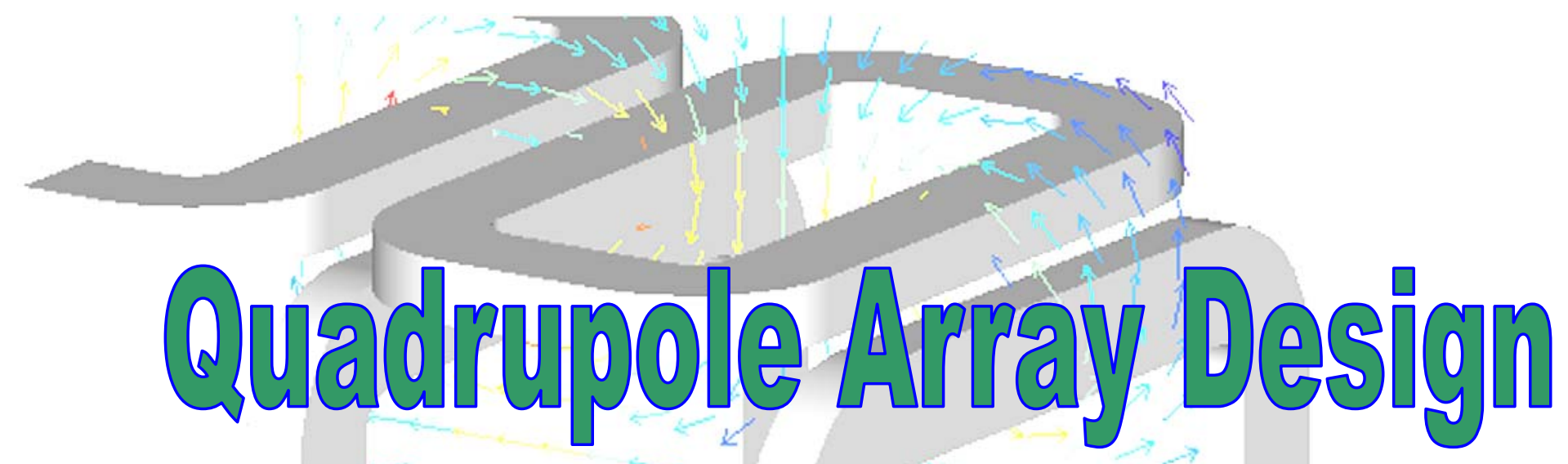

Carl Goodzeit, Rainer Meinke

DoE Award No. DE-FG02-04ER86205 


\section{Selection of Key Parameters}

In discussions with LBNL the parameters, listed in Table 1 , have been chosen for the STTR $3 \times 3$ quad array design. The parameters are in agreement with the RPD values.

The clear aperture in the array assembly (see sketch on next page) is $60 \mathrm{~mm}$, which matches the RPD value The integrated focusing strength in the RPD design is 34 tesla. This design achieves the integrated focusing strength with an operating gradient of $106 \mathrm{tes} / \mathrm{a} / \mathrm{m}$ at a length of about $320 \mathrm{~mm}$. Assuming a quadrupole length of 600 $\mathrm{mm}$ for the STTR quad array, requires an operating gradient of about 60 tesla/m, which significantly facilitates the coil design and should be a more cost effective solution for the array.

Using a quadrupole length of $600 \mathrm{~mm}$, instead of the originally assumed $150 \mathrm{~mm}$ (STTR proposal), will also allow for a better separation between coil-end and coil-center effects, when designing the edge termination scheme. 


\section{Clear Cell Aperture \& Cell Size}

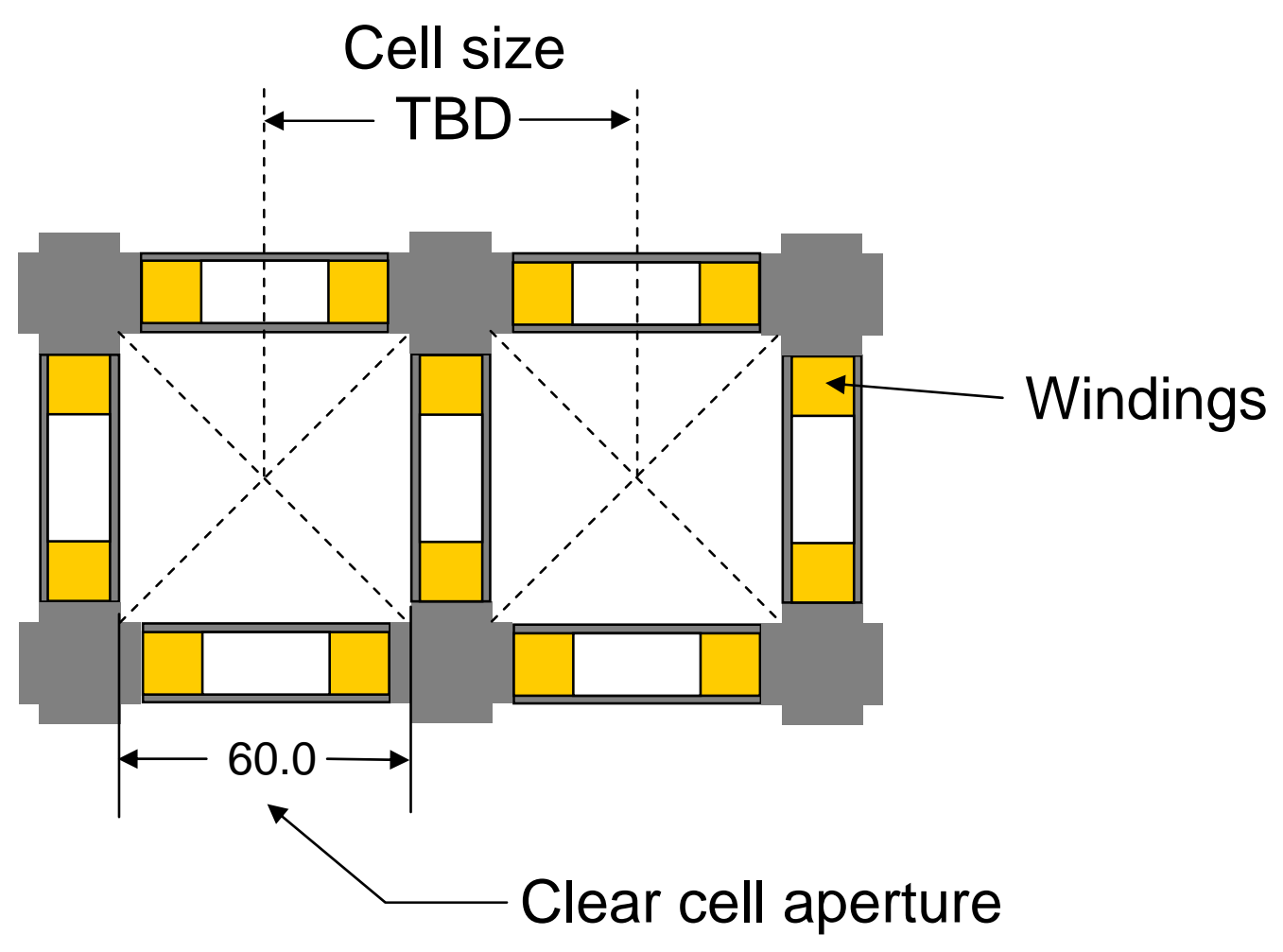

Dimensions are in $\mathrm{mm}$ 


\section{Quadrupole Array Design Goals}

\begin{tabular}{|c|c|c|}
\hline $3 \times 3$ Coil Array & $\begin{array}{r}\text { Sp } \\
\text { Desig }\end{array}$ & $\begin{array}{l}\text { cs I } \\
\text { Goals }\end{array}$ \\
\hline Parameter & Unit & Value \\
\hline Clear aperture $\left.{ }^{\star}\right)$ & $\mathrm{mm}$ & 60 \\
\hline Coil length & $\mathrm{mm}$ & 600 \\
\hline Gradient (short sample) & tesla/m & 85 \\
\hline Operational margin & $\%$ & 30 \\
\hline Coil thickness & $\mathrm{mm}$ & TBD \\
\hline Cell size & $\mathrm{mm}$ & TBD \\
\hline Flux sharing & $\%$ & TBD \\
\hline Coil type & \multicolumn{2}{|c|}{ double pancake } \\
\hline Field uniformity & & $<10 \mathrm{E}-3$ \\
\hline
\end{tabular}

Table 1. Quadrupole array parameter set

*) See sketch on next slide 


\section{Array Assembly Schematics}

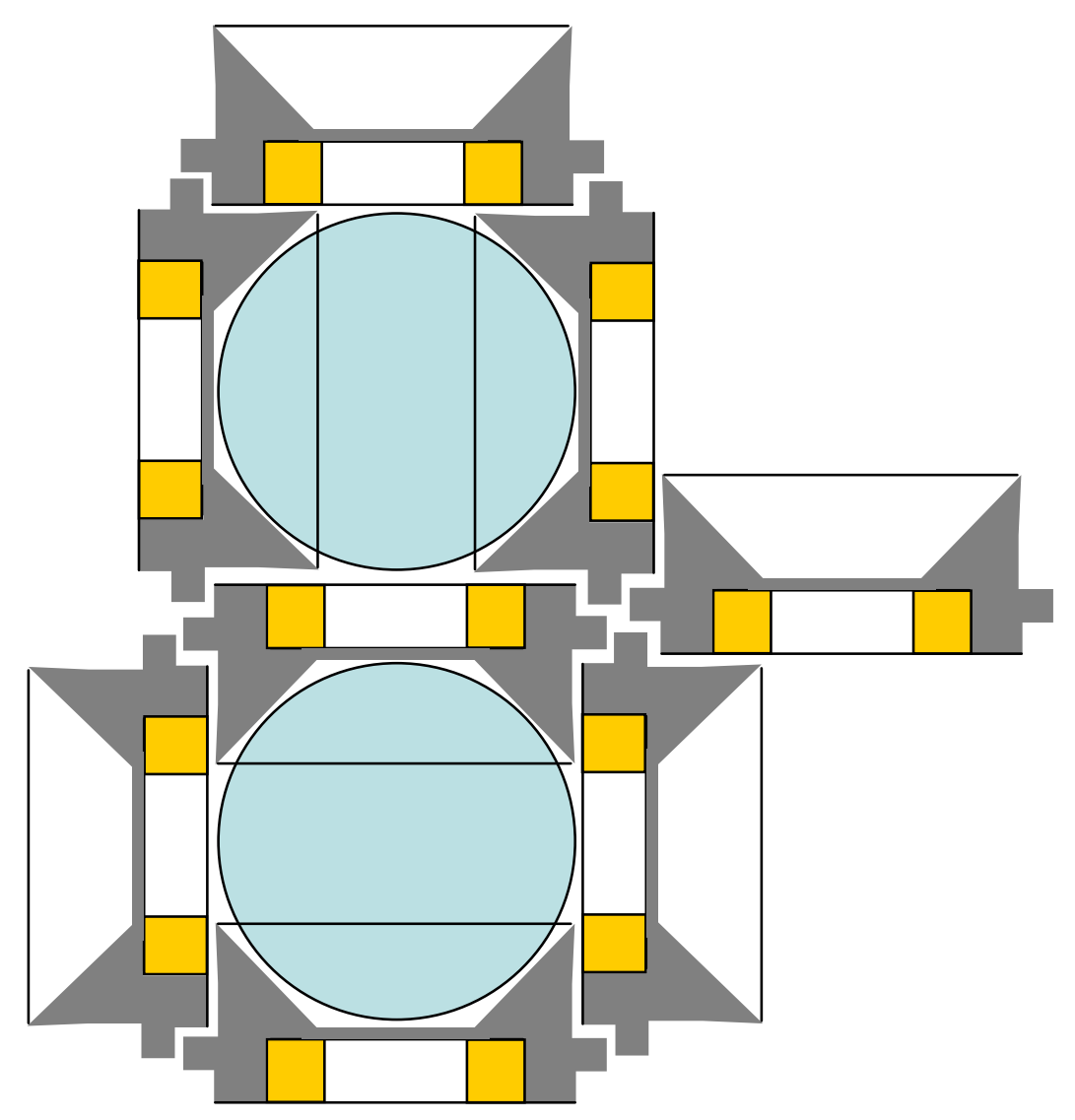

As for the HCX coils, we are using Al coil holders indicated in this sketch. The coils are inserted as for the $\mathrm{HCX}$ by heating the $\mathrm{Al}$ holder. In the array assembly the coils are supported from all sides.

The warping ${ }^{\star}$ ) of the holders, which we observed with the HCX coils, should not occur here. The triangular shaped profiles running along the winding should have sufficient bending strength.

The square corners, where the corner pieces mate, will guarantee a precise assembly.

Assemble drawn with spaces between the individual components to clarify the assembly

*) see next slide for further details. 


\section{HCX Manufacturing Experience}
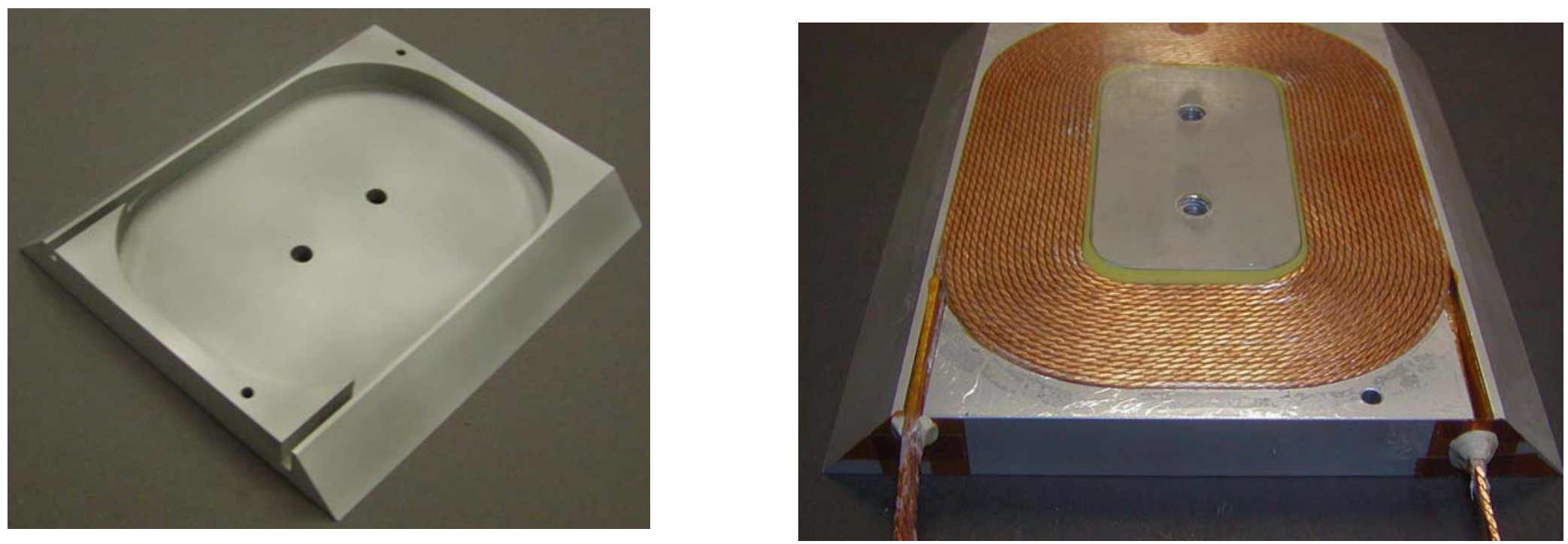

For both HCX manufacturing techniques, i.e., Nicolai's original and the AML's new one, we observed significant distortions of the Al-holders for the inner coils, after the coils were inserted. The back plane of the Al-holder was no longer flat. When placed on a precise surface table with the back plane down, under one or two corners there were gaps of more than 0.040”. No significant warpage was observed for the outer coils.

The back plane thickness of the Al-holder was $~ 0.080$ ” for the inner coils and $\sim 0.180$ " for the outer coils. 


\section{Schematics of Corner Pieces}

Space for corner piece

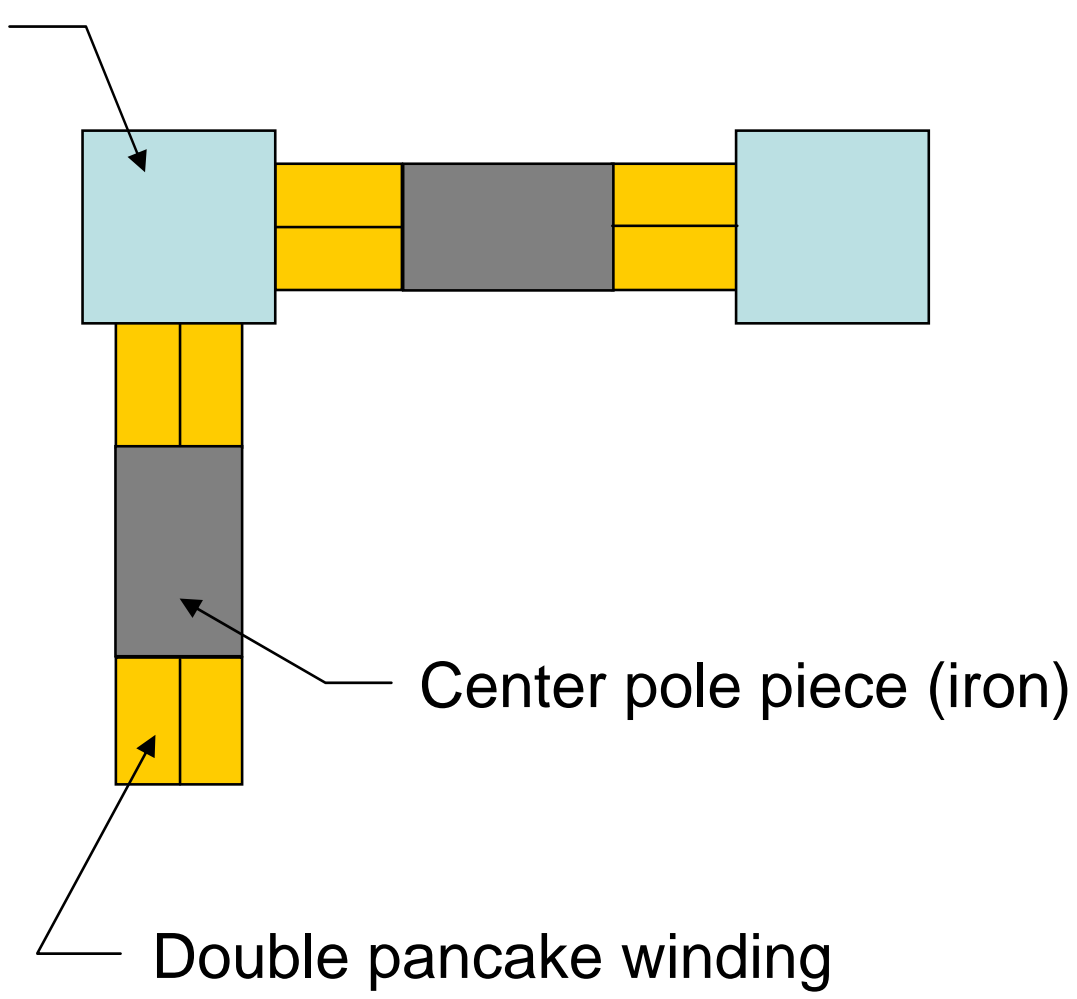




\section{Schematics of Corner Pieces}

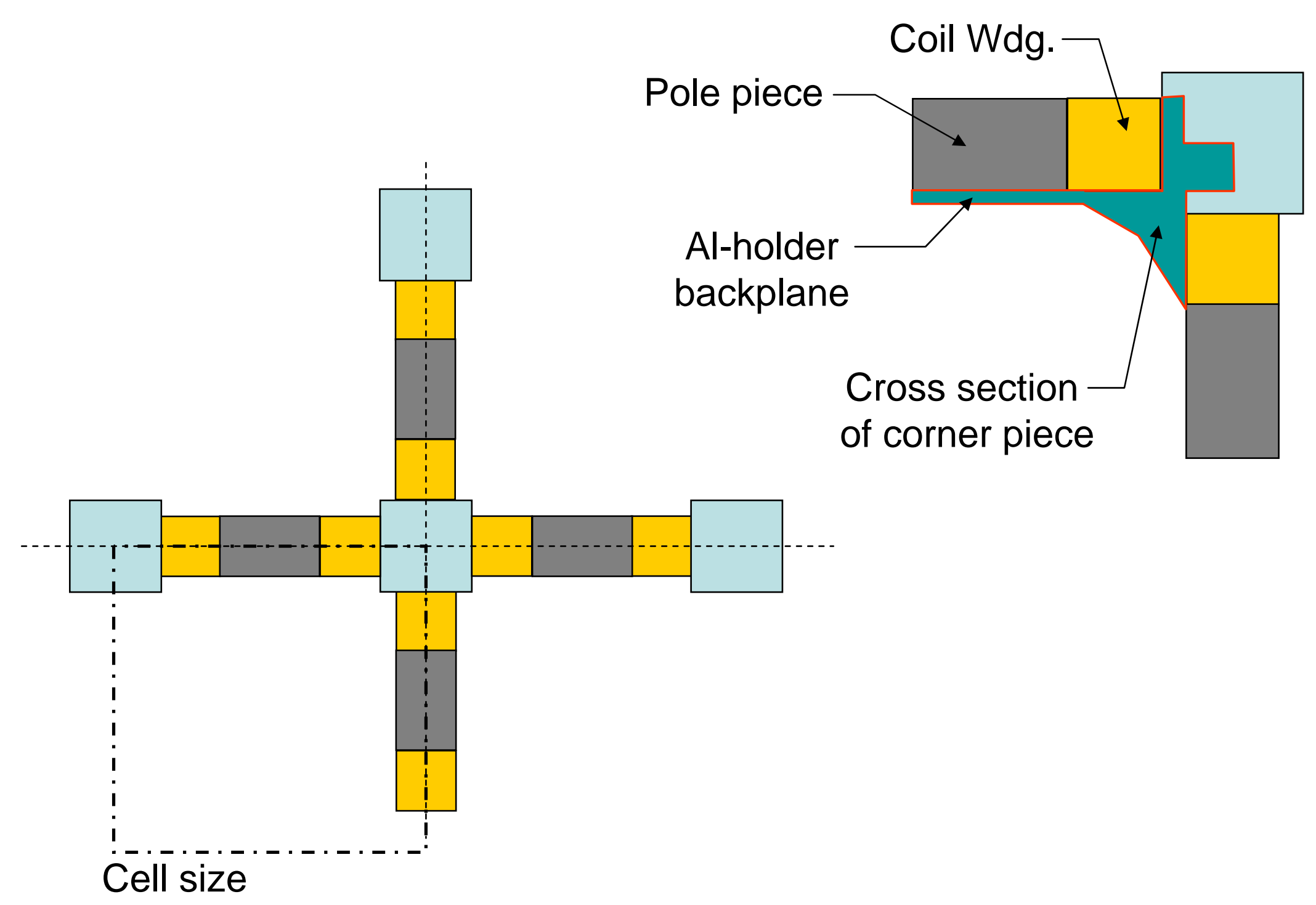




\section{Schematics of Corner Pieces}

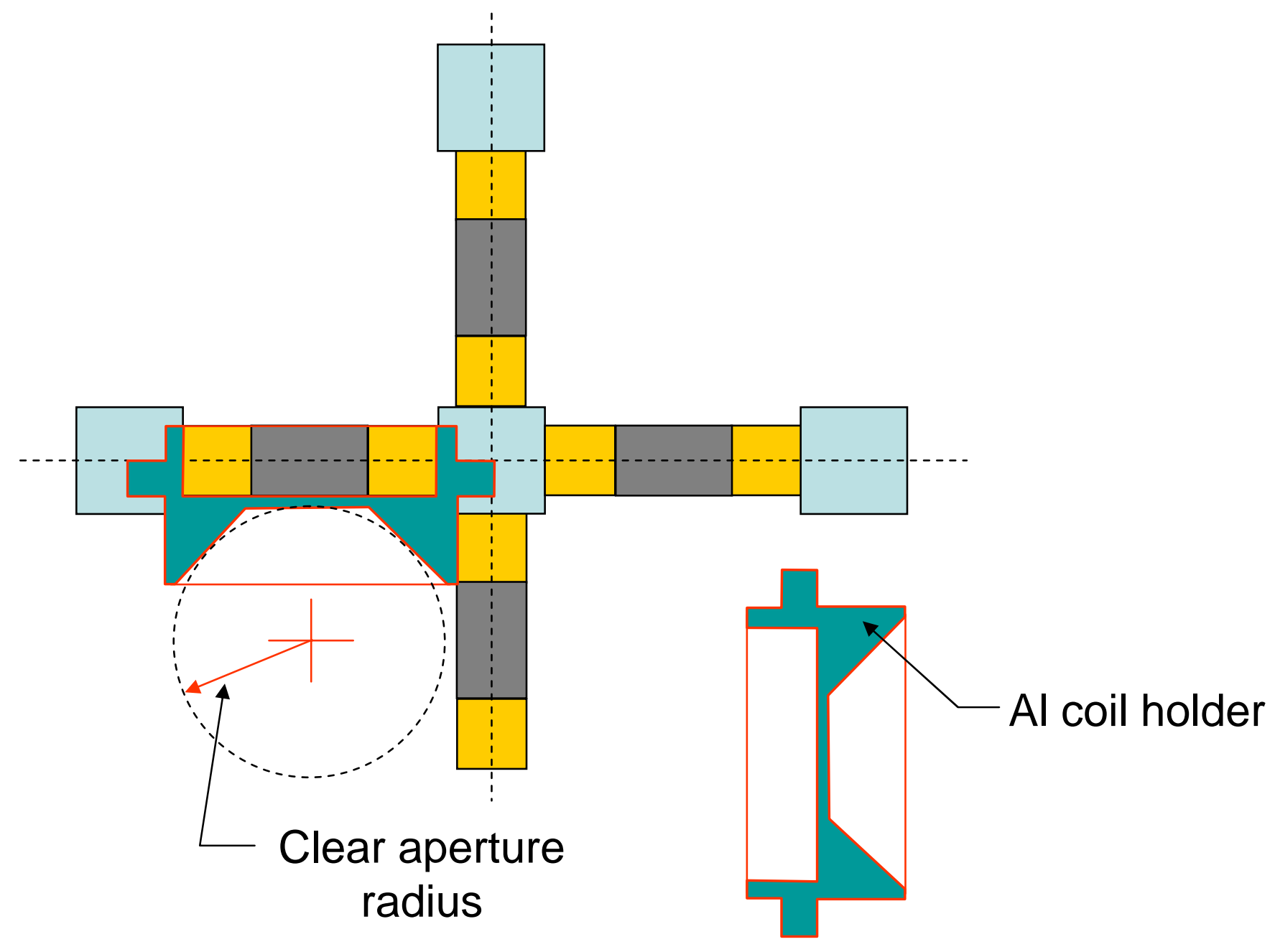




\section{Schematics of Corner Pieces}

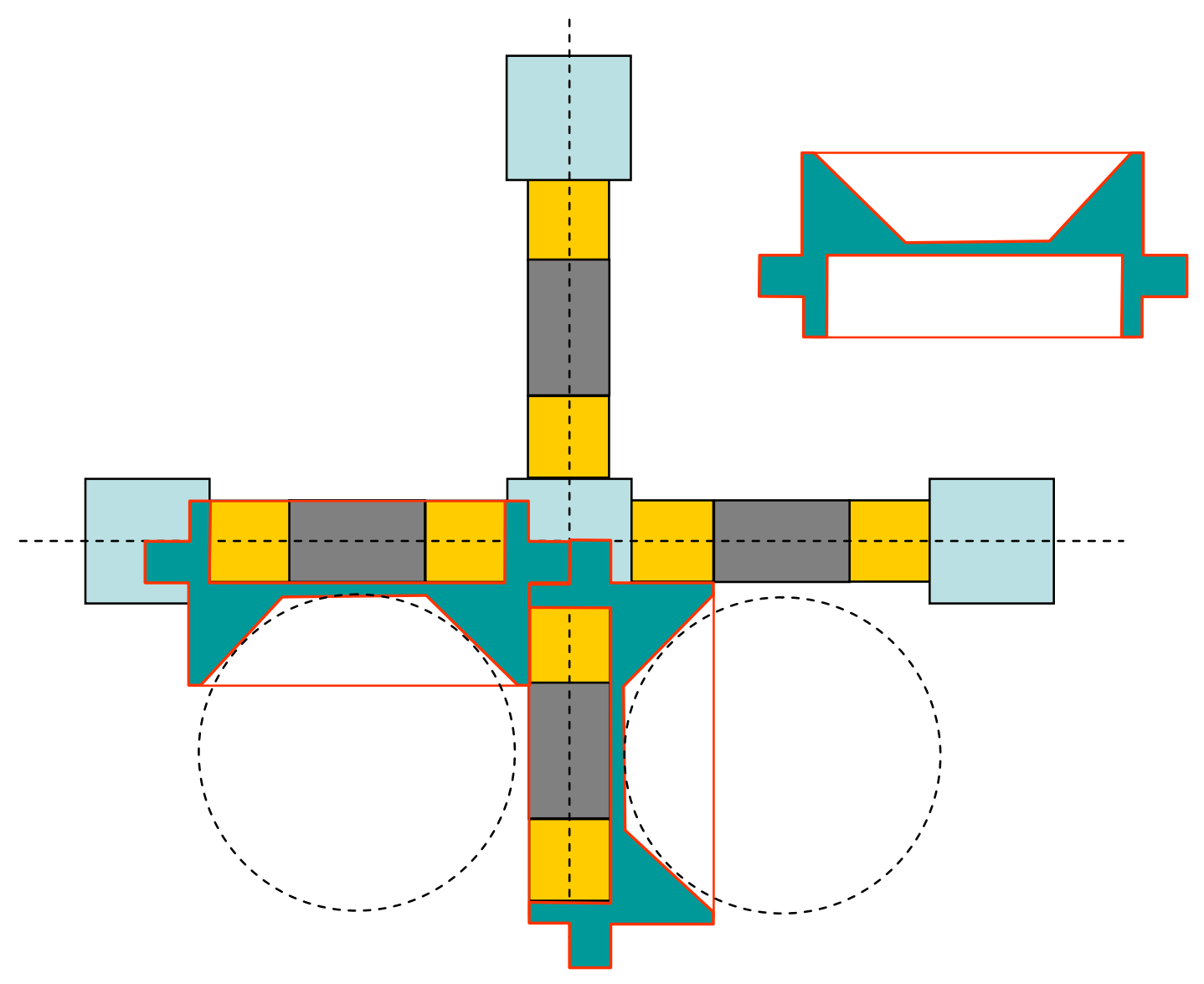




\section{Schematics of Corner Pieces}

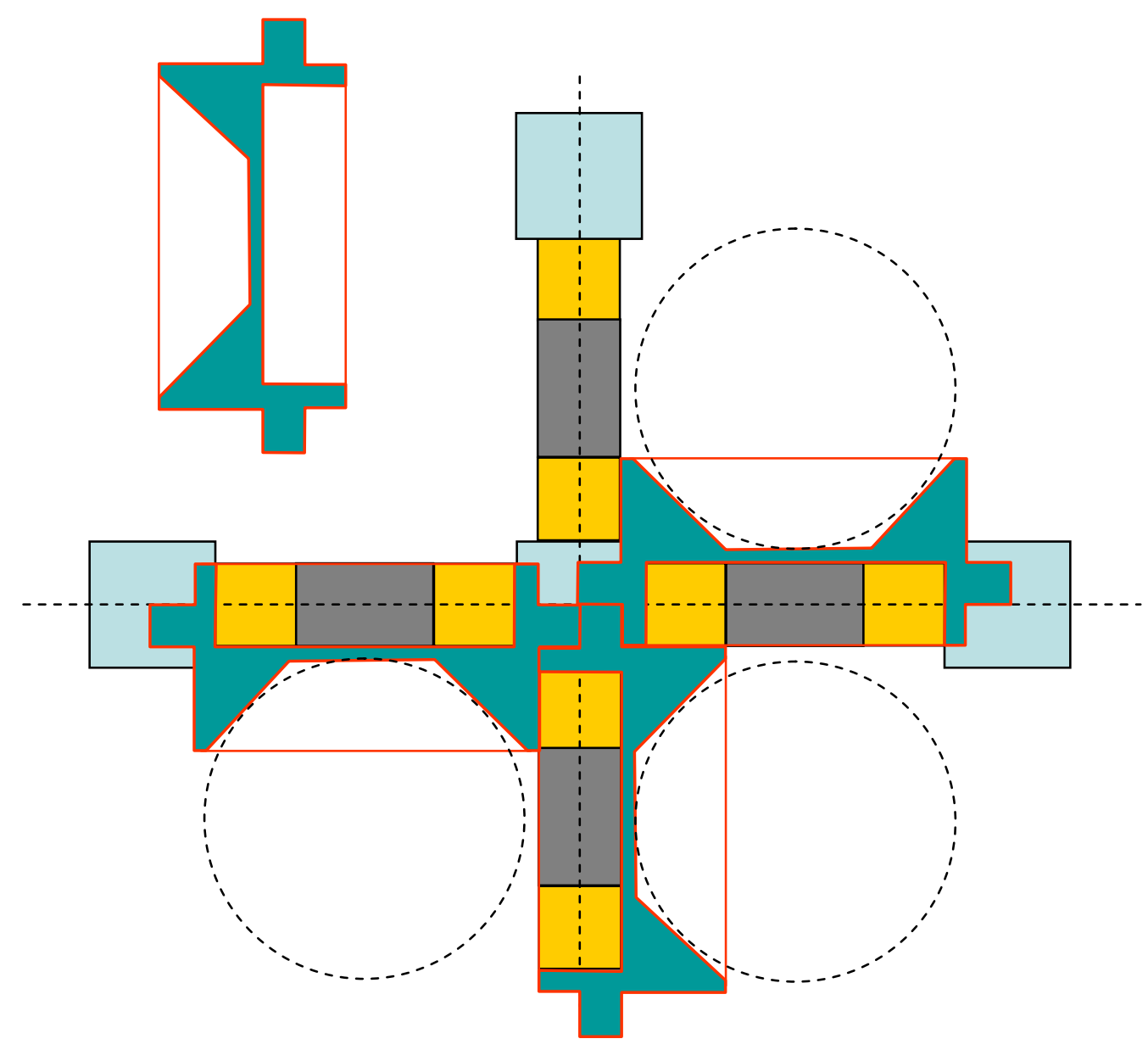




\section{Schematics of Corner Pieces}

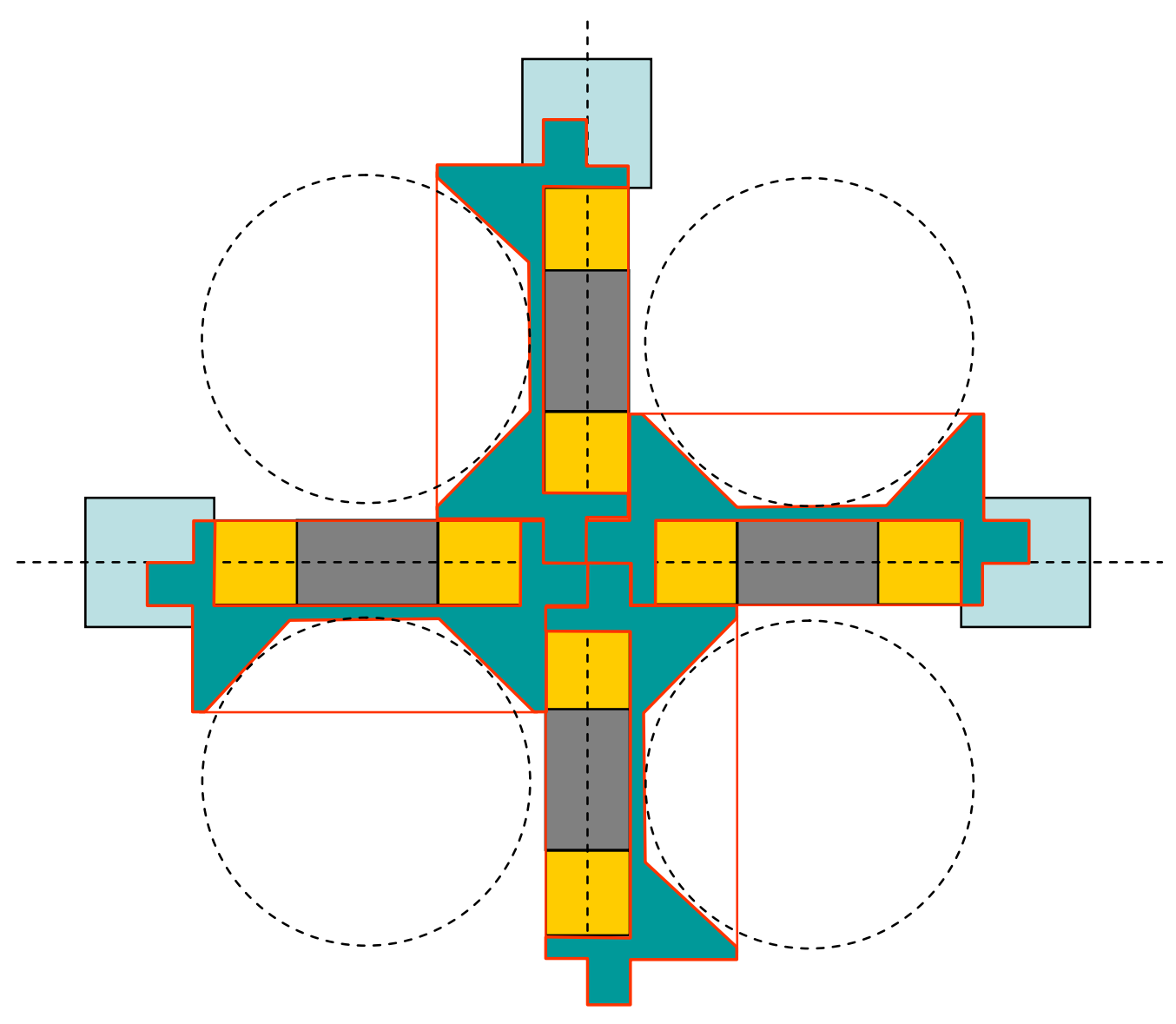




\section{External Support structure}

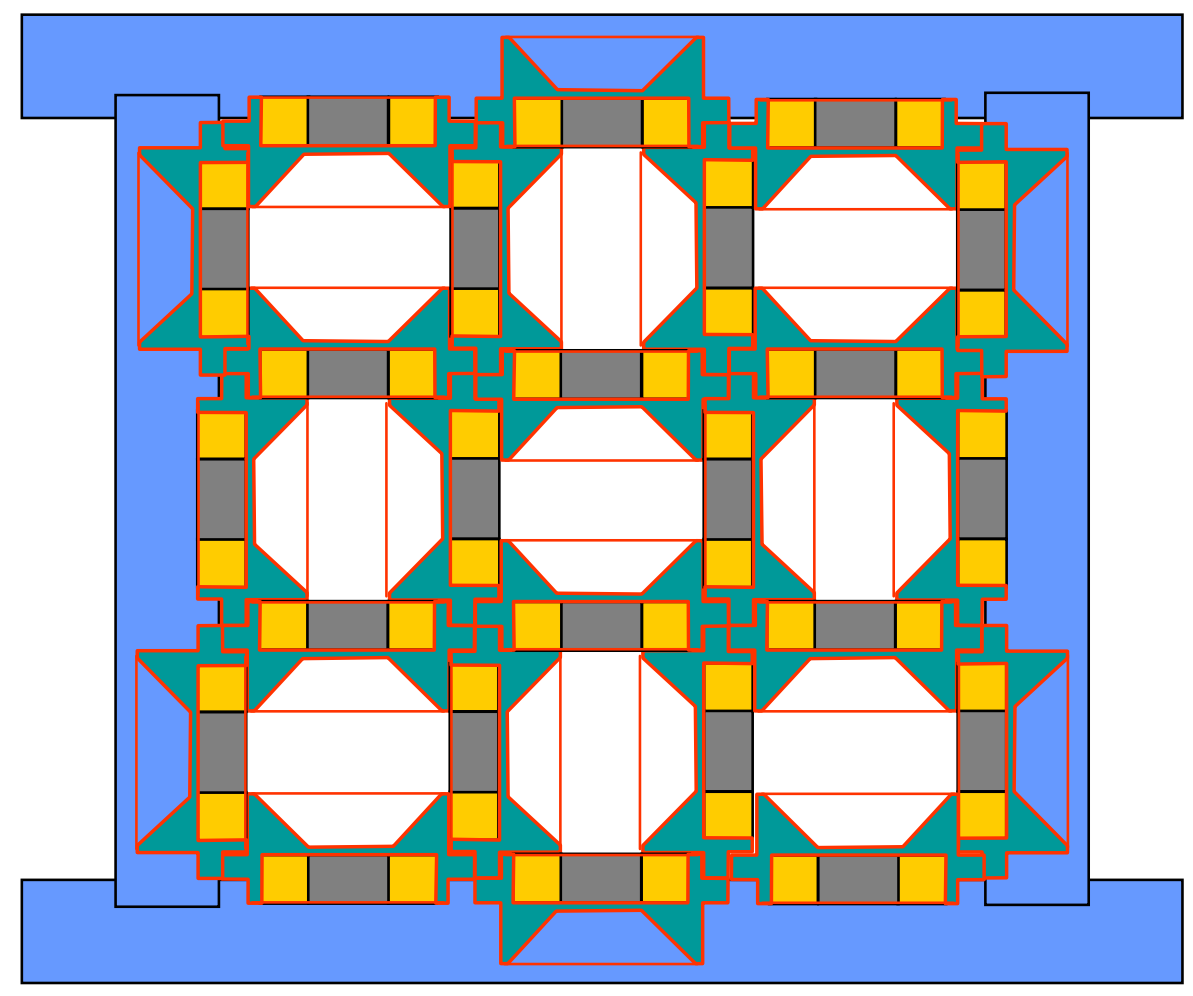

The schematically shown assembly can be easily supported on the outside, to achieve a precise and robust structure.

The outside support plates match the shape of the Al-coil holders.

$3 \times 3$ array assembly without edge termination coils 


\section{Advantages of Proposed Design}

The proposed modular design is based on individual but identical coils that can be mass produced. The experience and value engineering from the HCX manufacturing, which is based on double pancake coils has been incorporated in the array design. The Al-coil holders use the existing space of the cells to give optimum stability to each cell. Square, rectangular or other array shapes can be built up from these coils and the resulting structure can be supported from the outside.

The open apertures in the individual cells are alternating larger in the horizontal and vertical direction (see previous sketches). If beneficial for a multi-beam machine, elliptical beam tubes can be accommodated, making best use of the available space in the cells. 


\section{Stiffness of Al-Holders}

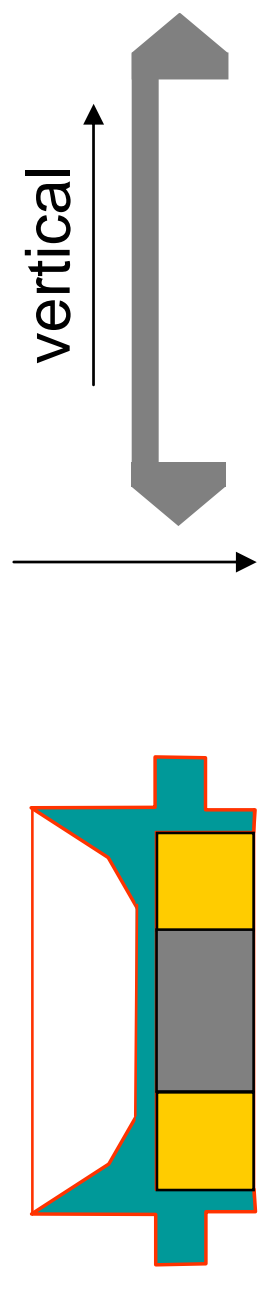

\section{HCX-Type Al-holder:}

The Al-holder shown here is very similar to the one used for the HCX. It is stiff in the vertical direction, but distorted in the horizontal direction. When placed on a surface table, the Al plate was not flat anymore after the coils were inserted. The triangular fins in the design below will make the plates significantly stiffer in the horizontal direction and serve other purposes as shown below.

horizontal

\section{Stiffened Al-holder:}

The chosen profile have sufficient bending strength to overcome the distortion problem, which we encountered with the HCX coils (see HCX manufacturing experience above).

In the array assembly the coils are also supported from both sides.

The material and the dimensions of the Al-holders has to be chosen appropriately. 


\section{Extruded Al Coil Holder Profile}

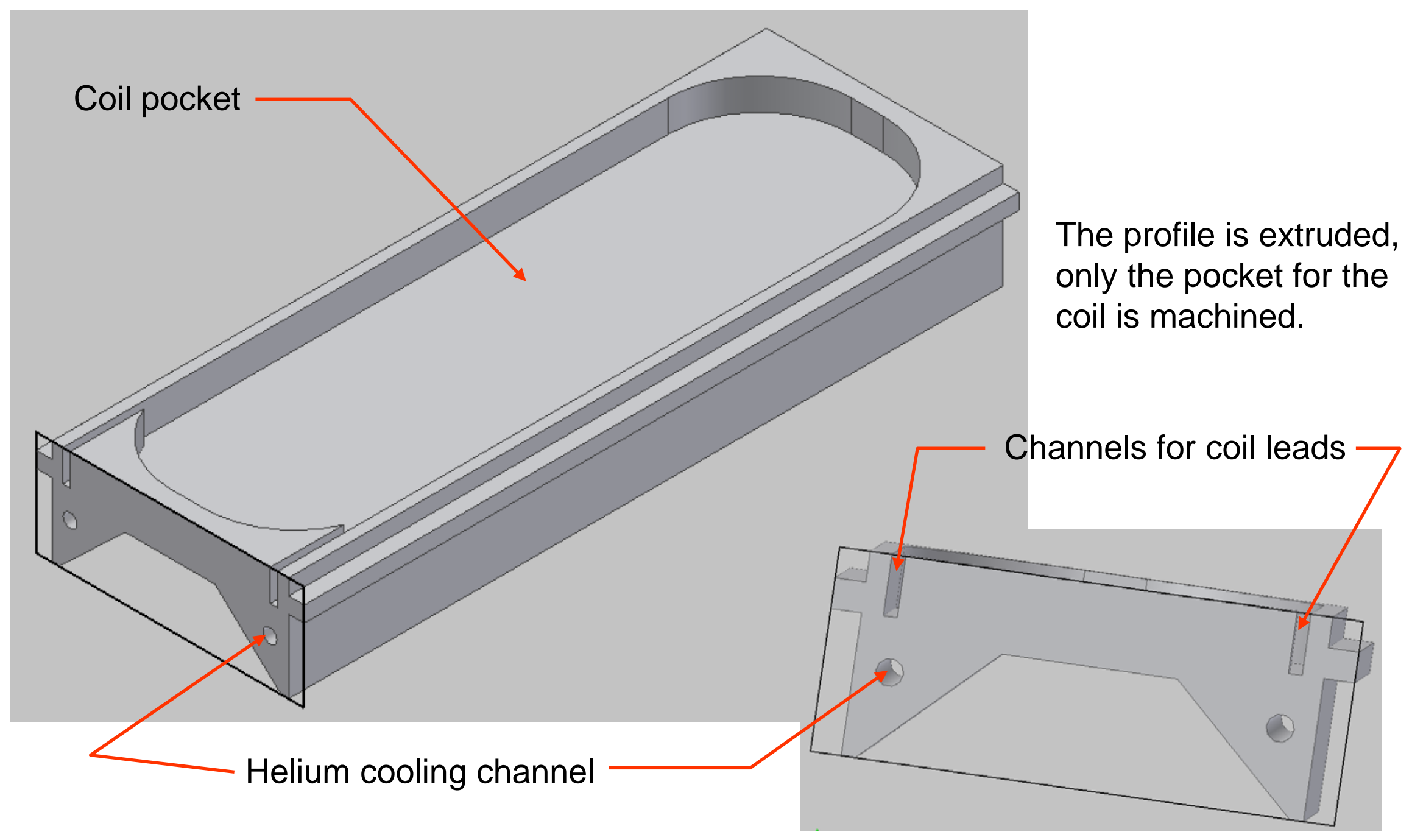




\section{Profile Assembly - Corner of 4 Cells}

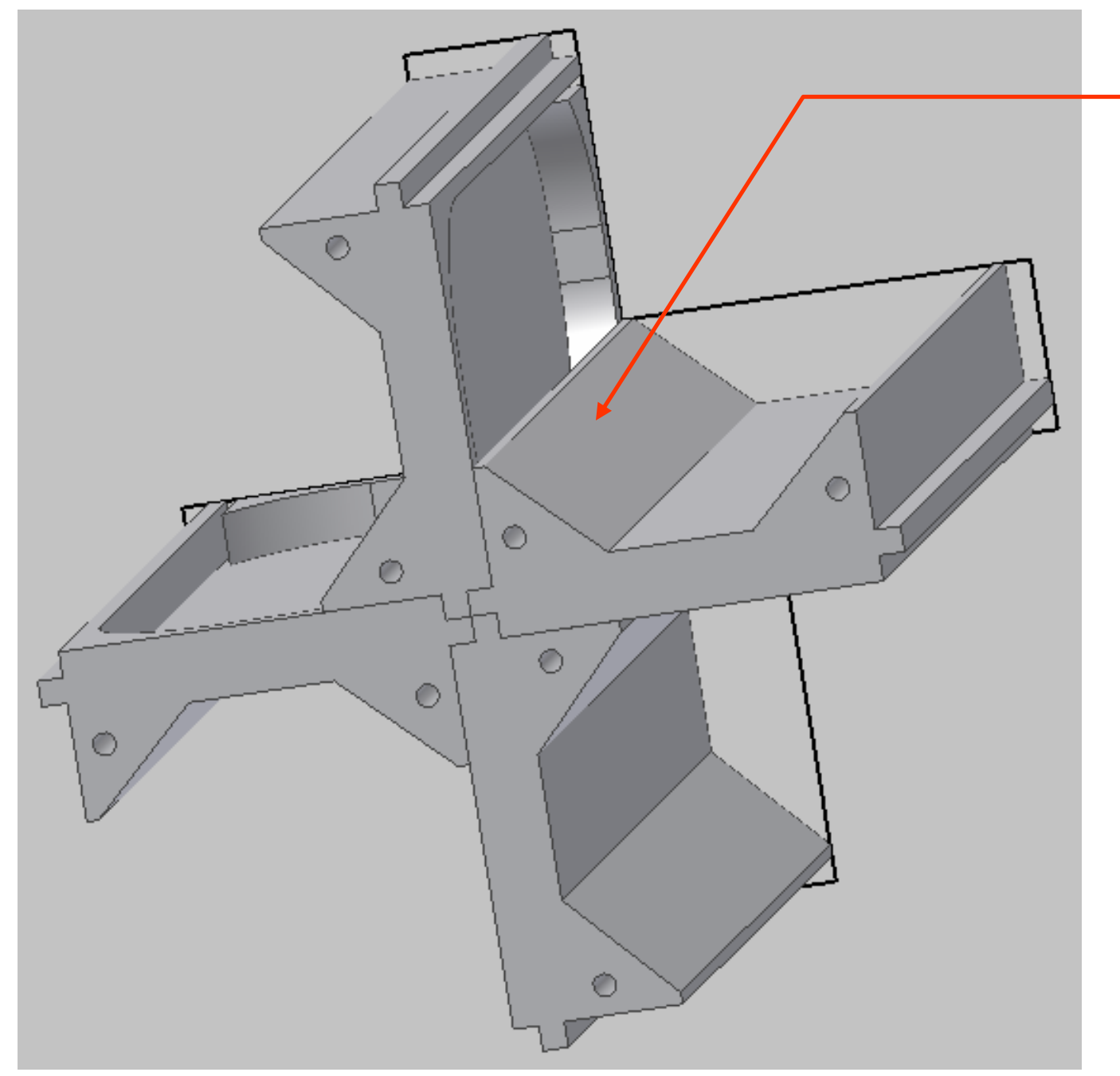

The triangular fins support the coils from the outside and could support the beam tubes if necessary.

The figure represents any corner inside the array, where the neighboring cells are joint together. The extruded noses guarantee the relative alignment of adjacent cells. 


\section{Profile Assembly - Walls of 1 Cell}

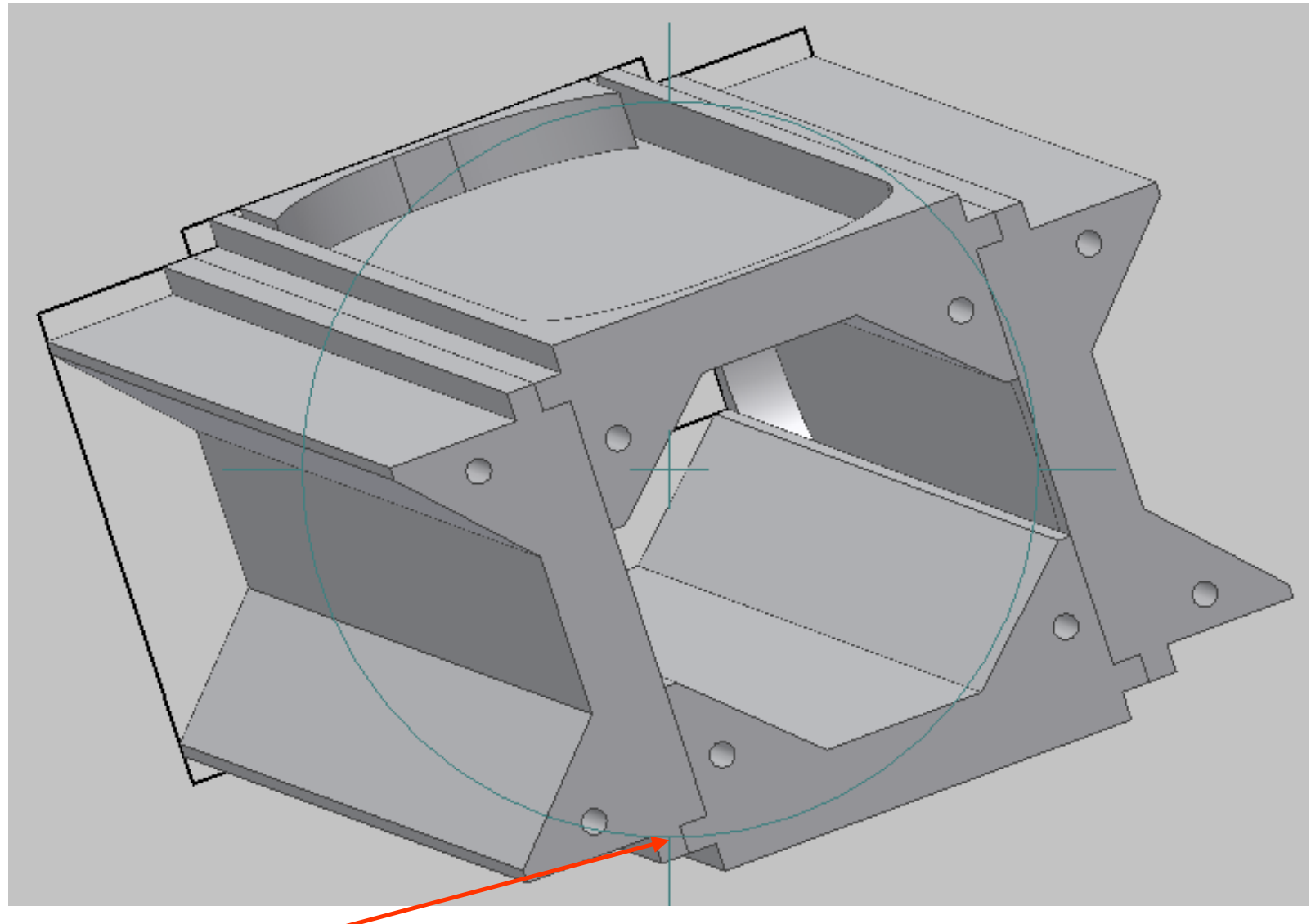

The interlocking profiles form a precise square coil. The miter joints used in the HCX design caused alignment problems in the coil manufacturing. 


\section{Mechanical tolerances of Al Profiles}

The extruded Al profiles, which are used as coil holders facilitate a costeffective mass production of the arrays. Commercially used extruded aluminum profiles (see next page) specify the mechanical tolerances as $0.2 \mathrm{~mm}$. We have measured some of the profiles and found that the actual tolerances are better $(\sim 0.1 \mathrm{~mm})$. Even without improving this tolerance in the mechanical dimensions, the resulting array would be rather accurate and the positional accuracy of the individual beam tubes and coils in the array should be well under $0.5 \mathrm{~mm}$. This alignment puts modest requirements on the steering magnets in an accelerator consisting of such quadrupole arrays. 


\section{Commercial Extruded Al Profiles}

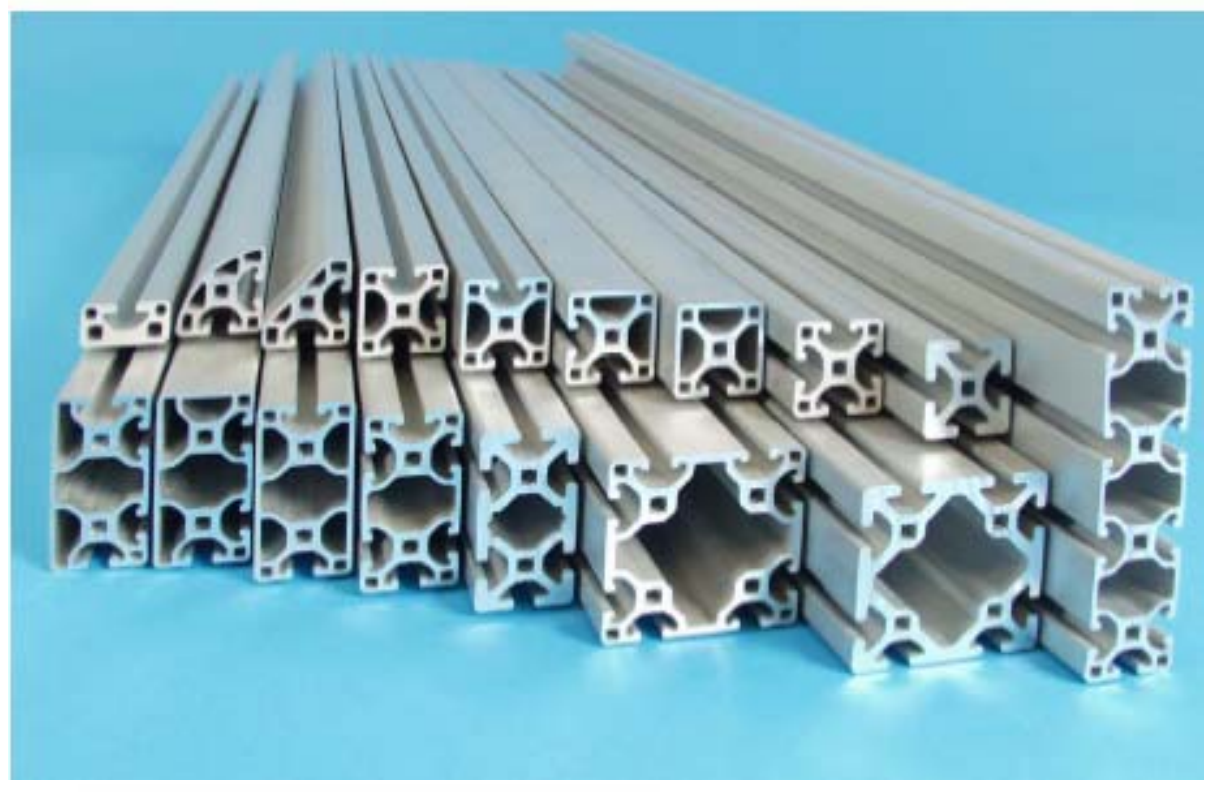

Al can be extruded accurately into large complex profiles. Length of commercial profiles as shown $6 \mathrm{~m}$.

A standard profile would be extruded for the quad array, which would require minimum machining for the coil pocket.

It would already have the correct cross section with helium cooling channels.

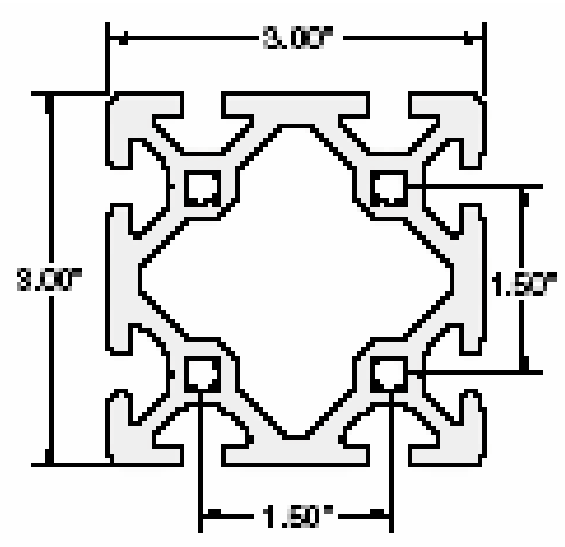

$11-3000$

\section{Company Information:}

Name: Parker Hannifin, Automation Actuator Div.

Address: 135 Quadral Dr.

City: Wadsworth

State: $\mathrm{OH}$

ZIP: 442810450

Country: USA

Phone: 888-775-4725

FAX: 330-334-3335

http://www.parker.com 


\section{Array Cryogenics}

The beam tubes in the quadrupole array are most likely the main heat load of the assembly. If the beam tube is at room temperature, it could constitute a major heat load, but also for a cold beam tube, energy deposition from the beam could be significant. It is therefore advantageous to cool the coils from the inside of the cell near the beam tube.

The channels, which are placed in the triangular fins of the Al profiles would serve this purpose, when helium is passed through.

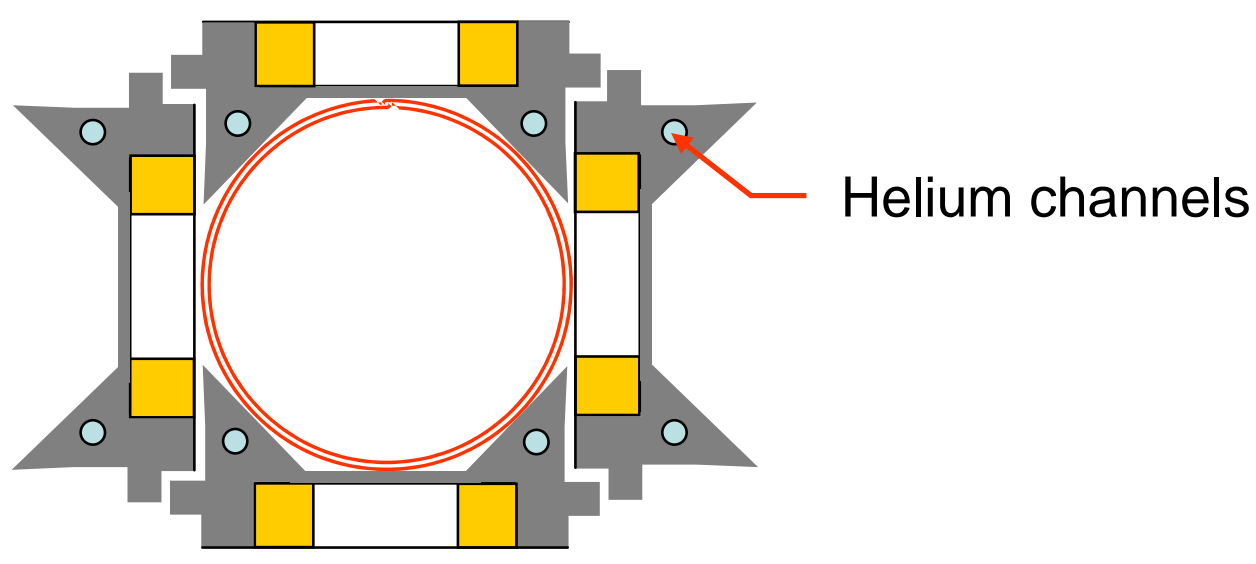




\section{Edge Termination Scheme Approach}

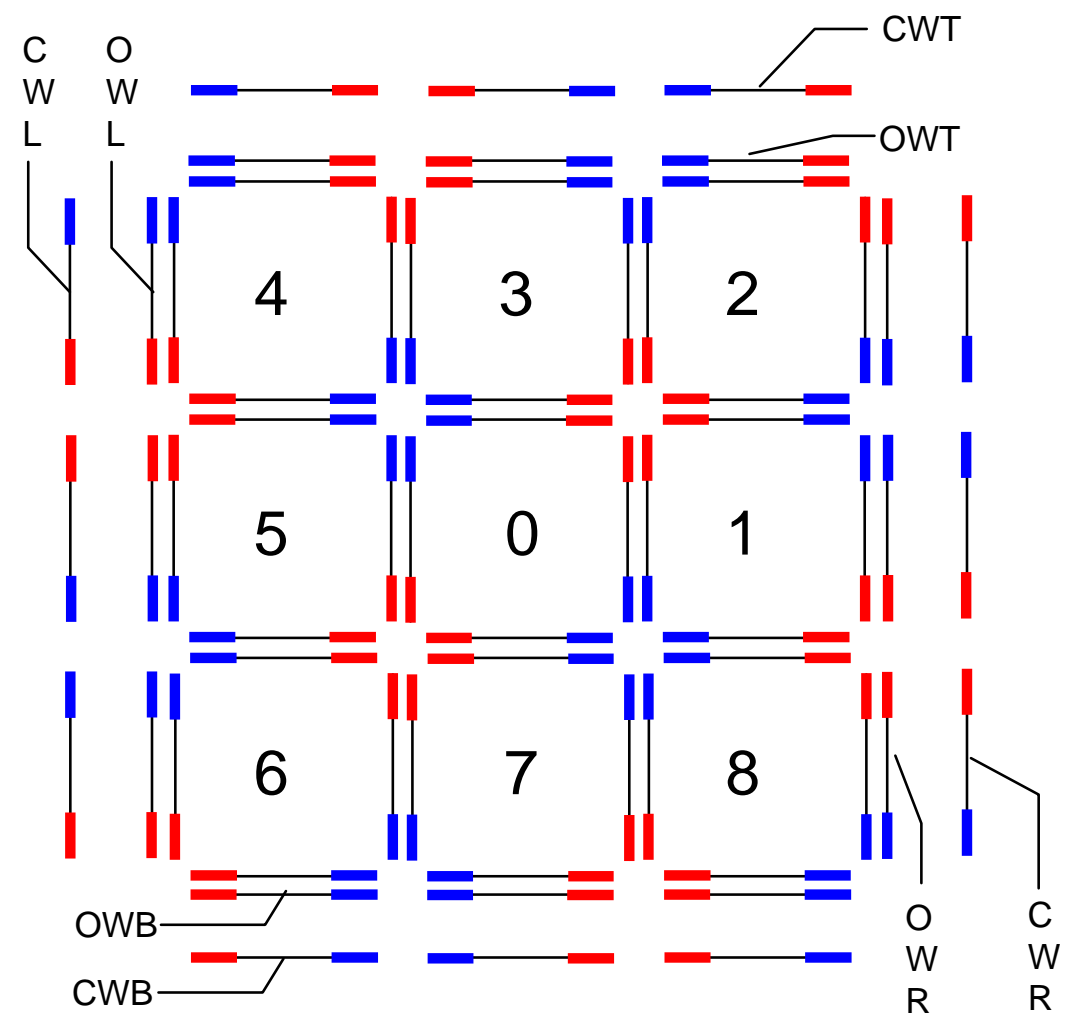

Single pancakes at closer distance than standard cell size.

If possible use same coils and array building blocks.

$\begin{array}{ll}\text { OWR: } & \text { Outer wall right } \\ \text { OWL: } & \text { Outer wall left } \\ \text { OWB: } & \text { Outer wall bottom } \\ \text { OWT: } & \text { Outer wall top } \\ & \\ \text { CWR: } & \text { Correction wall right } \\ \text { CWL: } & \text { Correction wall left } \\ \text { CWB: } & \text { Correction wall bottom } \\ \text { CWT: } & \text { Correction wall top }\end{array}$




\section{Edge Termination Scheme}

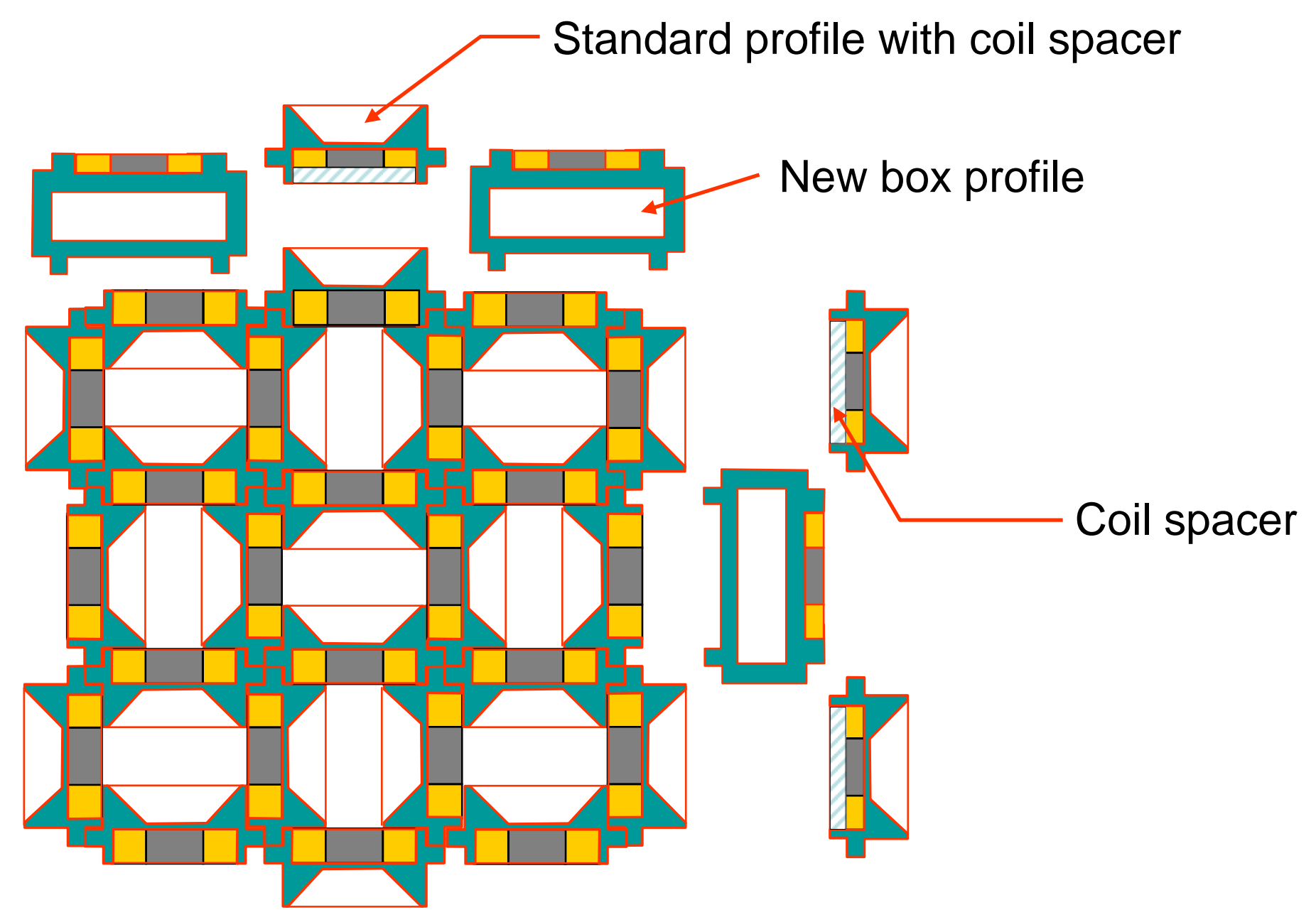




\section{Edge Termination Scheme}

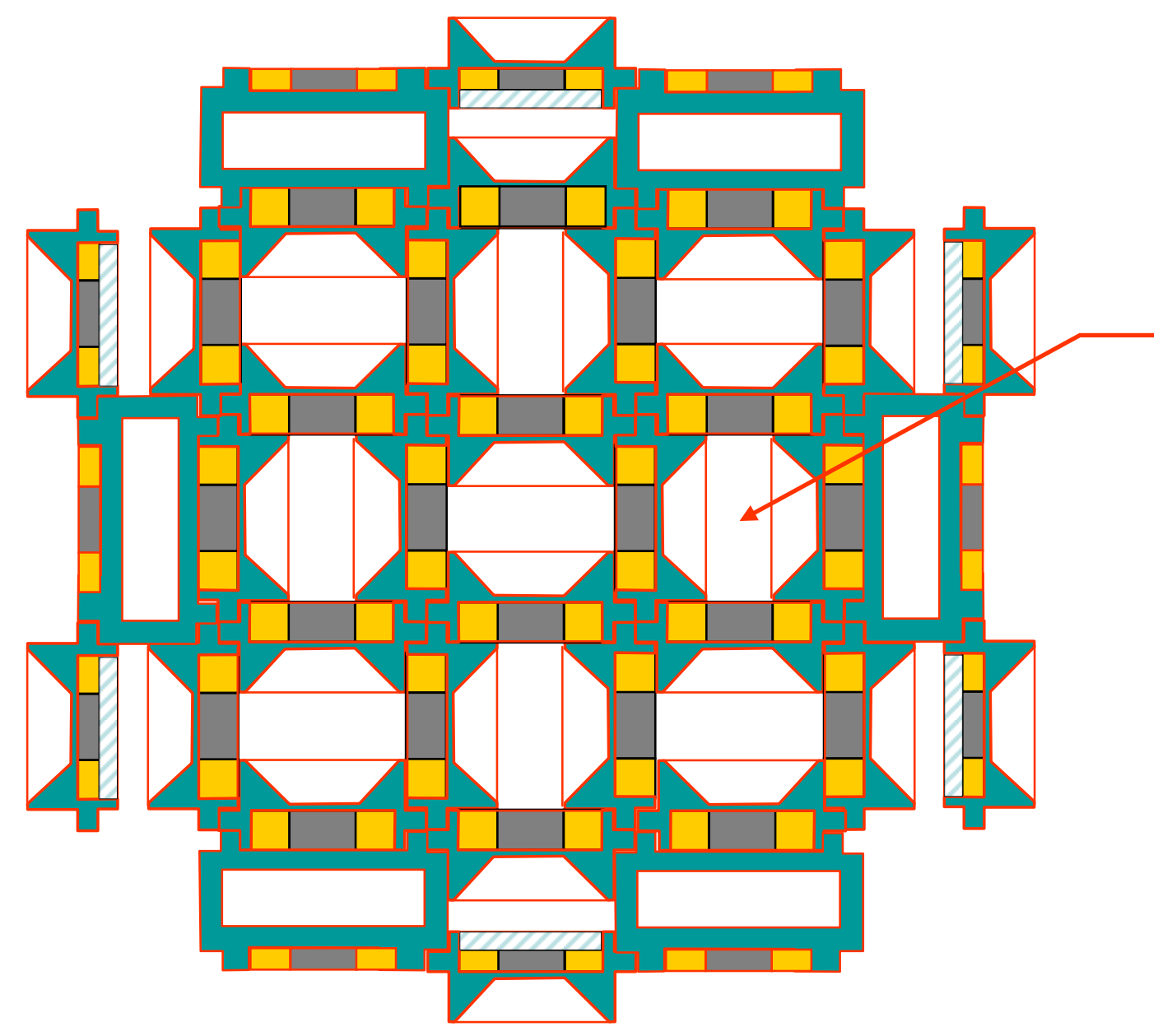

Side middle cells corrected using one new profile. 


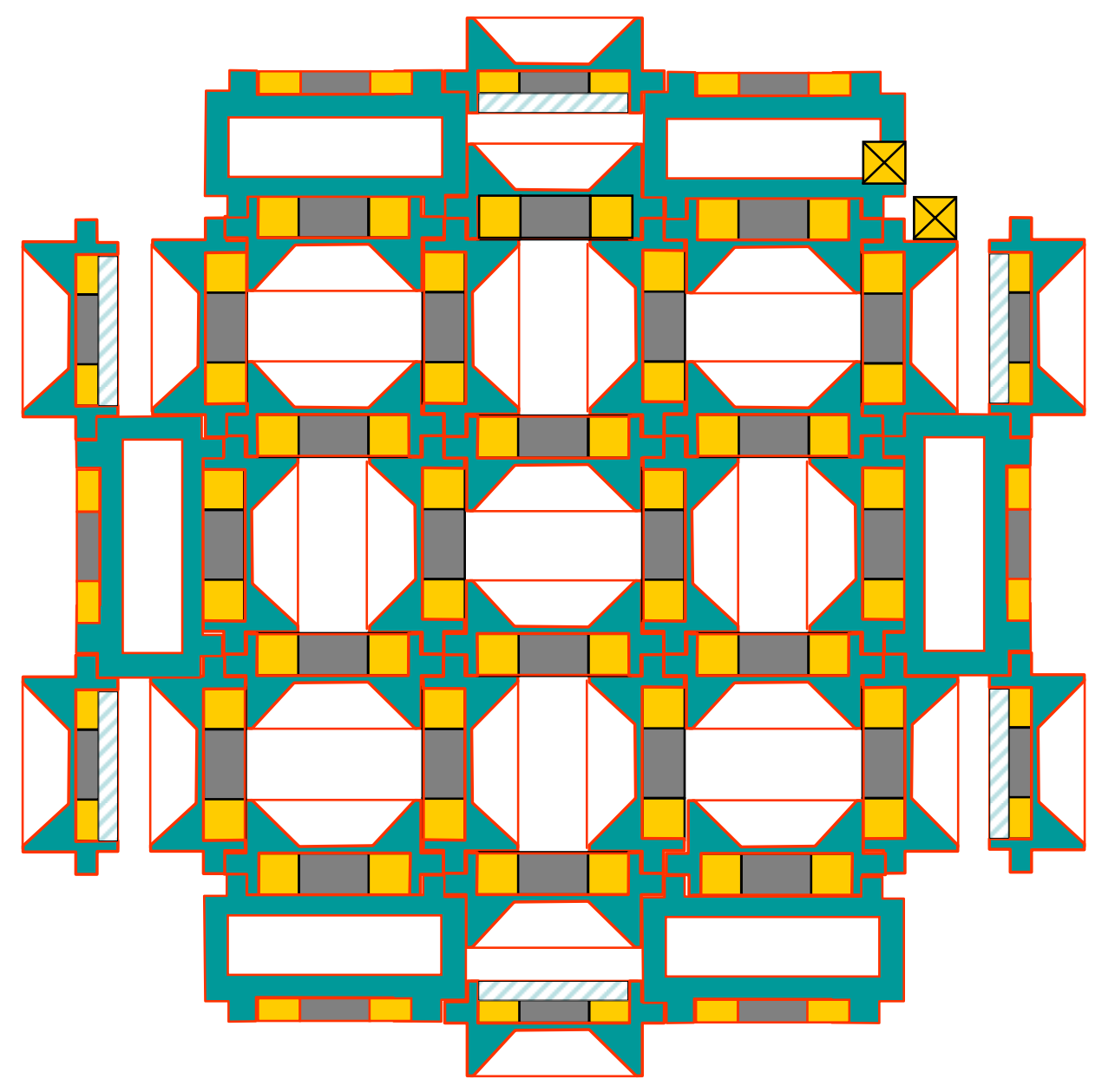




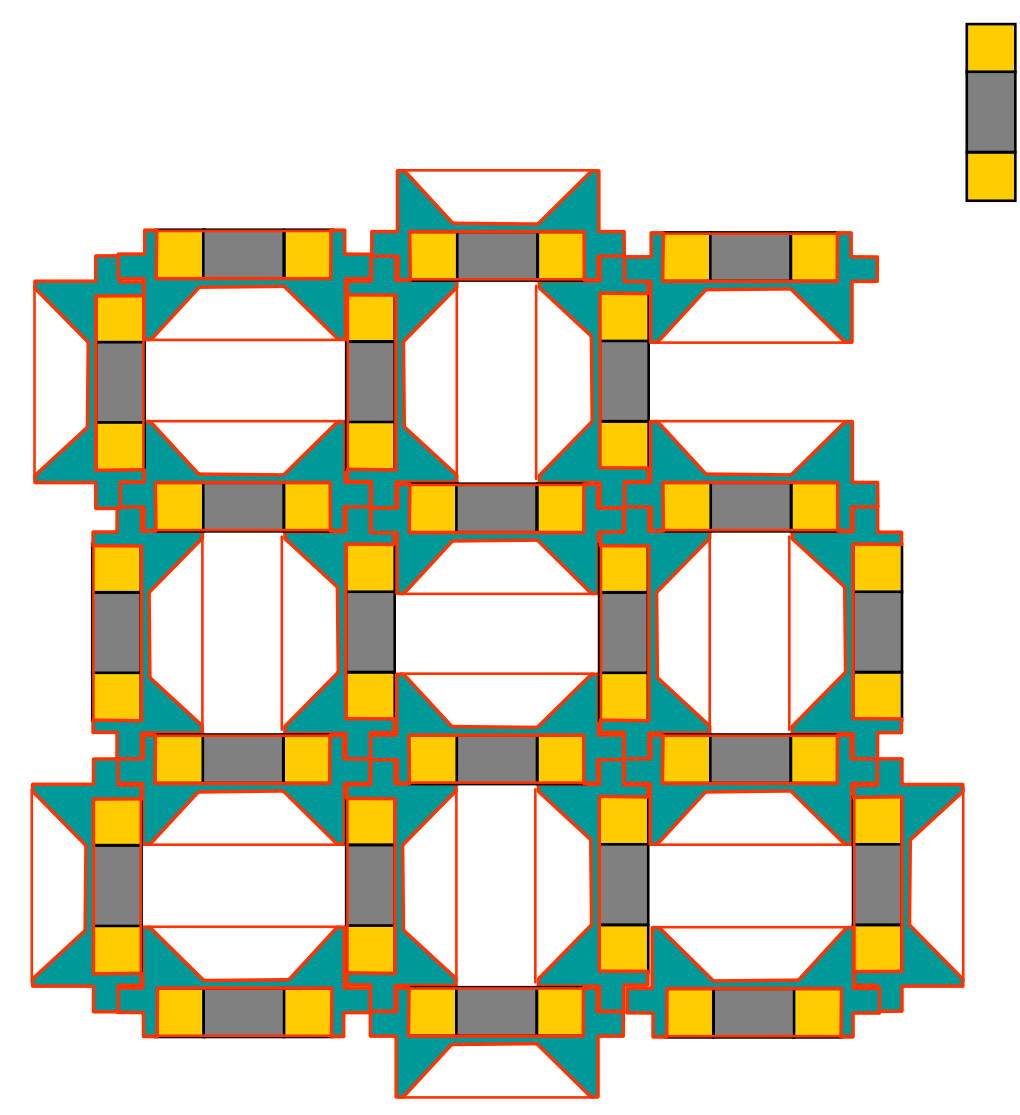




\section{Build-up of Larger Arrays}

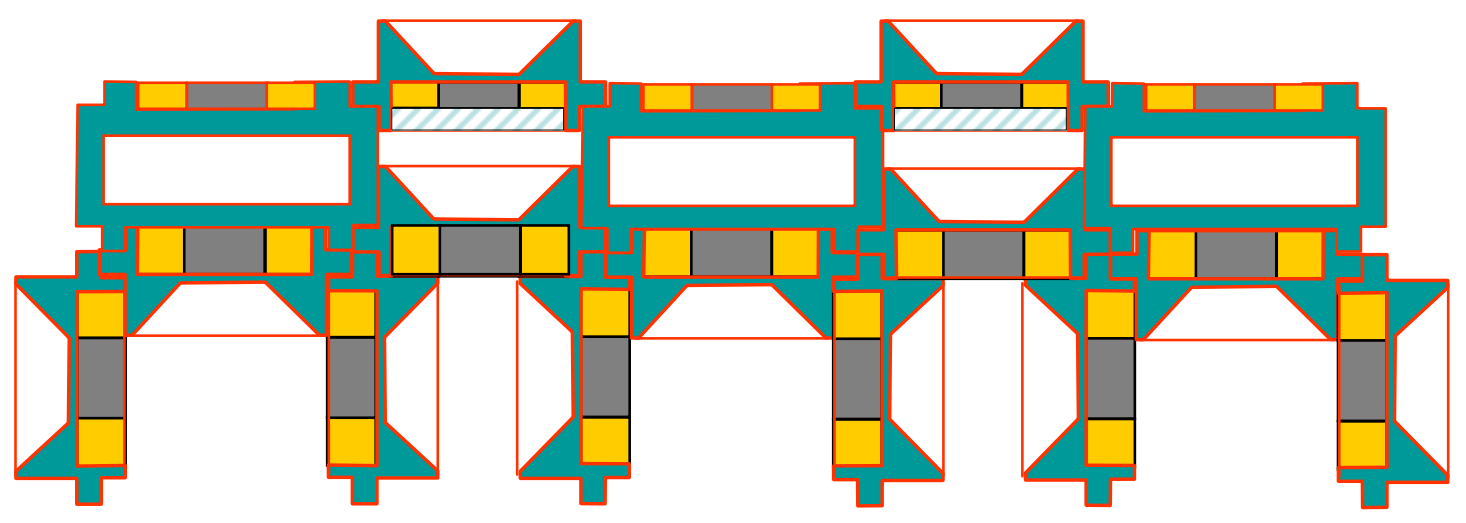

The two profiles allow to build arrays with any number of cells. 


\section{Optimzation of \\ Quadrupole Array Field Uniformity}

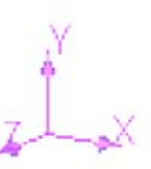

C. Goodzeit, R. Meinke, M. Ball AML

$1 / 24 / 2005$

DoE Award No. DE-FG02-04ER86205 


\section{Field Uniformity Optimization}

\section{Approach:}

Develop a fast and robust multi-parameter optimization code, which works in 2-D and ignores iron. Use the code to understand the behavior of field uniformity in the array and to develop an edge termination scheme.

After finding a realistic array with edge termination switch to a 3-D program (Ampere or Tosca), if necessary, compensate non uniformity resulting from the coil ends with an adjustment of the straight section. This can be done with the 2-D code again. Comparing the complete 3-D model with 2-D, the shift in MP content due to the ends and iron is known and the 2-D optimization can be used to readjust the geometry to compensate these MP's.

Excel has been used as the 2-D optimizer. The Excel "Solver" allows optimization to any target value with arbitrary constraints. An optimization of the complete $3 \times 3$ array takes about 30 seconds.

The geometry of the array is defined in a conventional spread sheet. Defining a target cell, e.g. the sum of various MP's squared, the Solver varies a set of "Parameter cells" until the optimum is found. 


\section{Code Developed}

- To enable the optimization with the Excel Solver, a set of user-defined functions have been developed.

$>$ FBlock: $\quad$ MP field $\left(B_{n}, A_{n}\right)$ for a single current block with spacer

> FCell: $\quad$ MP field $\left(B_{n}, A_{n}\right)$ for single quadrupole cell consisting of 8 current blocks

> FArray: $\quad$ MP field $\left(B_{n}, A_{n}\right)$ for each cell in a $3 \times 3$ array consisting of 9 quadrupole cells

- With this approach the field of any quad array configuration including edge termination can be calculated in a simple spread sheet approach (the standard functions like abs(), $\sin ()$ etc. now include field calculations).

> The MP field for an arbitrary configuration is calculated by placing such an equation into an Excel cell:

$>=$ FArray $(p 1, p 2, .)+$. FBlock $(q 1, q 2, .)+.F B l o c k(r 1, r 2, \ldots)$

> Clicking solver the field can be optimized in various ways 


\section{Geometry of Base Cell}

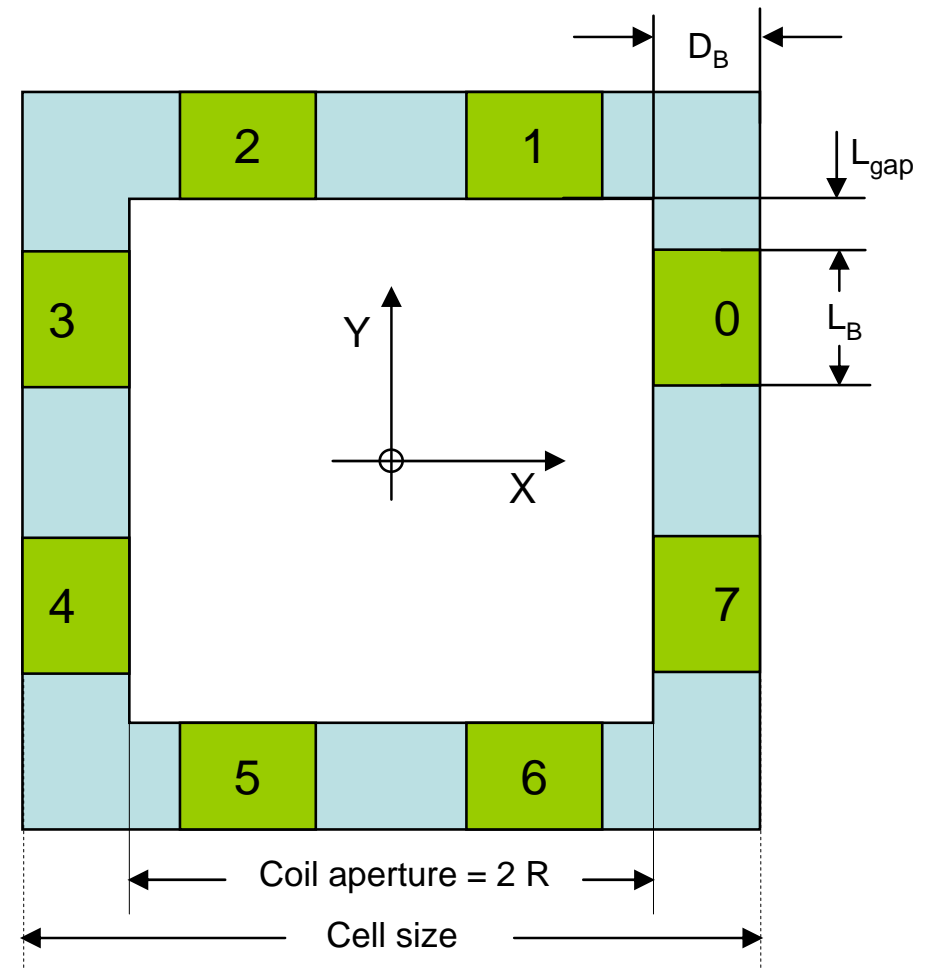

- As in the previous analysis the quadrupole cells are built up with 4 identical single pancake coils.

- In 2-D, each coil consists of 2 current blocks as shown in the sketch. The current blocks 1-2, 3-4, 5-6 and 7-0 form the 4 coils.

- The coils are described by 4 parameters:

$>\mathrm{L}_{\mathrm{B}}$ : Block length

> $\mathrm{D}_{\mathrm{B}}$ : Block width (cable width)

$>\mathrm{L}_{\text {gap }}$ : Gap in the corner

$>\mathrm{R}$ : $\quad$ Aperture radius

a The cell size in this model is given by:

$$
\text { cell size }=2 R+2 D_{B}
$$




\section{Spacer Description}

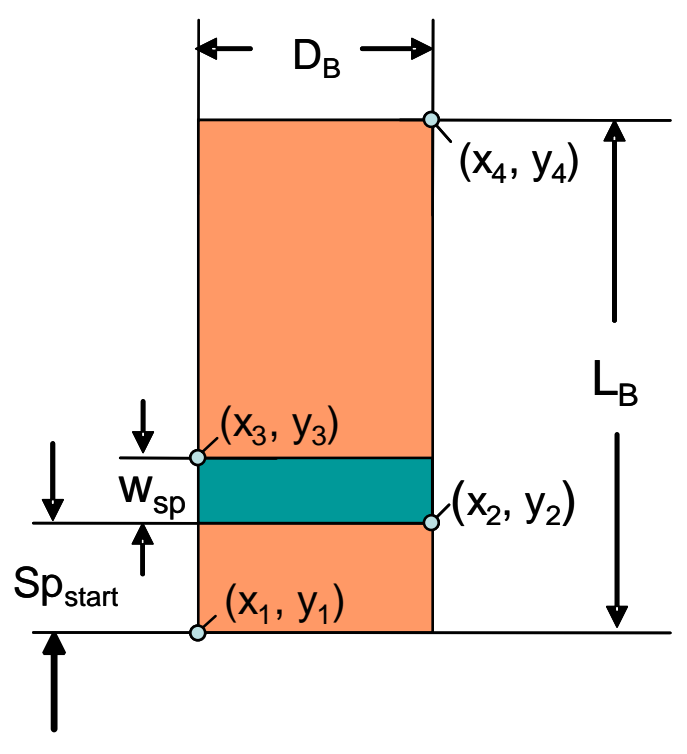

A spacer is introduced into each current block as indicated in the sketch.

The spacer is described by two parameters, i.e., the start location $\mathrm{SP}_{\text {start }}$, measured from the pole face and the width of the spacer, $\mathrm{W}_{\mathrm{sp}}$.

Such a spacer is introduced into the pancake winding as follows. After a certain number of turns a nonconducting, sufficiently solid material with the width of the cable is wrapped around the existing winding pattern as shown in the sketch below.

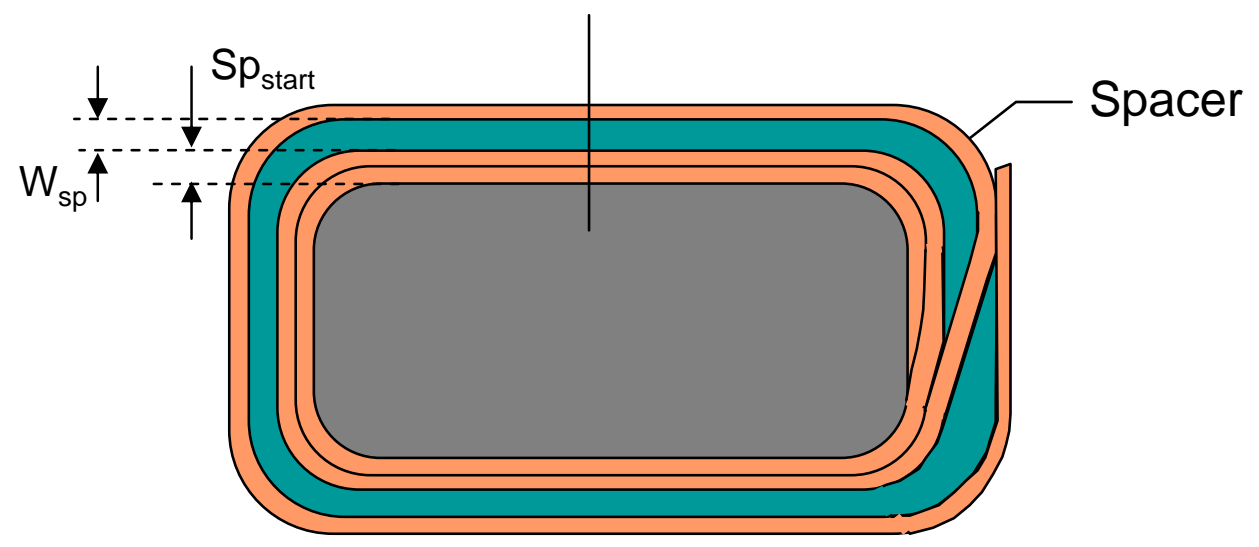




\section{Optimizing Cable Width}

In the optimization shown on the previous pages the spacer start is fixed to one cable thickness, i.e., $1.35 \mathrm{~mm}$. I have tried various other solutions with $2,3, \ldots$ cable width, but no solution can be found, where all higher-order MP are below 10 units. This result is confirmed by leaving this parameter also free. In this case the optimum start of the spacer is at $1.63 \mathrm{~mm}$, which could be accommodated with a cable of that width.

\begin{tabular}{|l|c|c|r|}
\hline \multicolumn{4}{|c|}{ Block Defining Parameters } \\
\hline Parameter & Name & Unit & Value \\
\hline Number of blocks per cell & lblock & - & 8 \\
\hline Aperture radius & Rap & m & 0.03000 \\
\hline Corner gap & Lgap & m & 0.00150 \\
\hline Block width (cable width) & DB & m & 0.00440 \\
\hline Block length & LB & m & 0.02079 \\
\hline Spacer distance from pole & SPstart & m & 0.00163 \\
\hline Spacer width & Wsp & m & 0.00766 \\
\hline
\end{tabular}

\begin{tabular}{|c|c|c|c|c|c|c|c|c|} 
& A1 & B1 & A5 & B5 & A9 & B9 & A13 & B13 \\
\hline Norm. Fields & 0.000 & 0.740 & $0.000 \mathrm{E}+00$ & $2.117 \mathrm{E}-07$ & $0.000 \mathrm{E}+00$ & $5.485 \mathrm{E}-07$ & $0.000 \mathrm{E}+00$ & $1.917 \mathrm{E}-06$ \\
\hline Units & & & $0.000 \mathrm{E}+00$ & 0.00211684 & $0.000 \mathrm{E}+00$ & $5.485 \mathrm{E}-03$ & $0.000 \mathrm{E}+00$ & $1.917 \mathrm{E}-02$ \\
\hline
\end{tabular}

In this case the target cell $=\mathrm{B} 5^{2}+\mathrm{B}^{2}+\mathrm{B} 13^{2}$ was minimized. All MPs are well below 1 unit. 


\section{Optimization for 4-mm Corner Gap}

\begin{tabular}{|l|c|c|r|}
\hline \multicolumn{4}{|c|}{ Block Defining Parameters } \\
\hline Parameter & Name & Unit & Value \\
\hline Number of blocks per cell & Iblock & - & 8 \\
\hline Aperture radius & Rap & $\mathrm{m}$ & 0.03000 \\
\hline Corner gap & Lgap & $\mathrm{m}$ & 0.00400 \\
\hline Block width (cable width) & DB & $\mathrm{m}$ & 0.00440 \\
\hline Block length & LB & $\mathrm{m}$ & 0.01795 \\
\hline Spacer distance from pole & SPstart & $\mathrm{m}$ & 0.00119 \\
\hline Spacer width & Wsp & $\mathrm{m}$ & 0.00896 \\
\hline
\end{tabular}

\begin{tabular}{|c|c|c|c|c|c|c|c|c|} 
& A1 & B1 & A5 & B5 & A9 & B9 & A13 & B13 \\
\hline Norm. Fields & 0.000 & 0.514 & $0.000 \mathrm{E}+00$ & $1.193 \mathrm{E}-08$ & $0.000 \mathrm{E}+00$ & $1.211 \mathrm{E}-08$ & $0.000 \mathrm{E}+00$ & $1.314 \mathrm{E}-08$ \\
\hline Units & & & $0.000 \mathrm{E}+00$ & 0.00011928 & $0.000 \mathrm{E}+00$ & $1.211 \mathrm{E}-04$ & $0.000 \mathrm{E}+00$ & $1.314 \mathrm{E}-04$ \\
\hline
\end{tabular}

All MPs are vanishing for a cable width and spacer start of $1.19 \mathrm{~mm}$, which is actually a very "attractive" value for the cable width. However, since 17.95 cannot be exactly made with a 1.19-mm cable, I recalculate the MP content for $15^{\star} 1.19 \mathrm{~mm}=17.8 \mathrm{~mm}$. It still gives a very good field quality without any reoptimization. The largest MP (B5) is 2.5 units.

\begin{tabular}{|c|c|c|c|c|c|c|c|c|} 
& A1 & B1 & A5 & B5 & A9 & B9 & A13 & B13 \\
\hline Norm. Fields & 0.000 & 0.505 & $0.000 \mathrm{E}+00$ & $2.536 \mathrm{E}-04$ & $0.000 \mathrm{E}+00$ & $2.495 \mathrm{E}-05$ & $0.000 \mathrm{E}+00$ & $3.120 \mathrm{E}-05$ \\
\hline Units & & & $0.000 \mathrm{E}+00$ & 2.53631555 & $0.000 \mathrm{E}+00$ & $2.495 \mathrm{E}-01$ & $0.000 \mathrm{E}+00$ & $3.120 \mathrm{E}-01$ \\
\hline
\end{tabular}




\section{Effect of Corner Gap Size}

The size of the corner gap has been varied and the $3 \times 3$ array MP content in the center cell optimized for each case:

\begin{tabular}{|c|r|r|r|r|}
\hline Lgap & \multicolumn{1}{|c|}{ Grad. } & \multicolumn{1}{c|}{ B5 } & \multicolumn{1}{c|}{ B9 } & \multicolumn{1}{c|}{ B13 } \\
\hline mm & \multicolumn{1}{c|}{ T/m } & \multicolumn{1}{c|}{ units } & \multicolumn{1}{c|}{ units } & \multicolumn{1}{c|}{ units } \\
\hline 1.00 & 103.7 & -1.3 & -5.5 & 2.3 \\
\hline 2.00 & 91.7 & 2.4 & -4.2 & 2.2 \\
\hline 3.00 & 77.6 & 4.6 & -3.3 & 1.3 \\
\hline 3.50 & 68.8 & 4.6 & -2.9 & 0.6 \\
\hline
\end{tabular}

Increasing the corner gap by $1 \mathrm{~mm}$ reduces the gradient for an array with optimized MP content by more than 10 tesla/m.

The calculated gradients shown above are for an engineering current density of $690 \mathrm{~A} / \mathrm{mm}^{2}$ 


\section{MP Content of All Cells in Array}

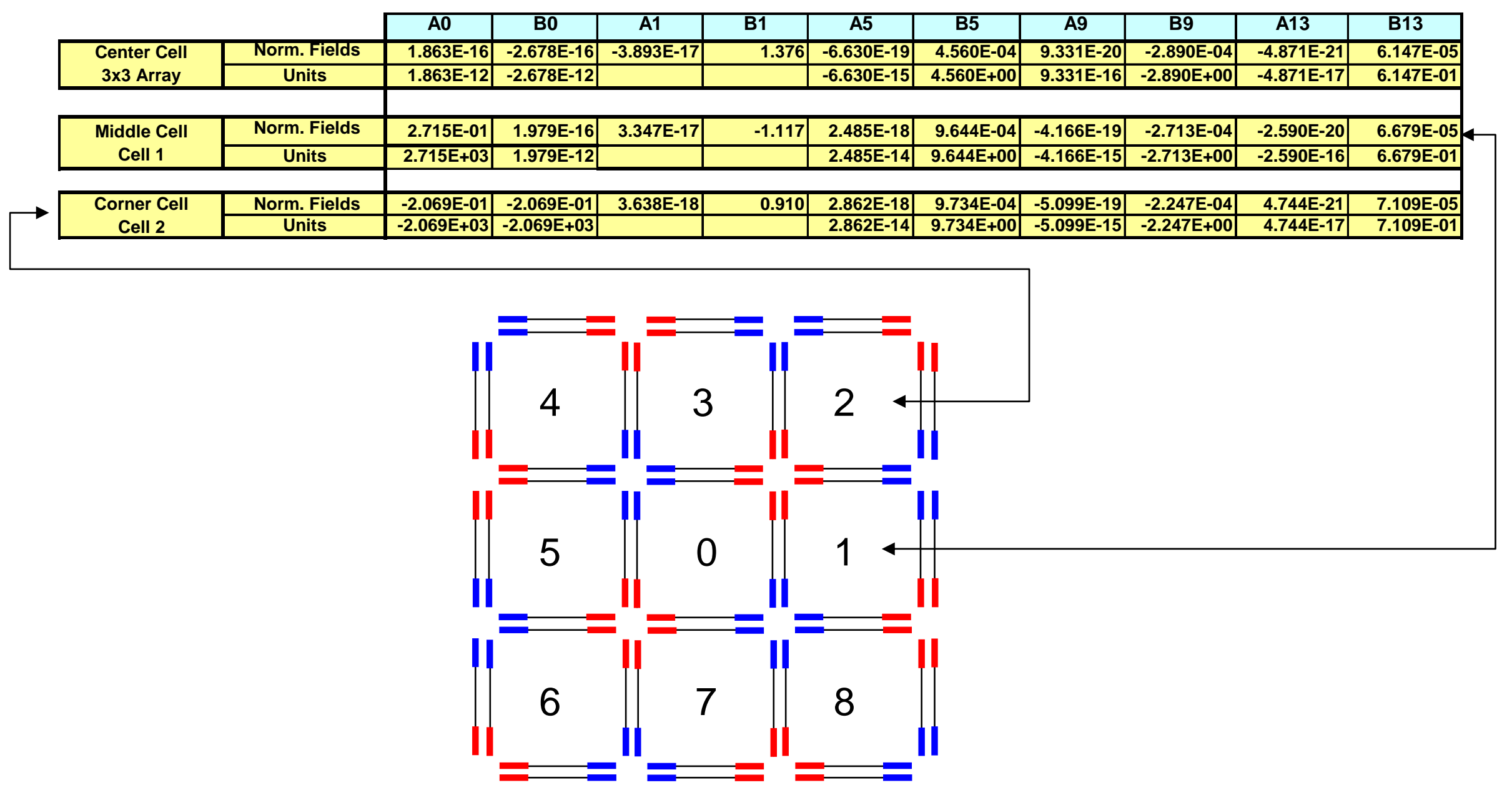




\section{Edge Termination: Next Steps}

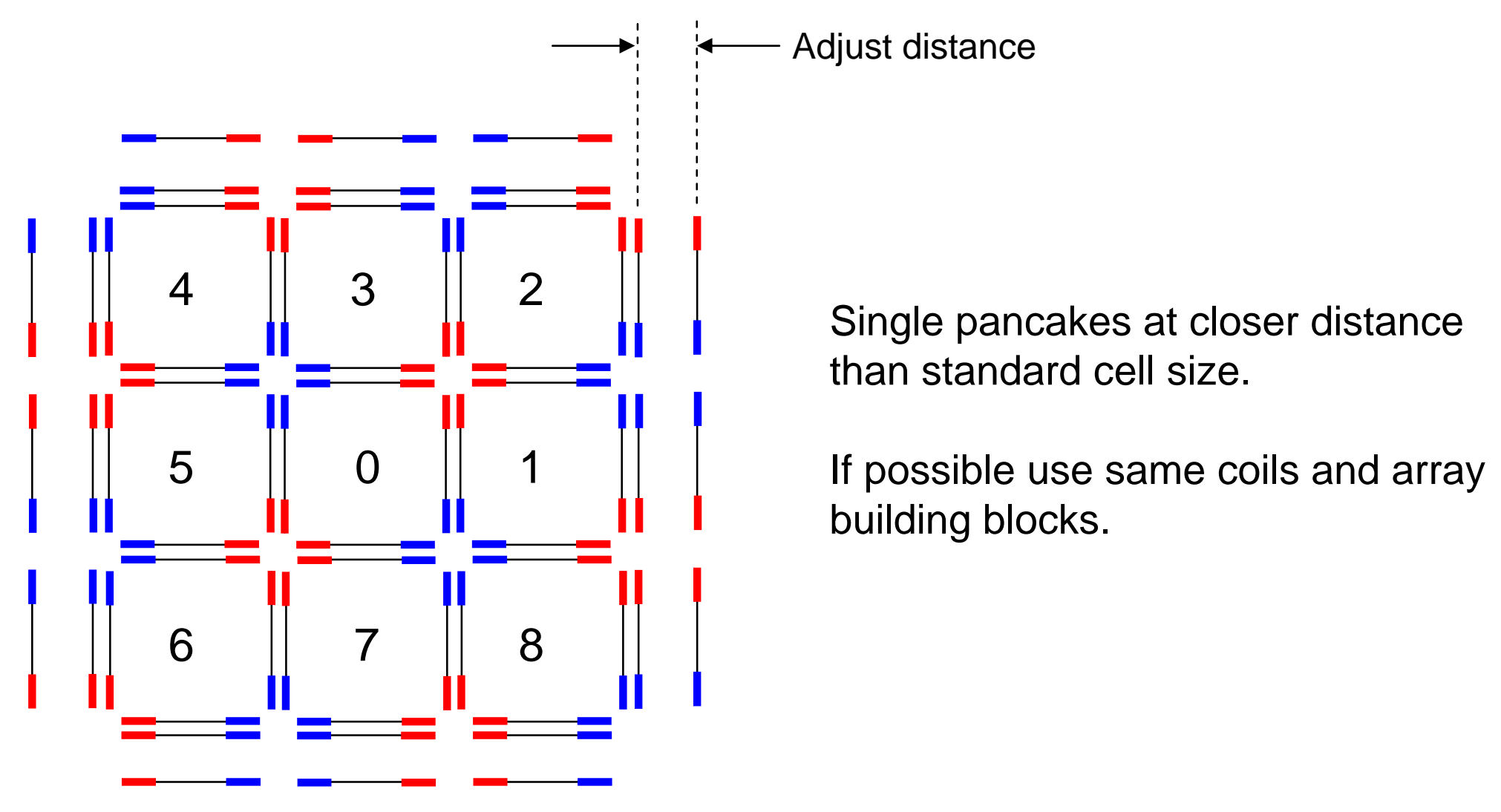




\section{Corner Cell Correction}

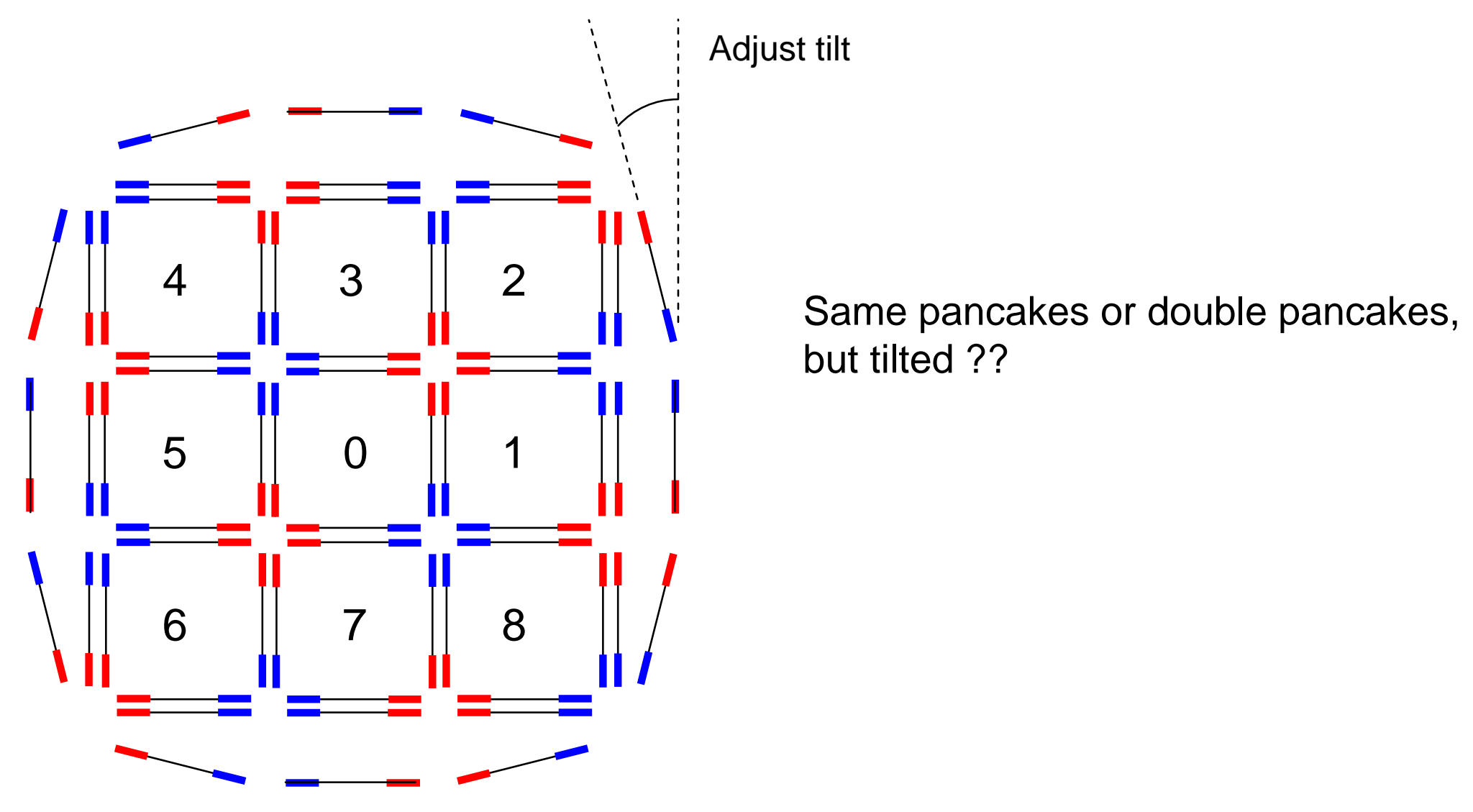




\section{Work In Progress}




\title{
Field Uniformity Optimization
}

of a

$3 \times 3$ Quadrupole Array

\author{
R. MeInhe \\ 2/28/2005
}

DoE Award No. DE-FG02-04ER86205 


\section{Mathematical Model of Cells and Current Blocks}

The performed field calculations start with a single cell consisting of 4 single-layer pancake coils (see Figure 1 on next page), which form the four walls of a square box as shown below. The winding of each pancake coil is described by 2 identical current blocks, e.g. 2 and 3 in the sketch, which contain a spacer. Each current block is described by 4 parameters; the length $L_{B}$, the width $D_{B}$, the start position of the spacer $\mathrm{SP}_{\text {start }}$, and the spacer width $\mathrm{W}_{\mathrm{sp}}$. Additionally, the parameter $\mathrm{L}_{\text {gap }}$ determines the position of the current blocks in the pancake winding, which determines the corner gap of the quadrupole cell.

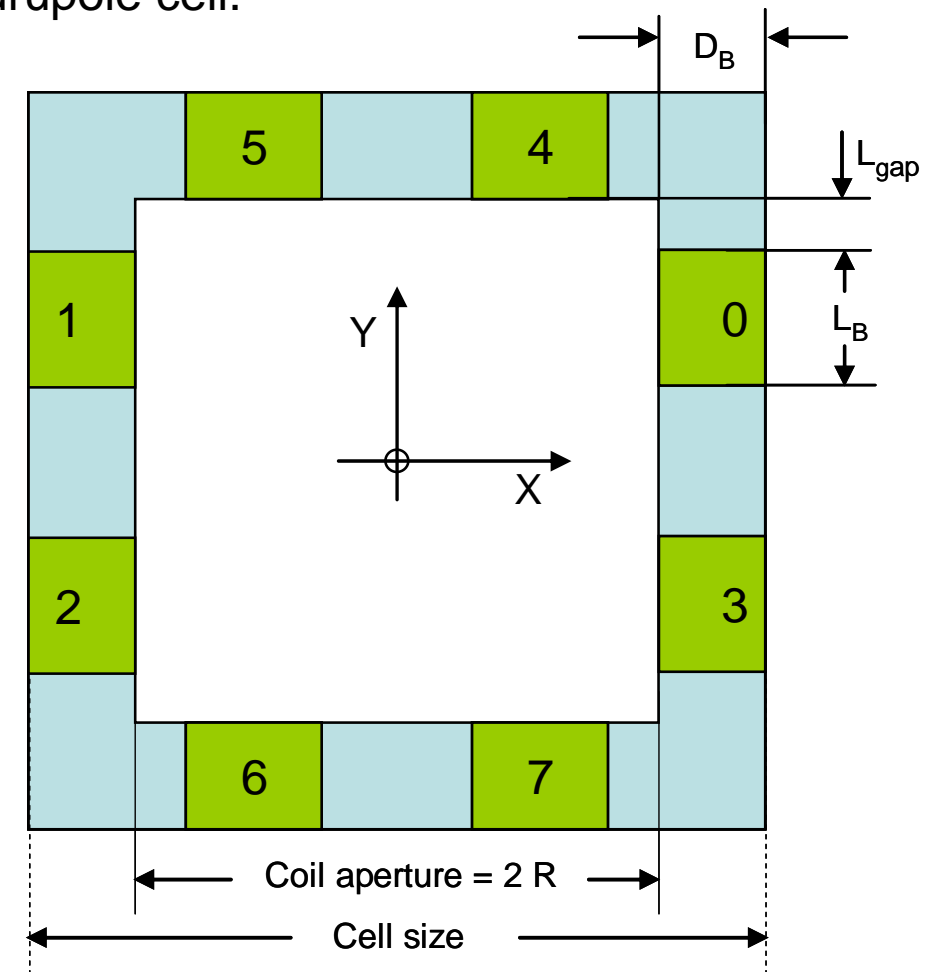

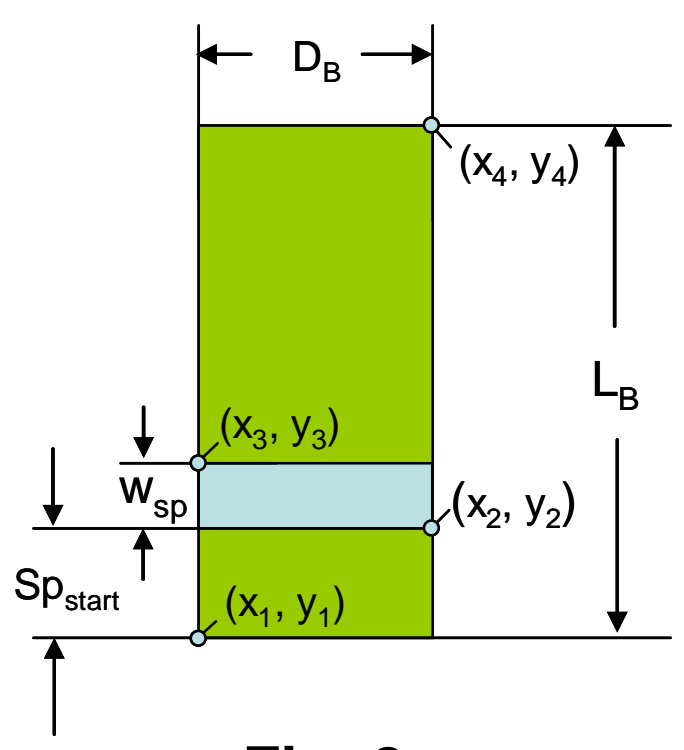

Fig. 2

Fig. 1 


\section{Calculation Procedure: From Single Cell to Array}

Fig. 3

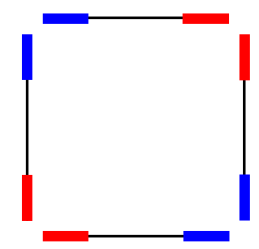

Base cell of array, single

pancake coils

Fig. 4
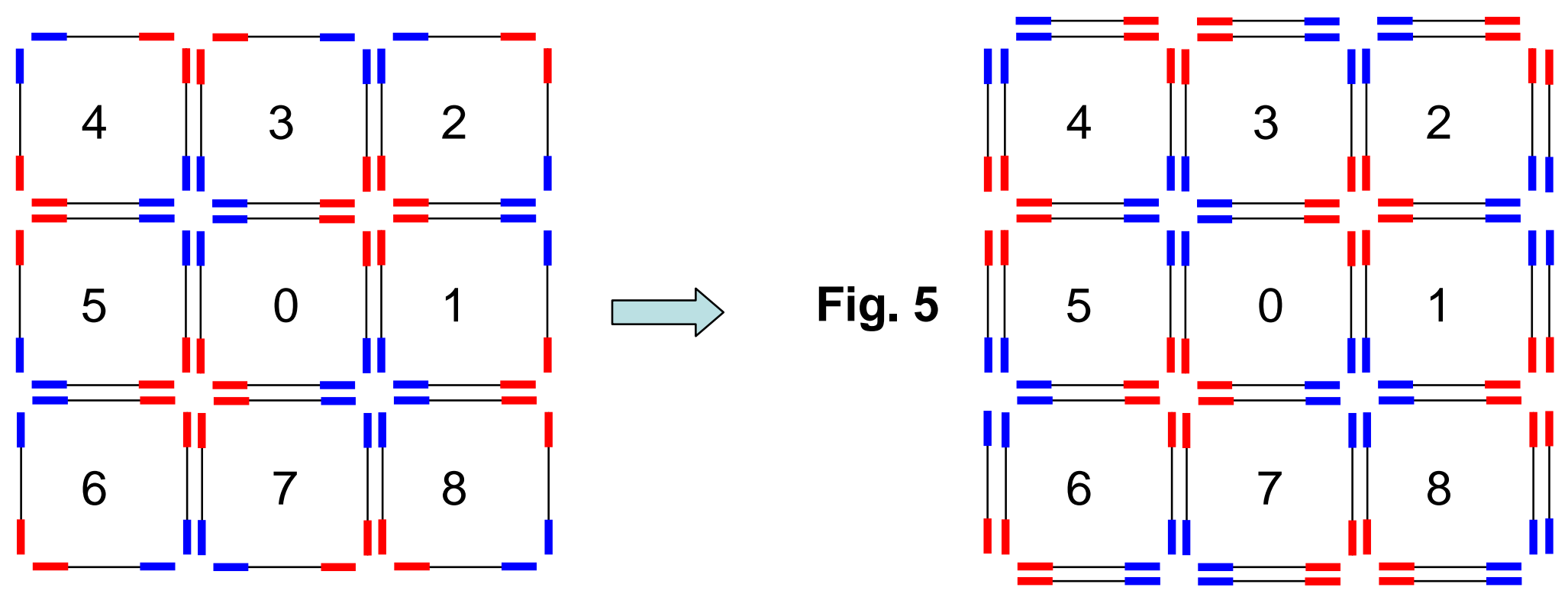

Array of $3 \times 3$ base cells

Complete $3 \times 3$ Array consisting of double pancake coils 


\section{Mathematical Model of the $3 \times 3$ Array}

Nine cells form the basic array as shown on the previous page (Figure 4). Since the cells consist of single-layer pancake coils, one coil layer is still missing on the outer boundary and is added to form the array as built form double pancake coils (shown in Figure 5).

Figure 6 on page 5 shows a complete layer of single-layer pancake correction coils surrounding the array. With the help of these coils the middle cells $(1,3,5,7)$ should be correctable. The distance of these correction coils from the outside of the array will be optimized to give best field uniformity in the middle array cells. Additionally these cells should have no significant dipole component, which would need to be corrected with dipole steering coils in an accelerator application of the array.

Extra coils are most likely needed to correct the corner cells $(2,4,6,8)$ as indicated in Fig. 7 . Tilting the coils of the outer wall towards the corners (see Figure 8 on page 6) might be a possibility to avoid the extra diagonal coils. 


\section{Possible Correction Schemes, Nomenclature}

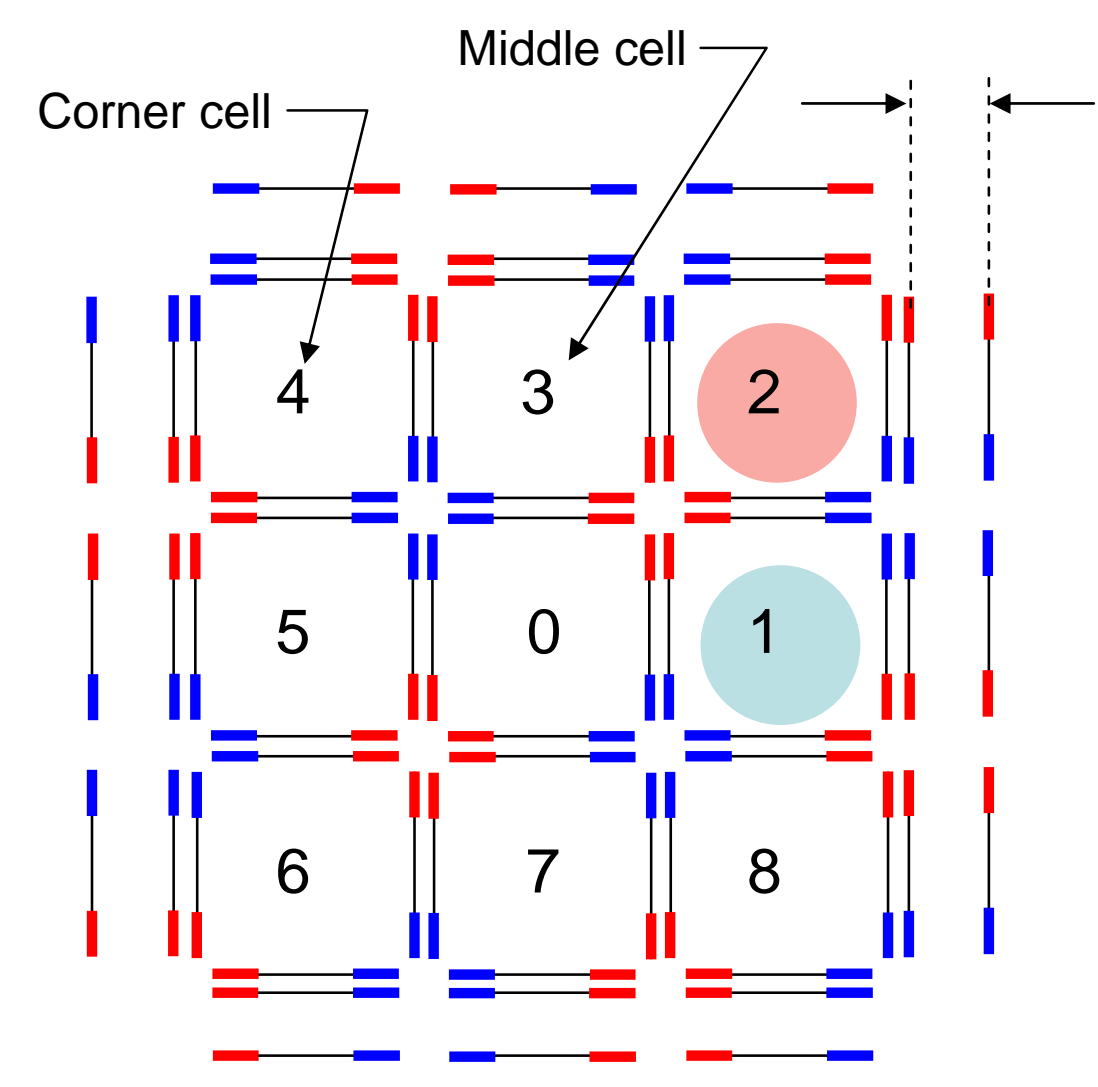

Fig. 6

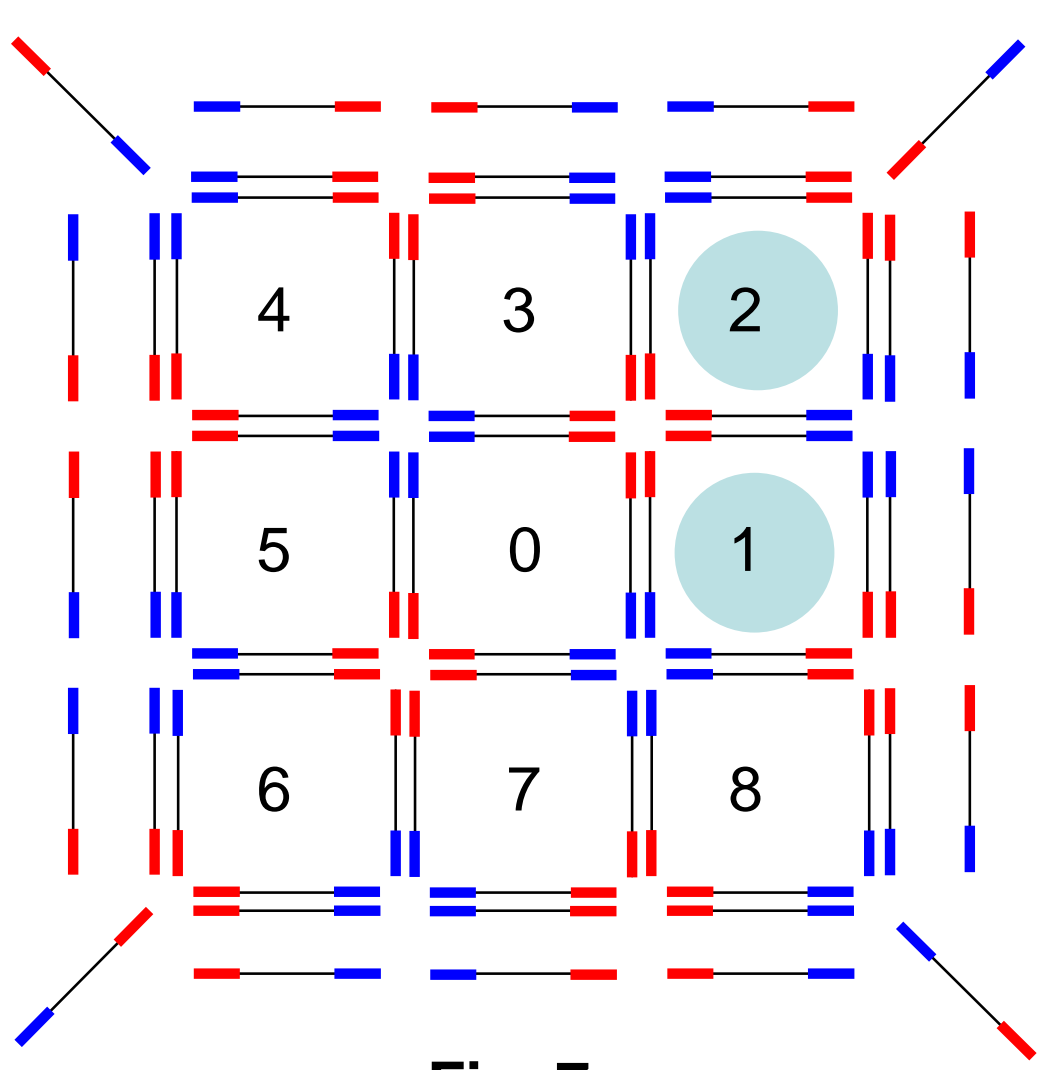

Fig. 7

The walls of the outer termination coils correct the middle cells $(1,3,5,7)$. Extra coils are needed for the corner cells $(2,4,6,8)$. 


\section{Possible Correction Schemes}

Fig. 8

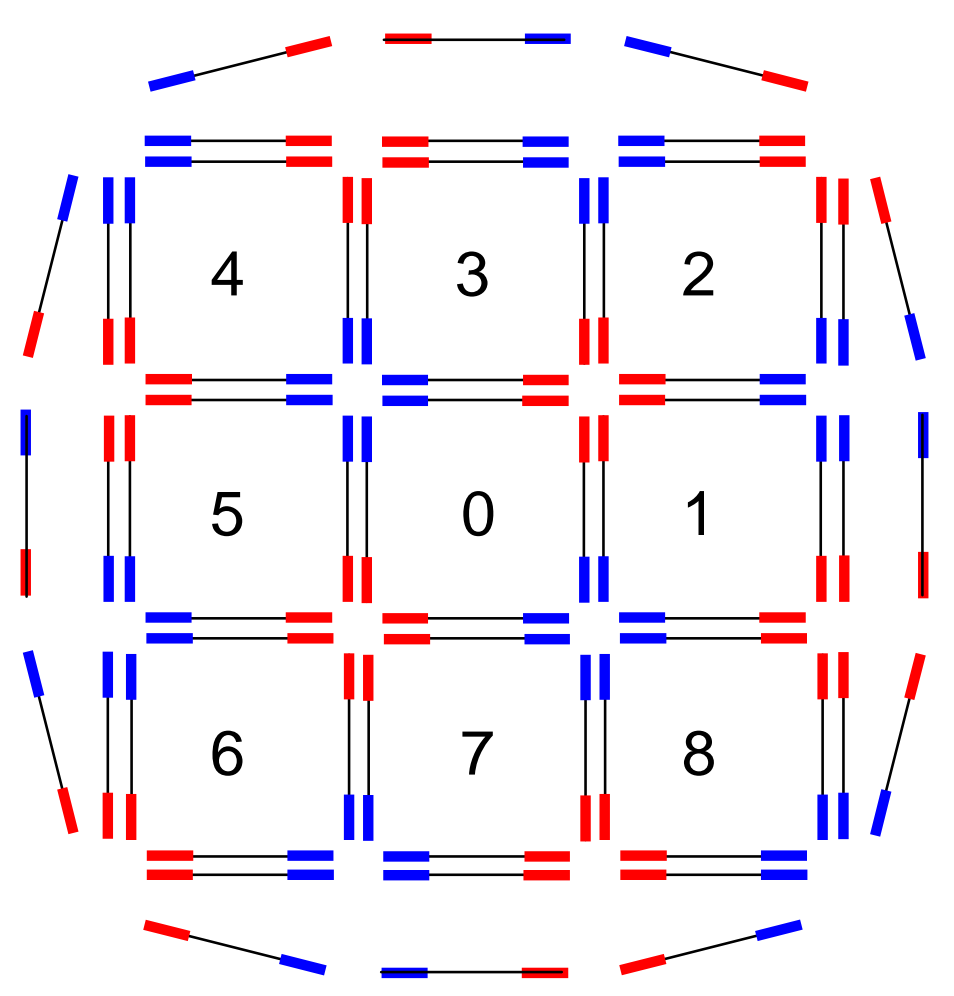

Tilting the correction coils in the outer walls might eliminate the need for the diagonal coils shown in Figure 7 on the previous page. 


\section{Correction Strategy}

$>$ Optimize in 2-D the center cell (cell 0) in the array, i.e., gradient and field uniformity by optimizing the corner gap, the block length, the spacer location and the spacer width.

> Put a wall of correction coils around to correct the middle cells $(1,3,5,7)$. Ideally these cells should have the same gradient as the center cell, no dipole and sufficiently small MP components.

D Experience has shown that these correction coils do not effect the center cell (cell 0 ) and no new optimization is needed when the outer correction coils are included.

$>$ Correct the corner cells $(2,4,6,8)$ with additional coils or by tilting the correction coils in the corners as shown on the previous slide.

$>$ If a 2-D solution has been found, calculate this configuration in 3-D with iron poles and determine the change in MP fields relative to 2-D.

> Re-run the 2-D optimization to compensate for the observed shift in MP fields.

> Use passive iron shielding on the outside to reduce stray magnetic fields. If the iron shield effects MP fields rerun 2-D optimization to compensate for this effect. 


\section{Step 1: Base Cell of Array}

Fig. 9

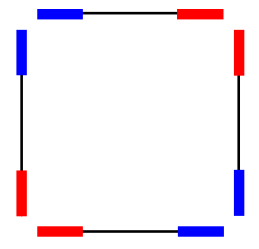

Base cell of array, single pancake coils

\begin{tabular}{|c|c|r|}
\hline \multicolumn{3}{|c|}{ Optimization of Cell } \\
\hline \multicolumn{2}{|c|}{ DefineTarget } & $1.241 \mathrm{E}-16$ \\
\hline Gradient & T/m & 32.71 \\
\hline A5 & units & 0.00 \\
\hline B5 & units & 0.00 \\
\hline A9 & units & 0.00 \\
\hline B9 & units & 0.00 \\
\hline A13 & units & 0.00 \\
\hline B13 & units & 0.00 \\
\hline
\end{tabular}

\section{5-mm Corner Gap}

\begin{tabular}{|l|c|c|r|}
\hline \multicolumn{4}{|c|}{ Block Defining Parameters } \\
\hline Parameter & Name & Unit & Value \\
\hline Number of blocks per cell & Iblock & - & 8 \\
\hline Aperture radius & Rap & $\mathrm{m}$ & 0.03000 \\
\hline Corner gap & Lgap & $\mathrm{m}$ & 0.00250 \\
\hline Block width (cable width) & DB & $\mathrm{m}$ & 0.00440 \\
\hline Block length & LB & $\mathrm{m}$ & 0.01966 \\
\hline Spacer distance from pole & SPstart & $\mathrm{m}$ & 0.00147 \\
\hline Spacer width & Wsp & $\mathrm{m}$ & 0.00812 \\
\hline Correction wall distance & DCW & $\mathrm{m}$ & 0.02650 \\
\hline
\end{tabular}

All reference radii are $20 \mathrm{~mm}$ in this document, i.e., 2/3 of aperture.

\section{Parameter Optimization:}

$$
\chi^{2}=\mathrm{B}_{5}{ }^{2}+\mathrm{B}_{9}{ }^{2}+\mathrm{B}_{13}{ }^{2} \text { (in units) }
$$




\section{Step 2: Array of $3 \times 3$ Base Cells}

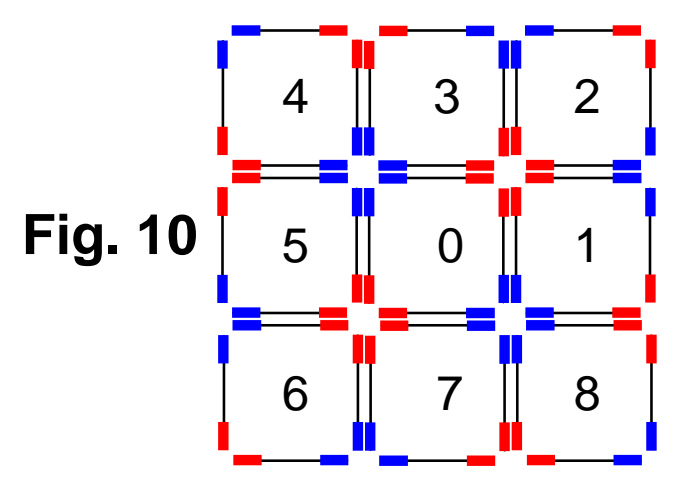

\section{Center Cell}

\begin{tabular}{|c|c|r|}
\hline \multicolumn{2}{|c|}{ Optimization of 3x3 Array } \\
\hline \multicolumn{2}{|c|}{ DefineTarget } & $1.616 \mathrm{E}-16$ \\
\hline Gradient & T/m & 75.39 \\
\hline A5 & units & 0.00 \\
\hline B5 & units & 0.00 \\
\hline A9 & units & 0.00 \\
\hline B9 & units & 0.00 \\
\hline A13 & units & 0.00 \\
\hline B13 & units & 0.00 \\
\hline
\end{tabular}

\section{5-mm Corner Gap}

\begin{tabular}{|l|c|c|r|}
\hline \multicolumn{4}{|c|}{ Block Defining Parameters } \\
\hline Parameter & Name & Unit & Value \\
\hline Number of blocks per cell & Iblock & - & 8 \\
\hline Aperture radius & Rap & $\mathrm{m}$ & 0.03000 \\
\hline Corner gap & Lgap & $\mathrm{m}$ & 0.00250 \\
\hline Block width (cable width) & DB & $\mathrm{m}$ & 0.00440 \\
\hline Block length & LB & $\mathrm{m}$ & 0.01962 \\
\hline Spacer distance from pole & SPstart & $\mathrm{m}$ & 0.00154 \\
\hline Spacer width & Wsp & $\mathrm{m}$ & 0.00851 \\
\hline Correction wall distance & DCW & $\mathrm{m}$ & 0.02650 \\
\hline
\end{tabular}




\section{Step 3: Complete 3×3 Array}

Fig. 11

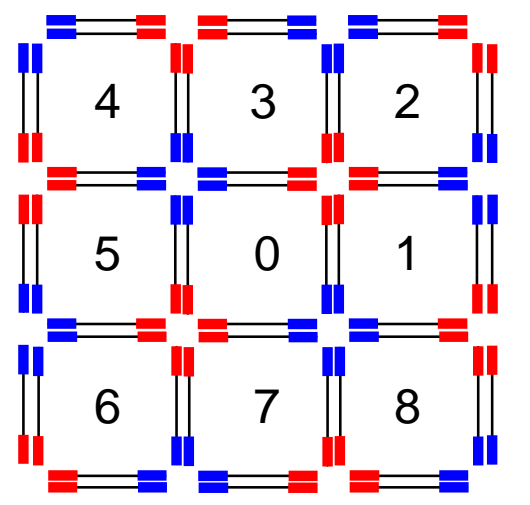

Include outer coils to form complete array consisting of double pancake coils.

No significant effect on field in center cell (0).
Center Cell

\begin{tabular}{|c|c|r|}
\hline \multicolumn{2}{|c|}{ Optimization of 3×3 Array } \\
\hline \multicolumn{2}{|c|}{ DefineTarget } & $2.192 \mathrm{E}-16$ \\
\hline Gradient & T/m & 73.53 \\
\hline A5 & units & 0.00 \\
\hline B5 & units & 0.00 \\
\hline A9 & units & 0.00 \\
\hline B9 & units & 0.00 \\
\hline A13 & units & 0.00 \\
\hline B13 & units & 0.00 \\
\hline
\end{tabular}

\section{5-mm Corner Gap}

\begin{tabular}{|l|c|c|r|}
\hline \multicolumn{4}{|c|}{ Block Defining Parameters } \\
\hline Parameter & Name & Unit & Value \\
\hline Number of blocks per cell & Iblock & - & 8 \\
\hline Aperture radius & Rap & $\mathrm{m}$ & 0.03000 \\
\hline Corner gap & Lgap & $\mathrm{m}$ & 0.00250 \\
\hline Block width (cable width) & DB & $\mathrm{m}$ & 0.00440 \\
\hline Block length & LB & $\mathrm{m}$ & 0.01963 \\
\hline Spacer distance from pole & SPstart & $\mathrm{m}$ & 0.00154 \\
\hline Spacer width & Wsp & $\mathrm{m}$ & 0.00849 \\
\hline Correction wall distance & DCW & $\mathrm{m}$ & 0.02650 \\
\hline \multicolumn{4}{|c}{ Cable width to $\mathbf{1 . 5 4}$} \\
\hline
\end{tabular}




\section{Complete $3 \times 3$ Array}

The conductor used for the HCX magnets had a thickness of $1.35 \mathrm{~mm}$. Since the cable thickness defines the spacer distance from the pole face, fields are recalculated for this conductor (re-optimized with 2 instead of 3 parameters). The effect on the field is modest.

\section{Center Cell}

\begin{tabular}{|c|c|r|}
\hline \multicolumn{2}{|c|}{ Optimization of 3×3 Array } \\
\hline \multicolumn{2}{|c|}{ DefineTarget } & $2.833 \mathrm{E}+00$ \\
\hline Gradient & $\mathrm{T} / \mathrm{m}$ & 79.48 \\
\hline A5 & units & 0.00 \\
\hline B5 & units & -0.12 \\
\hline A9 & units & 0.00 \\
\hline B9 & units & -0.45 \\
\hline A13 & units & 0.00 \\
\hline B13 & units & 1.62 \\
\hline
\end{tabular}

\section{5-mm Corner Gap}

\begin{tabular}{|l|c|c|r|}
\hline \multicolumn{4}{|c|}{ Block Defining Parameters } \\
\hline Parameter & Name & Unit & Value \\
\hline Number of blocks per cell & Iblock & - & 8 \\
\hline Aperture radius & Rap & $\mathrm{m}$ & 0.03000 \\
\hline Corner gap & Lgap & $\mathrm{m}$ & 0.00250 \\
\hline Block width (cable width) & DB & $\mathrm{m}$ & 0.00440 \\
\hline Block length & LB & $\mathrm{m}$ & 0.02097 \\
\hline Spacer distance from pole & SPstart & $\mathrm{m}$ & 0.00135 \\
\hline Spacer width & Wsp & $\mathrm{m}$ & 0.00886 \\
\hline Correction wall distance & DCW & $\mathrm{m}$ & 0.02650 \\
\hline
\end{tabular}

Reduce and fix cable width to $1.35 \mathrm{~mm}$ 


\section{Complete $3 \times 3$ Array}

For completeness the optimization is also done for a corner gap of $3 \mathrm{~mm}$. The quadrupole gradient is reduced by $12 \mathrm{tesla} / \mathrm{m}$ in comparison to the $2.5 \mathrm{~mm}$ gap. The optimum cable thickness is $1.43 \mathrm{~mm}$ for the $3-\mathrm{mm}$ corner gap case.

\section{Center Cell}

\begin{tabular}{|c|c|r|}
\hline \multicolumn{2}{|c|}{ Optimization of 3×3 Array } \\
\hline \multicolumn{2}{|c|}{ DefineTarget } & $1.663 \mathrm{E}-12$ \\
\hline Gradient & T/m & 67.57 \\
\hline A5 & units & 0.00 \\
\hline & & \\
& & \\
B5 & units & 0.00 \\
\hline A9 & units & 0.00 \\
\hline B9 & units & 0.00 \\
\hline A13 & units & 0.00 \\
\hline B13 & units & 0.00 \\
\hline
\end{tabular}

\section{3-mm Corner Gap}

\begin{tabular}{|l|c|c|r|}
\hline \multicolumn{4}{|c|}{ Block Defining Parameters } \\
\hline Parameter & Name & Unit & Value \\
\hline Number of blocks per cell & Iblock & - & 8 \\
\hline Aperture radius & Rap & $\mathrm{m}$ & 0.03000 \\
\hline Corner gap & Lgap & $\mathrm{m}$ & 0.00300 \\
\hline Block width (cable width) & DB & $\mathrm{m}$ & 0.00440 \\
\hline Block length & LB & $\mathrm{m}$ & 0.01905 \\
\hline Spacer distance from pole & SPstart & $\mathrm{m}$ & 0.00143 \\
\hline Spacer width & Wsp & $\mathrm{m}$ & 0.00881 \\
\hline Correction wall distance & DCW & $\mathrm{m}$ & 0.02650 \\
\hline
\end{tabular}

Cable width to $1.43 \mathrm{~mm}$ 


\section{Complete $3 \times 3$ Array}

Fixing the cable width to the nominal of $1.35 \mathrm{~mm}$ leads to a slight increase in gradient, but still significantly less than with the $2.5-\mathrm{mm}$ corner gap. The MP fields remain all below 1 unit in the center cell.

Center Cell
\begin{tabular}{|c|c|r|}
\hline \multicolumn{2}{|c|}{ Optimization of 3x3 Array } \\
\hline \multicolumn{2}{|c|}{ DefineTarget } & $5.950 \mathrm{E}-01$ \\
\hline Gradient & T/m & 70.80 \\
\hline A5 & units & 0.00 \\
\hline B5 & units & -0.05 \\
\hline A9 & units & 0.00 \\
\hline B9 & units & -0.11 \\
\hline A13 & units & 0.00 \\
\hline B13 & units & 0.76 \\
\hline
\end{tabular}

\begin{tabular}{l} 
3-mm Corner Gap \\
\begin{tabular}{|l|c|c|c|}
\hline \multicolumn{4}{|c|}{ Block Defining Parameters } \\
\hline Parameter & Name & Unit & Value \\
\hline Number of blocks per cell & Iblock & - & 8 \\
\hline Aperture radius & Rap & $\mathrm{m}$ & 0.03000 \\
\hline Corner gap & Lgap & $\mathrm{m}$ & 0.00300 \\
\hline Block width (cable width) & DB & $\mathrm{m}$ & 0.00440 \\
\hline Block length & LB & $\mathrm{m}$ & 0.01965 \\
\hline Spacer distance from pole & SPstart & $\mathrm{m}$ & 0.00135 \\
\hline Spacer width & Wsp & $\mathrm{m}$ & 0.00891 \\
\hline Correction wall distance & DCW & $\mathrm{m}$ & 0.02650 \\
\hline
\end{tabular} \\
educe and fix cable width to $\mathbf{1 . 3 5}$ \\
\hline
\end{tabular}

Reduce and fix cable width to $1.35 \mathrm{~mm}$ 


\section{Field in Edge Cells}

After having completed the optimization of the center array cell, we are considering the boundary cells. There are two types of boundary cells, the middle cells and the corner cells (see Figure 12 on the next page for cell nomenclature).

The field calculations done in Excel always sum over all current blocks of the complete array, no symmetry is assumed. Except for the dipole component of the corner cells no skew multipoles show up in the calculation and their values are therefore often suppressed in the tables shown on the following pages. The calculated skew components (except dipole as mentioned) are in the order of $10^{-15}$ or below (see Table 1). 


\section{Complete $3 \times 3$ Array, Field in Edge Cells}

Nomenclature:

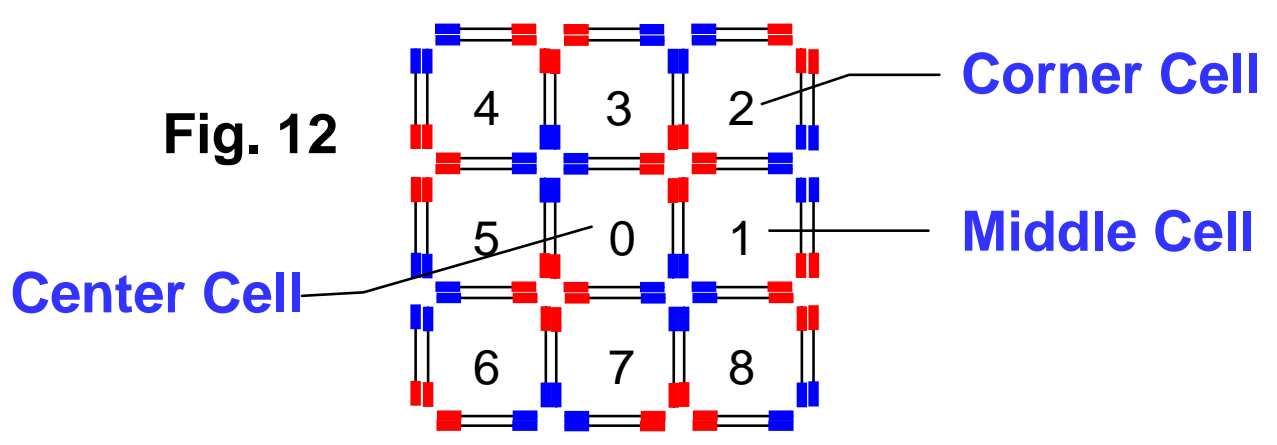

\begin{tabular}{|c|c|c|c|c|c|c|c|c|c|c|c|}
\hline \multirow{2}{*}{\multicolumn{2}{|c|}{ Table 1}} & \multicolumn{10}{|c|}{ Calculate MP Fields of Array } \\
\hline & & $\overline{\mathrm{AO}}$ & $\overline{\text { BO }}$ & $\overline{\mathrm{A1}}$ & $\overline{\mathrm{B} 1}$ & $\overline{\mathrm{A} 5}$ & B5 & $\overline{\mathrm{A} 9}$ & $\overline{\mathrm{B} 9}$ & $\overline{A 13}$ & $\overline{B 13}$ \\
\hline \multirow[t]{2}{*}{ Center Cell } & $\begin{array}{l}\text { Norm. } \\
\text { Fields }\end{array}$ & $-3.498 E-16$ & $-3.512 E-16$ & 2.225E-17 & 1.590 & $3.136 \mathrm{E}-18$ & $-1.197 \mathrm{E}-05$ & $-9.640 \mathrm{E}-20$ & $-4.546 E-05$ & $1.038 \mathrm{E}-20$ & 1.616E-04 \\
\hline & Units & $-3.498 \mathrm{E}-12$ & $-3.512 \mathrm{E}-12$ & & & 3.136E-14 & $-1.197 \mathrm{E}-01$ & $-9.640 \mathrm{E}-16$ & $-4.546 \mathrm{E}-01$ & $1.038 \mathrm{E}-16$ & $1.616 \mathrm{E}+00$ \\
\hline \multirow{2}{*}{$\begin{array}{l}\text { Middle Cell } \\
\quad \text { Cell } 1\end{array}$} & $\begin{array}{l}\text { Norm. } \\
\text { Fields }\end{array}$ & 9.084E-02 & 1.836E-16 & $6.548 \mathrm{E}-18$ & -1.498 & $6.298 \mathrm{E}-19$ & $1.056 \mathrm{E}-03$ & $2.338 \mathrm{E}-21$ & $-5.040 \mathrm{E}-05$ & 7.674E-21 & 1.713E-04 \\
\hline & Units & 9.084E+02 & 1.836E-12 & & & 6.298E-15 & $1.056 \mathrm{E}+01$ & 2.338E-17 & $-5.040 \mathrm{E}-01$ & 7.674E-17 & 1.713E+00 \\
\hline & & & & & & & & & & & \\
\hline \multirow{2}{*}{$\begin{array}{l}\text { Corner Cell } \\
\quad \text { Cell } 2\end{array}$} & $\begin{array}{l}\text { Norm. } \\
\text { Fields }\end{array}$ & $-1.112 E-01$ & $-1.112 E-01$ & $-6.749 E-18$ & 1.396 & 4.868E-18 & $2.258 \mathrm{E}-03$ & $6.564 \mathrm{E}-20$ & $-5.638 E-05$ & 1.806E-20 & 1.837E-04 \\
\hline & Units & $-1.112 E+03$ & $-1.112 E+03$ & & & $4.868 \mathrm{E}-14$ & $2.258 \mathrm{E}+01$ & 6.564E-16 & $-5.638 \mathrm{E}-01$ & 1.806E-16 & $1.837 E+00$ \\
\hline
\end{tabular}

All skew MP fields in all array cells are zero - Order(E-16) - except

skew dipoles in corner cells: 


\section{Complete $3 \times 3$ Array, Edge Cell Fields}

\section{No Edge Termination (skew MP's suppressed for clarity):}

\begin{tabular}{|c|c|c|c|c|c|c|c|c|c|c|c|}
\hline \multirow{2}{*}{\multicolumn{2}{|c|}{ Table 2}} & \multicolumn{10}{|c|}{ Calculate MP Fields of Array } \\
\hline & & $\overline{A 0}$ & $\overline{B 0}$ & A1 & B1 & A5 & B5 & A9 & B9 & A13 & B13 \\
\hline \multirow{2}{*}{ Center Cell } & $\begin{array}{l}\text { Norm. } \\
\text { Fields }\end{array}$ & $-3.498 \mathrm{E}-16$ & $-3.512 E-16$ & \#\#\# & 1.590 & \#\#\# & -1.197E-05 & \#\#\# & $-4.546 \mathrm{E}-05$ & \#\#\# & $1.616 \mathrm{E}-04$ \\
\hline & Units & $-3.498 \mathrm{E}-12$ & $-3.512 \mathrm{E}-12$ & & & \#\#\# & $-1.197 \mathrm{E}-01$ & \#\#\# & $-4.546 \mathrm{E}-01$ & \#\#\# & $1.616 \mathrm{E}+00$ \\
\hline \multirow{2}{*}{$\begin{array}{l}\text { Middle Cell } \\
\text { Cell } 1\end{array}$} & $\begin{array}{l}\text { Norm. } \\
\text { Fields }\end{array}$ & 9.084E-02 & 1.836E-16 & \#\#\# & -1.498 & \#\#\# & 1.056E-03 & \#\#\# & $-5.040 \mathrm{E}-05$ & \#\#\# & 1.713E-04 \\
\hline & Units & $9.084 \mathrm{E}+02$ & $1.836 \mathrm{E}-12$ & & & \#\#\# & $1.056 \mathrm{E}+01$ & \#\#\# & $-5.040 \mathrm{E}-01$ & \#\#\# & $1.713 E+00$ \\
\hline \multirow{2}{*}{$\begin{array}{l}\text { Corner Cell } \\
\quad \text { Cell } 2\end{array}$} & $\begin{array}{l}\text { Norm. } \\
\text { Fields }\end{array}$ & $-1.112 \mathrm{E}-01$ & $-1.112 \mathrm{E}-01$ & \#\#\# & 1.396 & \#\#\# & $2.258 \mathrm{E}-03$ & \#\#\# & $-5.638 \mathrm{E}-05$ & \#\#\# & $1.837 \mathrm{E}-04$ \\
\hline & Units & $-1.112 E+03$ & $-1.112 E+03$ & & & \#\#\# & $2.258 \mathrm{E}+01$ & \#\#\# & $-5.638 \mathrm{E}-01$ & \begin{tabular}{|l|}
$\# \# \#$ \\
\end{tabular} & $1.837 \mathrm{E}+00$ \\
\hline
\end{tabular}

\section{Center cell optimized as before:}

Corner gap $=2.5 \mathrm{~mm}$, spacer start (conductor thickness $=1.35 \mathrm{~mm}$ ).

Quadrupole fields in middle and corner cells are weaker than in the center cell. Drop of $\sim 13 \%$ between center and corner cell on the reference radius of $20 \mathrm{~mm}$.

Strong dipole fields $(\sim 10 \%)$ in middle and corner cells.

Maximum field non-uniformity of 23 units in corner cell. 


\section{Edge Termination Scheme}

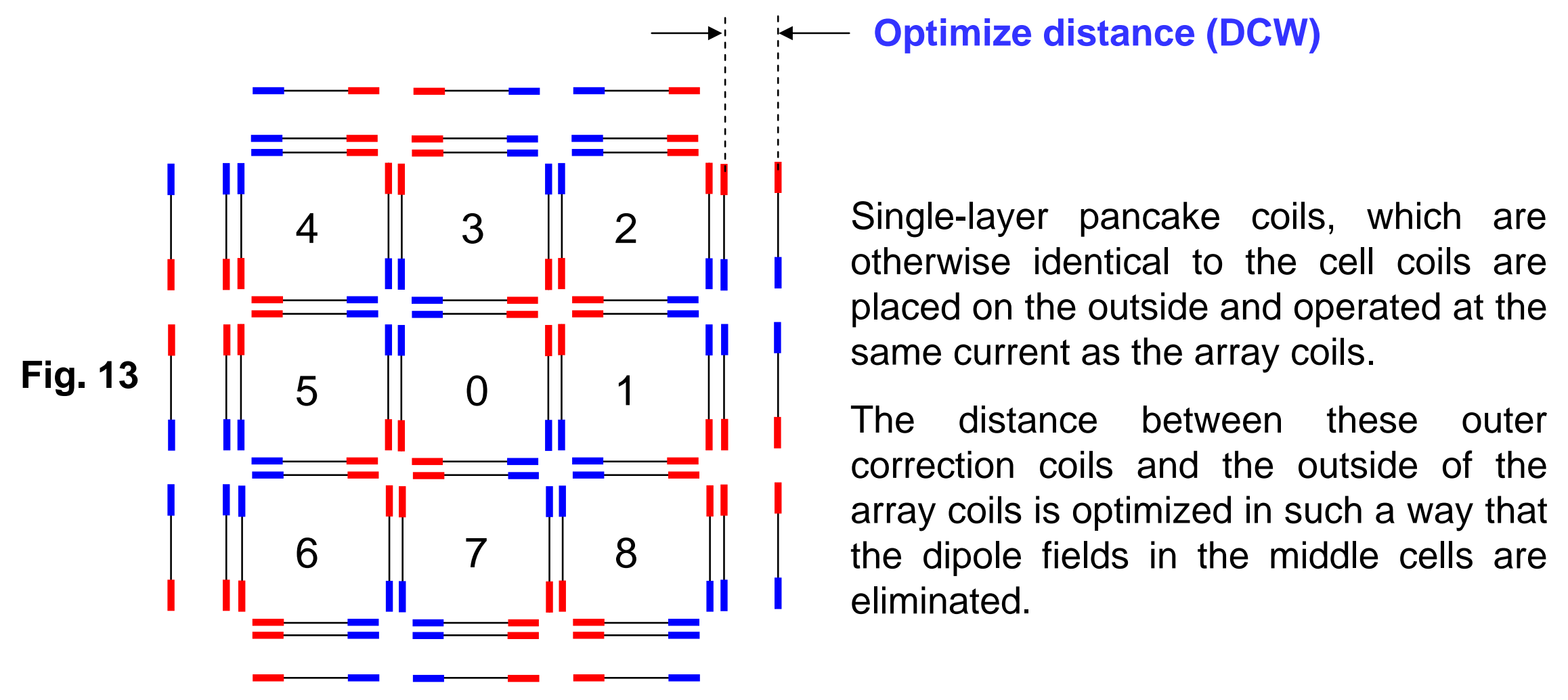

Place correction coils on the outside. Single pancakes with same geometry as main cell coils and same current. 


\section{Complete $3 \times 3$ Array, Edge Cell Fields}

\section{With Edge Termination (see previous slide):}

\begin{tabular}{|c|c|c|c|c|c|c|c|c|c|c|c|}
\hline \multirow[t]{2}{*}{ Table } & & \multicolumn{10}{|c|}{ Calculate MP Fields of Array } \\
\hline & & $\overline{\mathrm{AO}}$ & $\overline{B 0}$ & A1 & B1 & A5 & B5 & A9 & B9 & A13 & B13 \\
\hline \multirow[t]{2}{*}{ Center Cell } & $\begin{array}{l}\text { Norm. } \\
\text { Fields }\end{array}$ & $-2.958 \mathrm{E}-16$ & $-1.770 \mathrm{E}-16$ & \#\#\# & 1.572 & \#\#\# & $-5.069 E-05$ & \#\#\# & $-4.598 E-05$ & \#\#\# & $1.634 \mathrm{E}-04$ \\
\hline & Units & $-2.958 E-12$ & $-1.770 \mathrm{E}-12$ & & & \#\#\# & $-5.069 \mathrm{E}-01$ & \#\#\# & $-4.598 \mathrm{E}-01$ & \#\#\# & $1.634 \mathrm{E}+00$ \\
\hline \multirow{2}{*}{$\begin{array}{l}\text { Middle Cell } \\
\text { Cell } 1\end{array}$} & $\begin{array}{l}\text { Norm. } \\
\text { Fields }\end{array}$ & $-2.772 \mathrm{E}-04$ & $-1.168 E-17$ & \#\#\# & -1.561 & \#\#\# & 1.289E-03 & \#\#\# & $-4.857 \mathrm{E}-05$ & \#\#\# & 1.644E-04 \\
\hline & Units & $-2.772 \mathrm{E}+00$ & $-1.168 \mathrm{E}-13$ & & & \#\#\# & $1.289 \mathrm{E}+01$ & \begin{tabular}{|l|l|}
$\# \# \#$ \\
\end{tabular} & $-4.857 E-01$ & \#\#\# & $1.644 \mathrm{E}+00$ \\
\hline & & & & & & & & & & & \\
\hline \multirow{2}{*}{$\begin{array}{c}\text { Corner Cell } \\
\text { Cell } 2\end{array}$} & $\begin{array}{l}\text { Norm. } \\
\text { Fields }\end{array}$ & -7.187E-02 & $-7.187 \mathrm{E}-02$ & \#\#\# & 1.505 & \#\#\# & 2.808E-03 & \#\#\# & $-5.298 E-05$ & \#\#\# & $1.704 \mathrm{E}-04$ \\
\hline & Units & $-7.187 E+02$ & $-7.187 E+02$ & & & \#\#\# & $2.808 \mathrm{E}+01$ & \#\#\# & $-5.298 \mathrm{E}-01$ & \#\#\# & 1.704E +00 \\
\hline
\end{tabular}

Center cell optimized as before (current block geometry unchanged): Corner gap $=2.5 \mathrm{~mm}$, spacer start (conductor thickness $=1.35 \mathrm{~mm}$ ).

Distance of correction coils (DCW) optimized for middle cell: $\mathbf{D C W}=\mathbf{2 7} \mathbf{~ m m}$

Quadrupole field in middle cell within $1 \%$ of center cell

Dipole field in middle cell $\sim 3$ units

Maximum field non-uniformity in middle cell B5 = 13 units

No significant effect on center cell of array 


\section{Edge Termination Scheme WITHOUT coils}

The addition of correction coils at $27 \mathrm{~mm}$ on the outside of the $3 \times 3$ array leads to a significant increase in array size. Taking both sides into account the array size increase by about 1 cell size or 33\%.

It would be of interest to investigate, if the same correction can be achieved by changing the currents in the boundary cells of the array as schematically indicated in Figure 14 (bold lines).

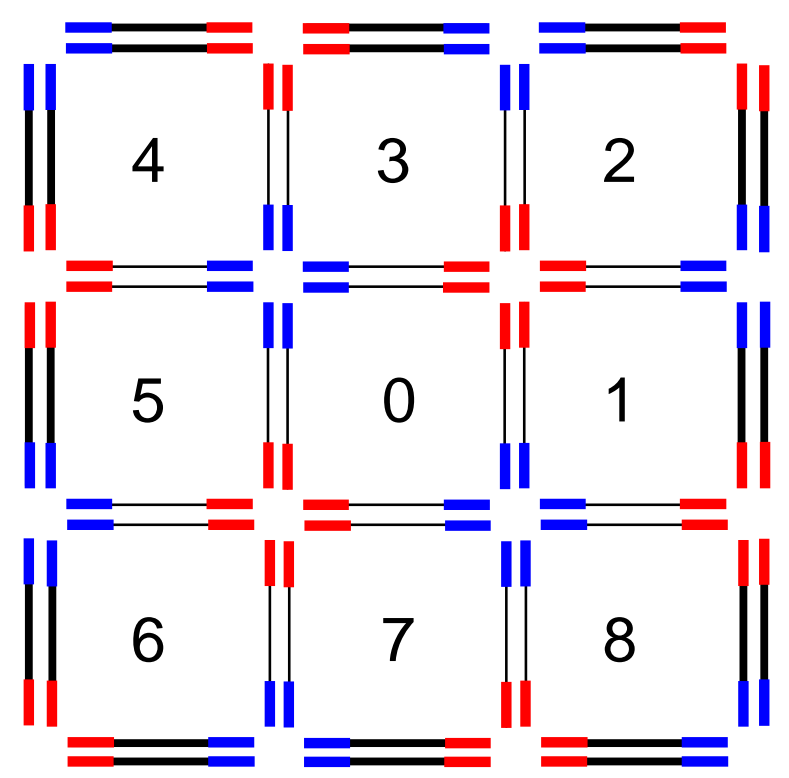

Fig. 14
The currents in all coils on the array boundary are increased by using a shunt power supply. Block structure and spacer locations are unchanged, i.e., all coils are identical.

Such a solution, if it works, would significantly simplify the array. For the $3 \times 3$ array (24 coils) the additional 12-16 coils for the edge termination scheme are saved.

Disadvantage of this solution is that the current margin in the edge coils is reduced. 


\section{Edge Termination Scheme WITHOUT coils}

\begin{tabular}{|c|c|c|c|c|c|c|c|c|c|c|c|}
\hline \multirow{2}{*}{\multicolumn{2}{|c|}{ Table 4}} & \multicolumn{10}{|c|}{ Calculate MP Fields of Array } \\
\hline & & A0 & BO & A1 & B1 & A5 & B5 & A9 & B9 & A13 & B13 \\
\hline \multirow[t]{2}{*}{ Center Cell } & $\begin{array}{l}\text { Norm. } \\
\text { Fields }\end{array}$ & $5.708 \mathrm{E}-16$ & $-2.970 \mathrm{E}-16$ & \#\#\# & 1.576 & \#\#\# & $-1.240 \mathrm{E}-05$ & 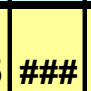 & $-4.761 \mathrm{E}-05$ & \#\#\# & $1.660 \mathrm{E}-04$ \\
\hline & Units & $5.708 \mathrm{E}-12$ & $-2.970 \mathrm{E}-12$ & & & \#\#\# & $-1.240 \mathrm{E}-01$ & \#\#\# & $-4.761 \mathrm{E}-01$ & \#\#\# & $1.660 \mathrm{E}+00$ \\
\hline \multirow{3}{*}{$\begin{array}{l}\text { Middle Cell } \\
\text { Cell } 1\end{array}$} & & & & & & & & & & & \\
\hline & Fields & $-1.004 \mathrm{E}-03$ & $1.809 \mathrm{E}-16$ & $|\# \# \#|$ & -1.570 & |\#\#\# & $1.046 \mathrm{E}-03$ & \#\#\# & $-5.197 \mathrm{E}-05$ & \#\#\# & $1.739 \mathrm{E}-04$ \\
\hline & Units & $-1.004 E+01$ & $1.809 \mathrm{E}-12$ & & & \#\#\# & $1.046 \mathrm{E}+01$ & \#\#\# & 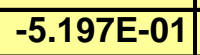 & $\# \# \#$ & $1.739 \mathrm{E}+00$ \\
\hline \multirow{3}{*}{$\begin{array}{l}\text { Corner Cell } \\
\text { Cell } 2\end{array}$} & & & & & & & & & & & \\
\hline & $\begin{array}{l}\text { Norm. } \\
\text { Fields }\end{array}$ & $-5,609 \mathrm{E}-02$ & $-5,609 \mathrm{E}-02$ & $\mid \# \# \#$ & 1.526 & \#\#\# & $2.309 \mathrm{E}-03$ & \#\#\# & $-5,808 \mathrm{E}-05$ & | $\# \# \#$ & $1863 \mathrm{E}-04$ \\
\hline & Units & $-5.609 \mathrm{E}+02$ & $-5.609 \mathrm{E}+02$ & & & \#\#\# & $2.309 \mathrm{E}+01$ & \#\#\# & $-5.808 \mathrm{E}-01$ & \#\#\# & $1.863 \mathrm{E}+00$ \\
\hline
\end{tabular}

Center cell optimized as before:

Corner gap $=2.5 \mathrm{~mm}$, spacer start (conductor thickness $=1.35 \mathrm{~mm}$.

\section{NO EDGE TERMINATION!}

Current in edge coils increased by $17.7 \%$

Quad field in middle cell within $0.5 \%$ of center cell

Dipole field in middle cell $\sim 0$

Maximum field non-uniformity in middle cell

B5 $=10.5$ units

\begin{tabular}{|l|c|c|r|}
\hline \multicolumn{4}{|c|}{ Block Defining Parameters } \\
\hline Parameter & Name & Unit & Value \\
\hline Number of blocks per cell & Iblock & - & 8 \\
\hline Aperture radius & Rap & $\mathrm{m}$ & 0.03000 \\
\hline Corner gap & Lgap & $\mathrm{m}$ & 0.00250 \\
\hline Block width (cable width) & DB & $\mathrm{m}$ & 0.00440 \\
\hline Block length & LB & $\mathrm{m}$ & 0.02099 \\
\hline Spacer distance from pole & SPstart & $\mathrm{m}$ & 0.00135 \\
\hline Spacer width & Wsp & $\mathrm{m}$ & 0.00887 \\
\hline Correction wall distance & DCW & $\mathrm{m}$ & 0.02700 \\
\hline
\end{tabular}

No significant effect on center cell of array 


\section{Edge Termination with Coils versus Increased Current}

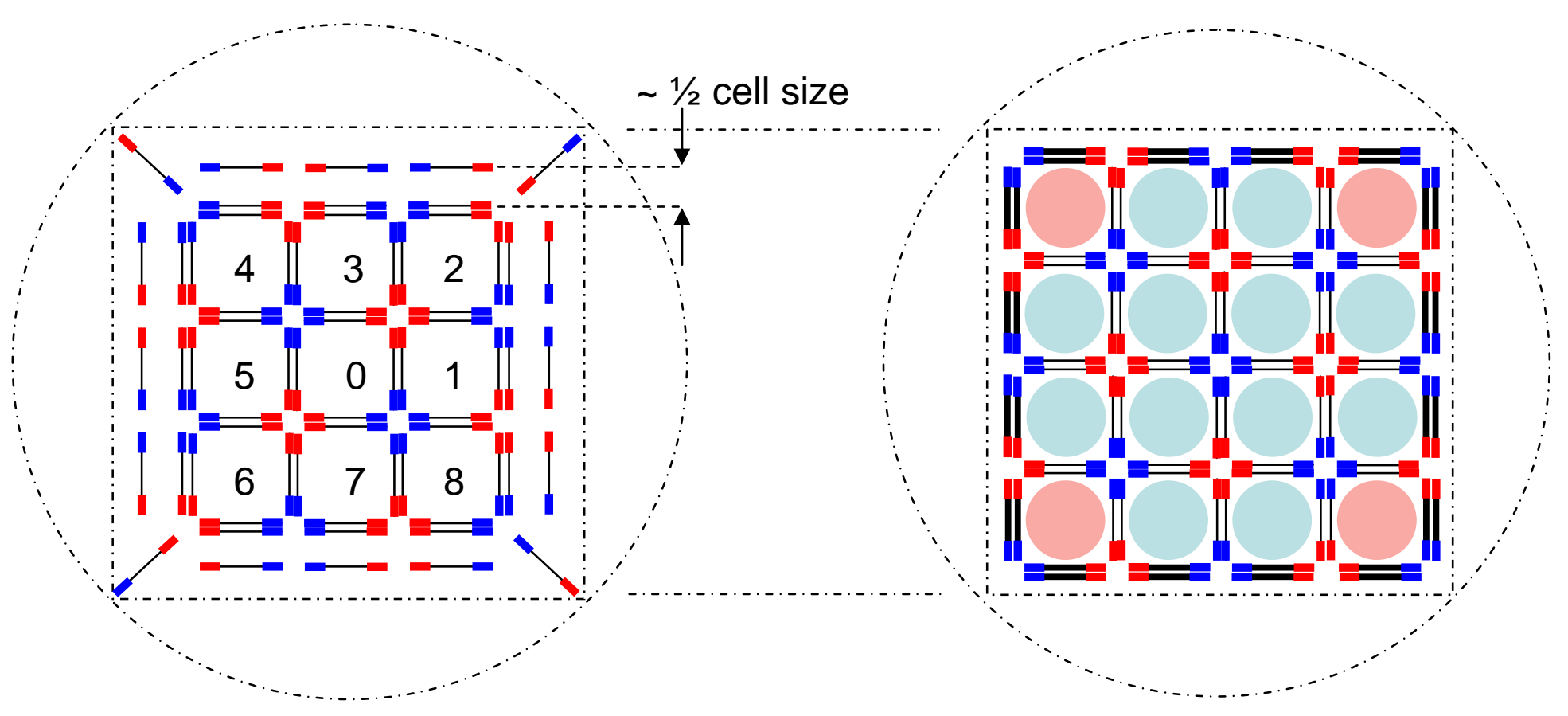

Fig. 15

Fig. 16

The solution with increased currents in the boundary cells gives a useful array except for the corner cells. However, a $4 \times 4$ array with 12 useful cells would fit into the same space as the $3 \times 3$ array with only 9 useful cells (assuming that a correction for the corner cells can be found), as shown in Figures 15 and 16. 


\section{Edge Termination Scheme WITHOUT coils}

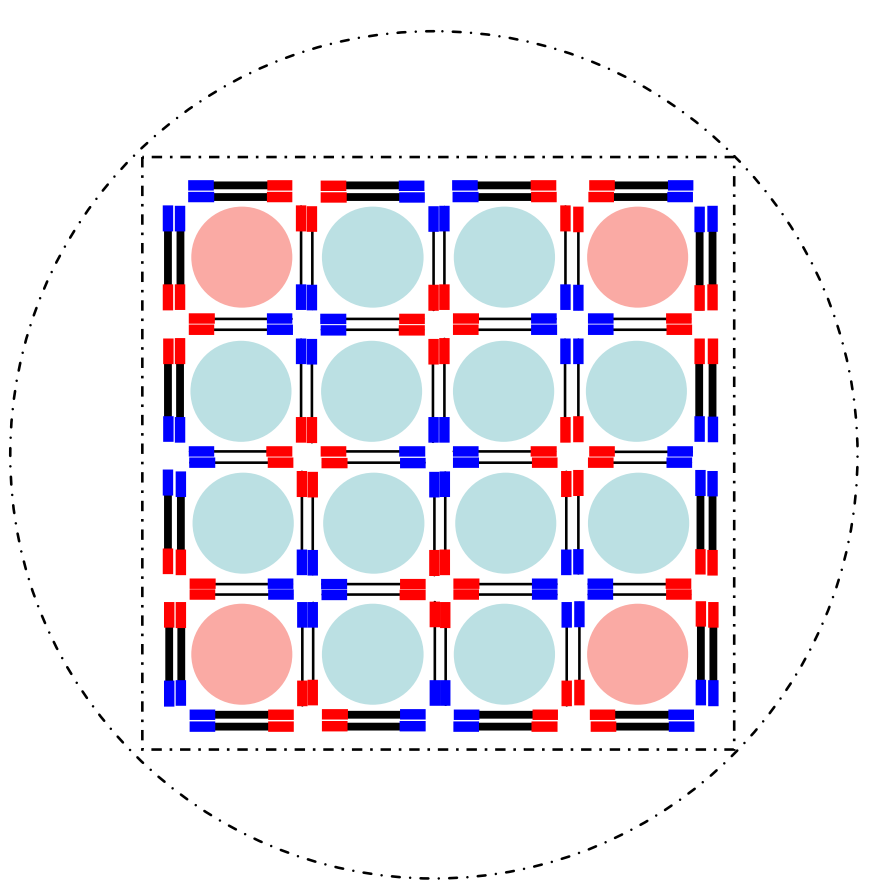

Fig. 17

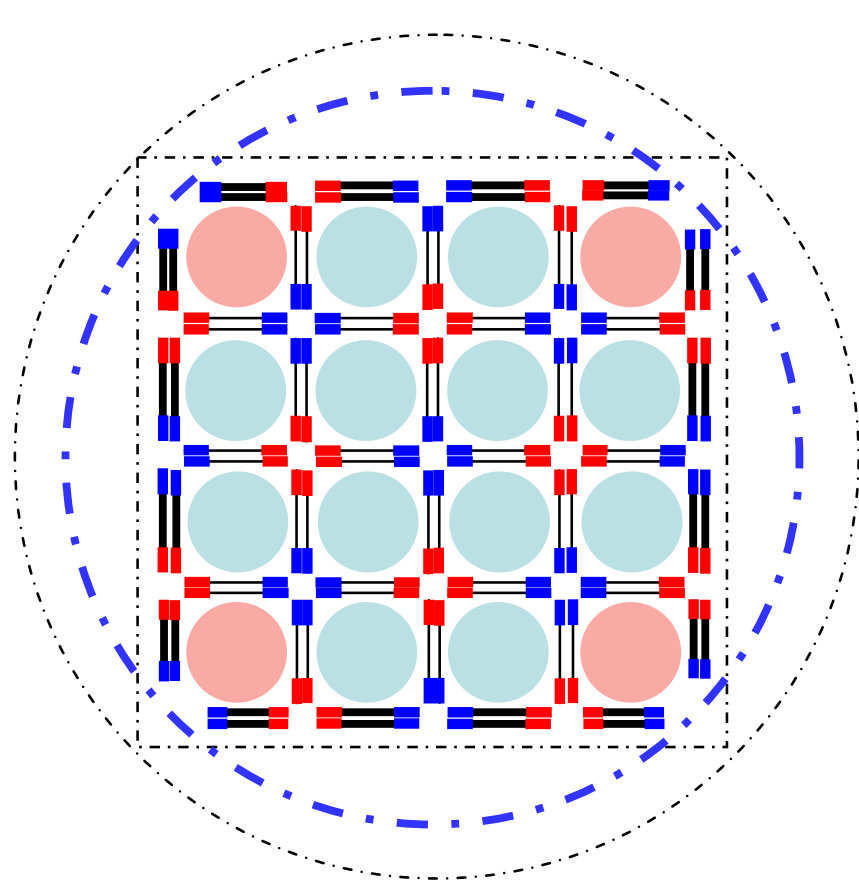

Fig. 18

By reducing the width of the corner cell coils in a $4 \times 4$ array, this version would even fit into a significantly smaller circle than the $3 \times 3$ array (see Figures 17 and 18) leading to additional cost savings. 


\section{Image Current Effect}

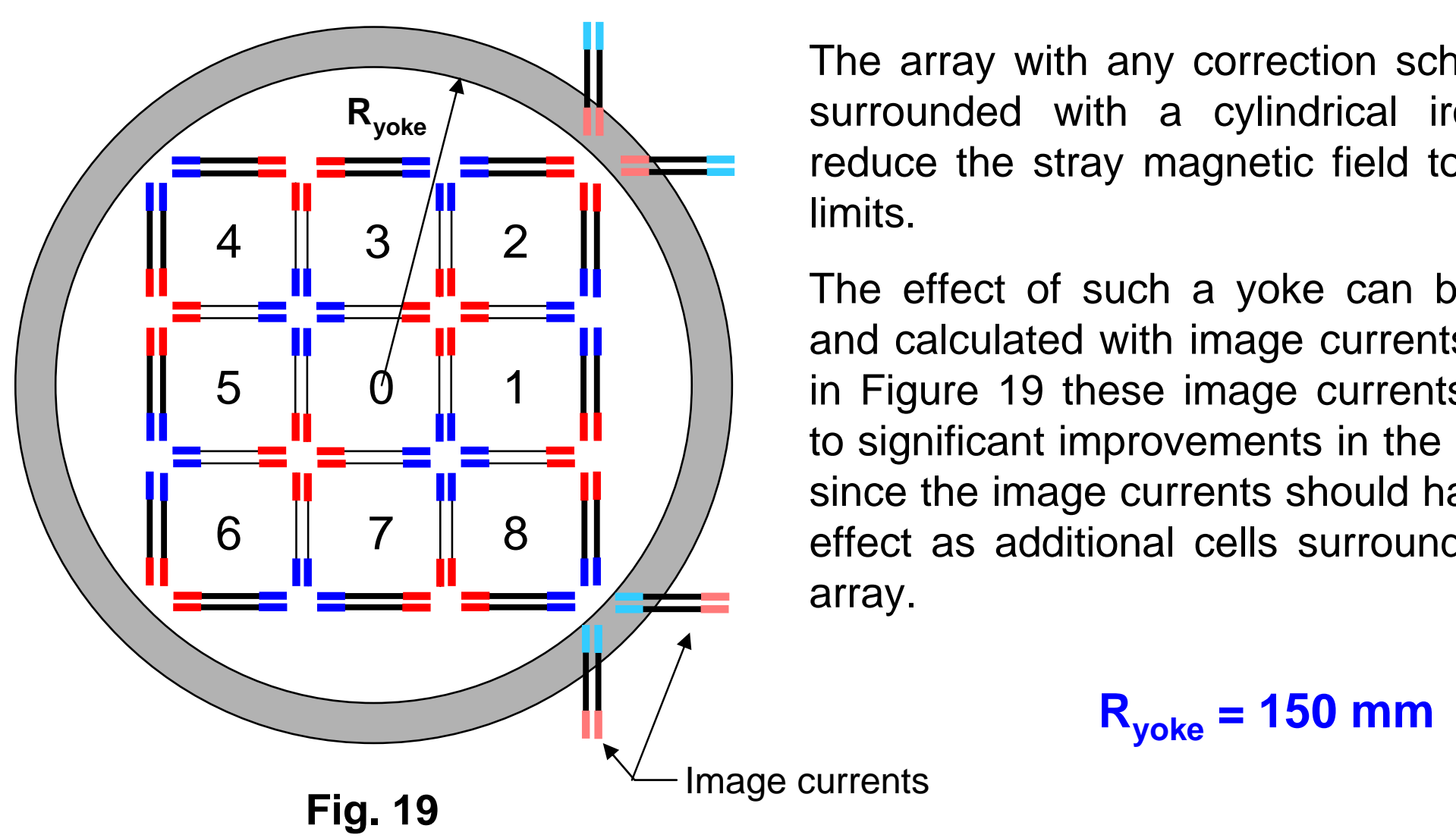

For a cylindrical iron yoke with infinite permeability $\mu$ a physical current at the position $(\mathbf{r}, \phi)$ has a corresponding image current given by $\left(\mathbf{R}_{\text {yoke }} \mathbf{2} \mathbf{r}, \phi\right)$. For infinite $\mu$ of the iron the two currents are equal. 


\section{Edge Termination Scheme WITHOUT coils}

$150 \mathrm{~mm}$ Iron Yoke, Shunt current increase $=1.175$ (compare with Table 4)

\begin{tabular}{|c|c|c|c|c|c|c|c|c|c|c|c|}
\hline \multirow{2}{*}{\multicolumn{2}{|c|}{ Table 5}} & \multicolumn{10}{|c|}{ Calculate MP Fields of Array } \\
\hline & & A0 & B0 & A1 & B1 & A5 & B5 & A9 & B9 & 13 & B13 \\
\hline \multirow[t]{2}{*}{ Center Cell } & $\begin{array}{l}\text { Norm. } \\
\text { Fields }\end{array}$ & $9.005 \mathrm{E}-17$ & $-1.703 E-16$ & \#\#\# & 1.590 & \#\# & $-6.449 \mathrm{E}-05$ & \#\# & $-4.600 \mathrm{E}-05$ & \#\# & 1.621E-04 \\
\hline & Units & $9.005 \mathrm{E}-13$ & $-1.703 \mathrm{E}-12$ & & & \#\# & $-6.449 \mathrm{E}-01$ & \#\# & $-4.600 \mathrm{E}-01$ & \#\# & $1.621 \mathrm{E}+00$ \\
\hline \multirow{3}{*}{$\begin{array}{l}\text { Middle Cell } \\
\text { Cell } 1\end{array}$} & Norm. & & & & & & & & & & \\
\hline & Fields & 5.654E-04 & $3.741 \mathrm{E}-16$ & \#\#\# & -1.550 & \#\# & $1.039 \mathrm{E}-03$ & \#\# & $-5.129 \mathrm{E}-05$ & $\# \#$ & $1.734 \mathrm{E}-04$ \\
\hline & Units & $5.654 \mathrm{E}+00$ & 3.741E-12 & & & \#\# & $1.039 \mathrm{E}+01$ & \#\# & $-5.129 \mathrm{E}-01$ & $\# \#$ & $1.734 \mathrm{E}+00$ \\
\hline \multirow{3}{*}{$\begin{array}{c}\text { Corner Cell } \\
\text { Cell } 2\end{array}$} & Norm. & & & & & & & & & & \\
\hline & Fields & $-5.698 E-02$ & $-5.698 \mathrm{E}-02$ & \#\#\# & 1.539 & \#\# & $2.219 \mathrm{E}-03$ & $\# \#$ & $-5.601 E-05$ & $\# \#$ & $1.818 \mathrm{E}-04$ \\
\hline & Units & $-5.698 E+02$ & $-5.698 E+02$ & & & \#\# & $2.219 \mathrm{E}+01$ & \#\# & $-5.601 \mathrm{E}-01$ & $\# \#$ & $1.818 \mathrm{E}+00$ \\
\hline
\end{tabular}

Quadrupole variation between center and middle cell: $\sim 2.5 \%$

Dipole field in middle cells: $\sim 0$;

$B_{5}$ in middle cell: $<11$ units;

The only effect of the concentric iron yoke is a slight increase in the quadrupole fields, but does not improve the fields in the corner cells. 


\section{Check Image Current Effect}

The outer concentric iron yoke has a small effect on all quadrupole fields, which increase by about $1.5 \%$. However, there is no significant effect on the dipole fields in the middle and corner cells, and the MP fields in all cells remain practically unchanged.

In order to test the image current calculation, the center cell (see Figure 3 on page 3 ) is surrounded by an iron yoke and the effect of the iron yoke on the MP fields is compared in Tables 6 and 7 . The calculation shows the expected strong effect. The quadrupole field increases by $\sim 35 \%$.

Table 6: Center cell without iron yoke:

\begin{tabular}{|c|c|c|c|c|c|c|c|c|c|c|}
\hline & AO & BO & A1 & B1 & A5 & B5 & A9 & B9 & A13 & B13 \\
\hline Norm. Fields & $0.000 \mathrm{E}+00$ & $-1.804 E-16$ & 0.000 & 0.684 & $0.000 E+00$ & $6.535 \mathrm{E}-05$ & $0.000 E+00$ & 4.677E-04 & $0.000 E+00$ & 2.895E-04 \\
\hline Units & & & & & $0.000 \mathrm{E}+00$ & 6.535E-01 & $0.000 \mathrm{E}+00$ & $4.677 \mathrm{E}+00$ & $0.000 \mathrm{E}+00$ & $2.895 E+00$ \\
\hline
\end{tabular}

Table 7: Center cell with iron yoke at $\mathrm{R}=50 \mathrm{~mm}$ :

\begin{tabular}{|c|c|c|c|c|c|c|c|c|c|c|}
\hline & & & & & & & & & \\
& A0 & B0 & A1 & B1 & A5 & B5 & A9 & B9 & A13 & B13 \\
\hline Norm. Fields & $0.000 \mathrm{E}+00$ & $0.000 \mathrm{E}+00$ & 0.000 & 0.933 & $0.000 \mathrm{E}+00$ & $-1.154 \mathrm{E}-03$ & $3.795 \mathrm{E}-19$ & $3.430 \mathrm{E}-04$ & $0.000 \mathrm{E}+00$ & $2.125 \mathrm{E}-04$ \\
\hline Units & & & & & $0.000 \mathrm{E}+00$ & $-1.154 \mathrm{E}+01$ & $3.795 \mathrm{E}-15$ & $3.430 \mathrm{E}+00$ & $0.000 \mathrm{E}+00$ & $2.125 \mathrm{E}+00$ \\
\hline
\end{tabular}




\section{Corner Cell Correction}

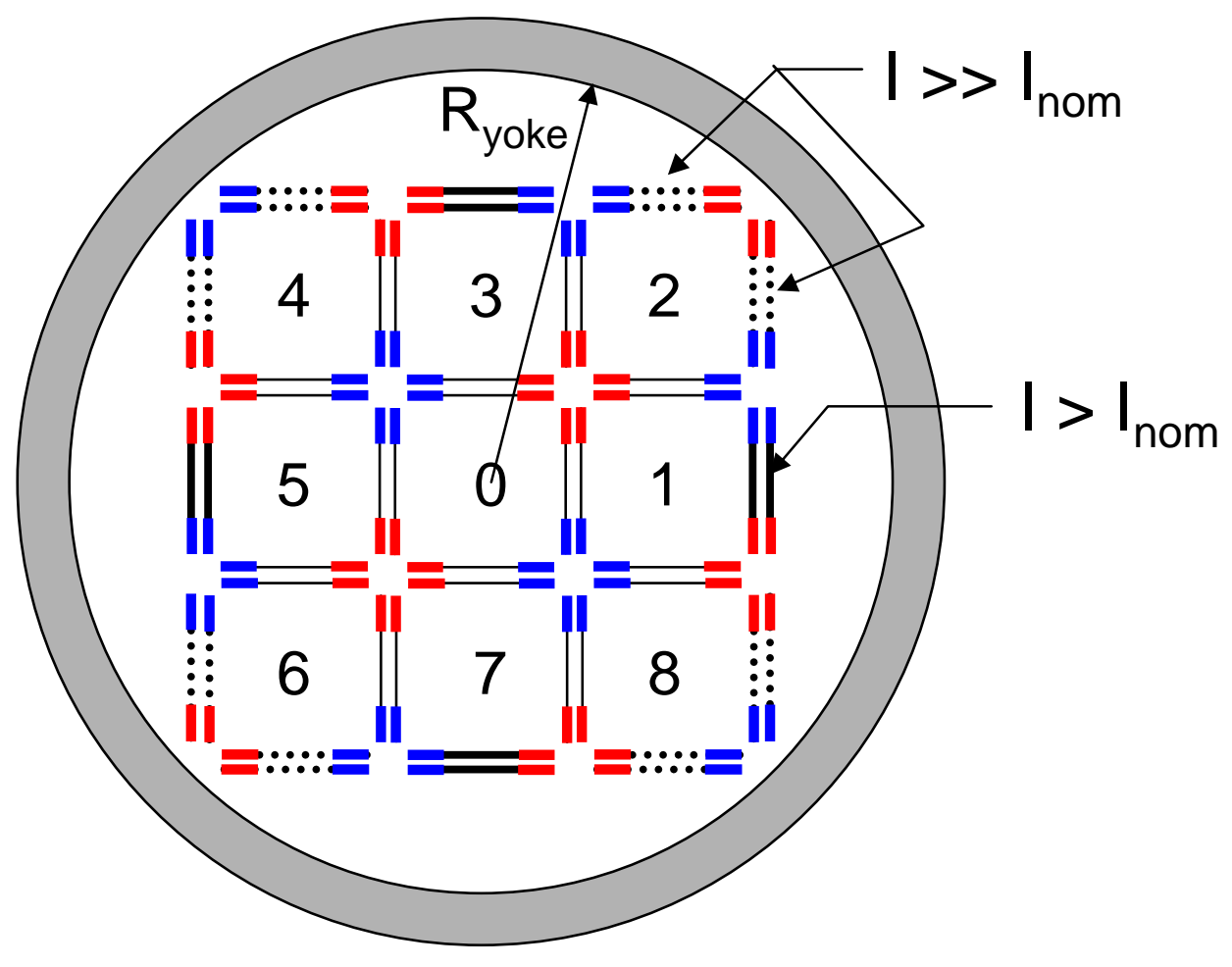

Try different currents in edge coils of corner cells and mid-cells

To gain more understanding of the required correction scheme, different currents are used in the mid-cells and corner cells of the array boundary. A significant increase of the outer corner coil currents should allow to correct the corner cell fields. 


\section{Effect of Different Shunt Currents in Mid and Corner Cells}

$150 \mathrm{~mm}$ Iron Yoke,

Shunt current scale factor ICM $=1.135$

Shunt current scale factor ICC $=1.350$

\begin{tabular}{|c|c|c|c|c|c|c|c|c|c|c|c|}
\hline & & \multicolumn{10}{|c|}{ Calculate MP Fields of Array } \\
\hline & & $\overline{\mathrm{AO}}$ & B0 & A1 & B1 & A5 & B5 & A9 & B9 & 13 & B13 \\
\hline \multirow[t]{2}{*}{ Center Cell } & $\begin{array}{l}\text { Norm. } \\
\text { Fields }\end{array}$ & $-6.125 \mathrm{E}-16$ & $-4.117 \mathrm{E}-16$ & \#\#\# & 1.492 & $\# \#$ & $-6.420 \mathrm{E}-05$ & \#\# & $-2.941 E-06$ & \#\# & 1.363E-05 \\
\hline & Units & $-6.125 E-12$ & $-4.117 \mathrm{E}-12$ & & & \#\# & $-6.420 \mathrm{E}-01$ & \#\# & $-2.941 E-02$ & \#\# & $1.363 E-01$ \\
\hline \multirow{3}{*}{$\begin{array}{l}\text { Middle Cell } \\
\quad \text { Cell } 1\end{array}$} & Norm. & & & & & & & & & & \\
\hline & Fields & $1.060 \mathrm{E}-04$ & $3.440 \mathrm{E}-16$ & \#\#\# & -1.440 & $\# \#$ & $8.588 \mathrm{E}-04$ & $\# \#$ & $-5.190 \mathrm{E}-06$ & $\# \#$ & $1.449 \mathrm{E}-05$ \\
\hline & Units & $1.060 \mathrm{E}+00$ & $3.440 \mathrm{E}-12$ & & & \#\# & $8.588 \mathrm{E}+00$ & \#\# & $-5.190 \mathrm{E}-02$ & \#\# & 1.449E-01 \\
\hline \multirow{3}{*}{$\begin{array}{l}\text { Corner Cell } \\
\text { Cell } 2\end{array}$} & & & & & & & & & & & \\
\hline & $\begin{array}{l}\text { Norm. } \\
\text { Fields }\end{array}$ & 2.514E-03 & $2.514 \mathrm{E}-03$ & \#\#\# & 1.535 & \#\# & 2.532E-03 & \#\# & $-9.401 \mathrm{E}-06$ & \#\# & 1.524E-05 \\
\hline & Units & $2.514 \mathrm{E}+01$ & $2.514 \mathrm{E}+01$ & & & \#\# & $2.532 \mathrm{E}+01$ & \#\# & $-9.401 \mathrm{E}-02$ & \#\# & $1.524 \mathrm{E}-01$ \\
\hline
\end{tabular}

Quadrupole variation: +-3\%

Dipole field in middle cells: $\sim 0$; $\quad$ Dipole field in corner cells: $2.5 \mathrm{e}-3$

$B_{5}$ in middle cell: $<9$ units; $\quad B_{5}$ in corner cells: 25 units

\section{Corner cells can be corrected !}




\section{Outer Correction Coils with Unequal Currents}

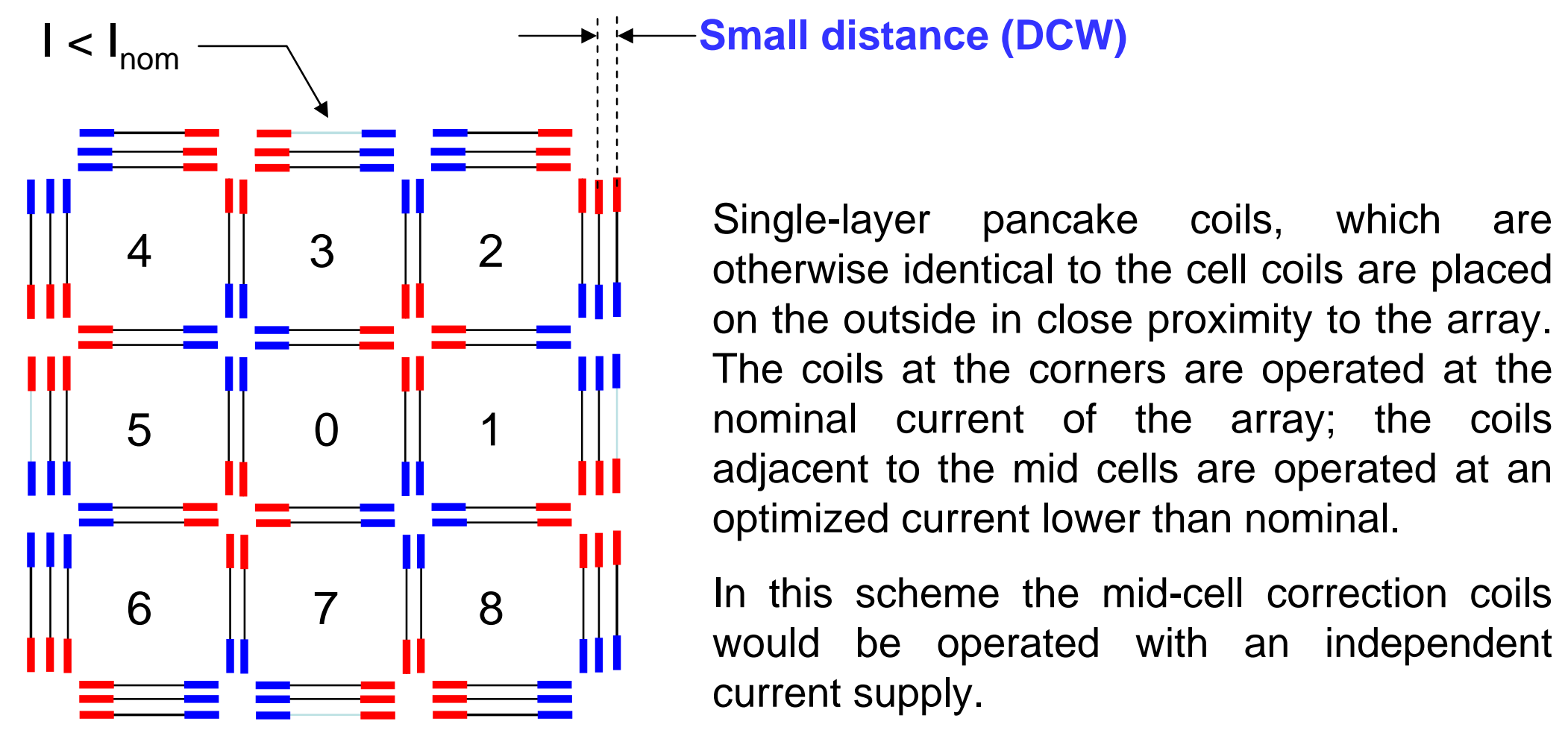

Place correction coils on the outside in close proximity to keep the array as small as possible. Single pancakes with same geometry as main cell coils and same current. 


\section{Outer Correction Coils with Unequal Currents}

Distance of correction coils:

Mid-cell correction current:

Corner cell correction current:
$10.05 \mathrm{~mm}$ (optimized)

$0.4^{*} I_{\text {nom }}$ (optimized)

Inom

\begin{tabular}{|c|c|c|c|c|c|c|c|c|c|c|c|}
\hline & & \multicolumn{10}{|c|}{ Calculate MP Fields of Array } \\
\hline & & AO & BO & A1 & B1 & A5 & B5 & A9 & B9 & A13 & B13 \\
\hline \multirow[t]{2}{*}{ Center Cell } & $\begin{array}{l}\text { Norm. } \\
\text { Fields }\end{array}$ & $-2.928 \mathrm{E}-16$ & $-2.658 E-16$ & \#\#\# & 1.575 & \#\#\# & $-6.559 \mathrm{E}-05$ & \#\#\# & $-4.587 \mathrm{E}-05$ & \#\#\# & 1.631E-04 \\
\hline & Units & $-2.928 \mathrm{E}-12$ & $-2.658 \mathrm{E}-12$ & & & \#\#\# & $-6.559 \mathrm{E}-01$ & \#\#\# & $-4.587 \mathrm{E}-01$ & \#\#\# & $1.631 \mathrm{E}+00$ \\
\hline \multirow{2}{*}{$\begin{array}{l}\text { Middle Cell } \\
\text { Cell } 1\end{array}$} & $\begin{array}{l}\text { Norm. } \\
\text { Fields }\end{array}$ & 1.094E-03 & $1.694 \mathrm{E}-16$ & \#\#\# & -1.571 & \#\#\# & 9.957E-04 & \#\#\# & -5.757E-05 & \#\#\# & $1.637 \mathrm{E}-04$ \\
\hline & Units & 1.094E+01 & 1.694E-12 & & & \#\#\# & $9.957 \mathrm{E}+00$ & \begin{tabular}{|l|l|}
$\# \# \#$ \\
\end{tabular} & $-5.757 \mathrm{E}-01$ & \#\#\# & $1.637 \mathrm{E}+00$ \\
\hline \multirow{2}{*}{$\begin{array}{l}\text { Corner Cell } \\
\quad \text { Cell } 2\end{array}$} & $\begin{array}{l}\text { Norm. } \\
\text { Fields }\end{array}$ & 4.178E-04 & 4.178E-04 & \#\#\# & 1.605 & \#\#\# & 3.967E-03 & \#\#\# & $-1.135 E-04$ & \#\#\# & 1.616E-04 \\
\hline & Units & $4.178 \mathrm{E}+00$ & $4.178 \mathrm{E}+00$ & & & \#\#\# & $3.967 \mathrm{E}+01$ & \begin{tabular}{|l|}
$\# \# \#$ \\
\end{tabular} & $-1.135 E+00$ & \#\#\# & $1.616 \mathrm{E}+00$ \\
\hline
\end{tabular}

Quadrupole variation: $<1 \%$

Dipole field in middle cells: $\sim 0$; $\quad$ Dipole field in corner cells: $\sim 0$

$\mathrm{B}_{5}$ in middle cell: 10 units; $\quad \mathrm{B}_{5}$ in corner cells: 40 units 


\section{Summary}

Two possible correction schemes have been developed:

\section{Scheme-1:}

(:) No correction coils. The total number of coils is the smallest possible.

(:) The resulting array is very small.

(2) Currents in all boundary coils are increased by about $17 \%$ with the help of a shunt power supply. Part of all of this could be done with iron poles in the middle of these coils, maybe eliminating the shunt currents.

$:$ Corner cells are not usable.

\section{Scheme-2:}

(:) Single-layer pancakes surround the array boundary.

(-) Array size is relatively small due to close proximity of correction coils.

(:) All coils have identical geometry (accept single and double layers).

(:) All cells in the array are usable.

(2) 50\% more cells than Scheme 1 for $3 \times 3$ array

: Mid-cell boundary correction coils need extra power supply. 


\section{Summary}

For arrays larger than $3 \times 3$ Scheme-1 is the more cost-effective approach.

For arrays with a small number of cells the comparison is as follows:

\section{Scheme-1:}

$3 \times 3$ array with correction scheme has 36 coils and 9 usable cells, i.e., 4 coils per usable cell.

\section{Scheme-2:}

$4 \times 4$ array has 40 coils with 12 usable cells, i.e., 3.33 coils per usable cell Same size as $3 \times 3$ array 


\section{Using an Iron Shield in a 3 x 3 Array (Pt. 2) \\ C. Goodzeit, M. Ball, R. Meinke}

\section{FOREWORD}

A preliminary study (TN-05-02-23-1) indicated that the use of an iron layer around the periphery of the $3 \times 3$ array may provide passive shielding to the array to:

1. Even out the quadrupole gradient in all the cells

2. Minimize the normal dipole components in the side cells

3. Minimize both the normal and skew dipole components in the corner cells

4. Reduce the external field to an acceptable level

A further study using AMPERES has investigated more of the effect of an iron shield on the fields in a 3 x 3 quadrupole array with respect to the above objectives. This was done by varying some of the geometric parameters of the iron shield shown in Figure 1.

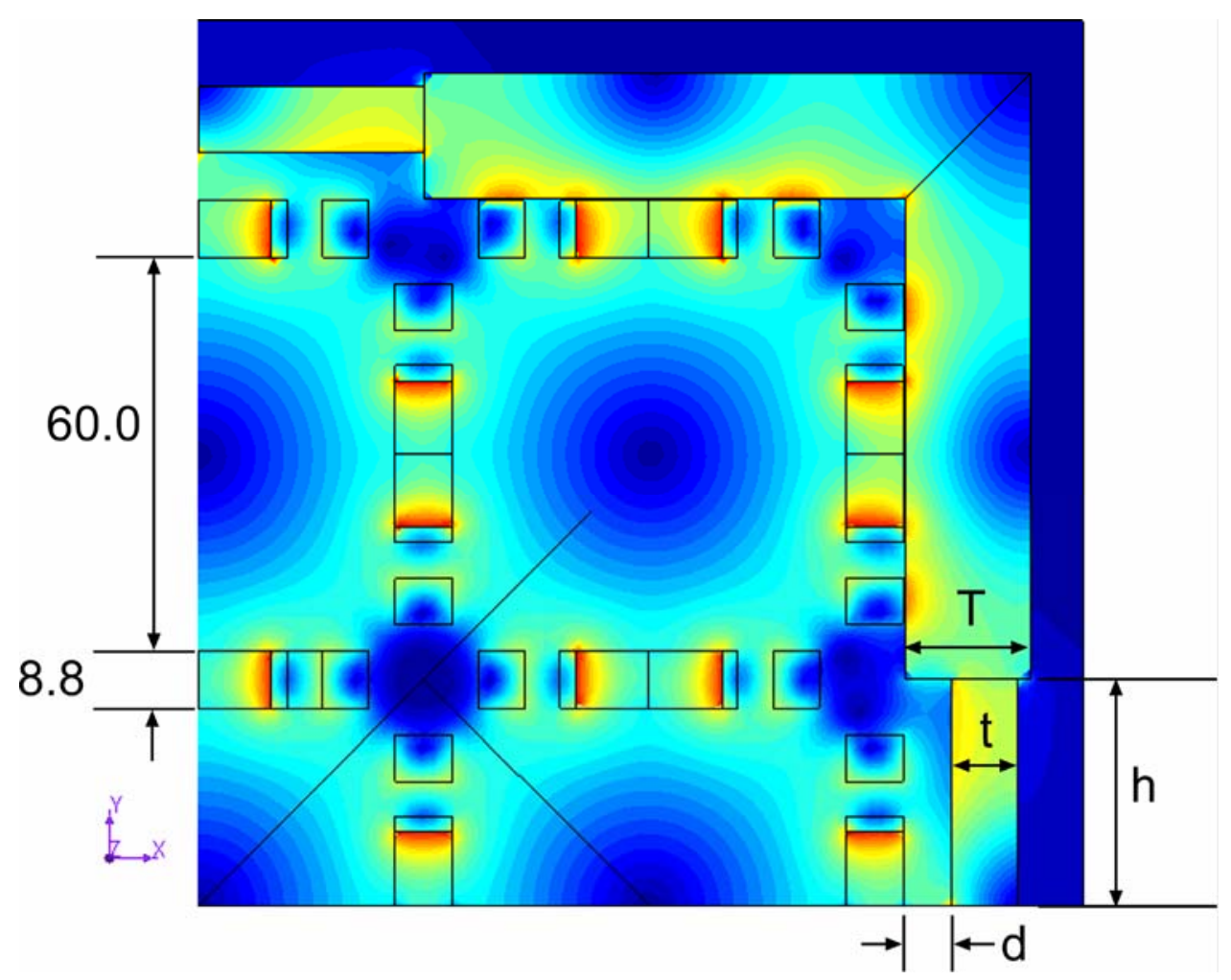

Figure 1. Example used in parametric study of an iron shield around a $3 \times 3$ array.

In this case a stepped shield was used with the parameters shown: $\mathrm{T}$ is the thickness of the shield on the periphery of the corner cell and $t$ is the thickness of the shield on the periphery of the side cell. The displacement of the side cell shield from the surface of the coil is given by $\mathrm{d}$. The dimension $\mathbf{h}$ for the side shield is fixed at $34.4 \mathrm{~mm}$ which is one half of the cell spacing.

\section{Discussion}

The coil blocks used in this array are an interim reference design with a single wedge as shown in Figure 2. The center cell dodecapole is optimized using R. Meinke's method [1] However, at present this method only works with coils that do not have an iron pole. 
Consequently, since iron poles have been included in all coils in this study, there is an offset in the dodecapole harmonic in the center cell. [Note: all multipole field values are determined at $\mathrm{r}=$ $20 \mathrm{~mm}$.]

\section{Reference Design Block Dimensions}

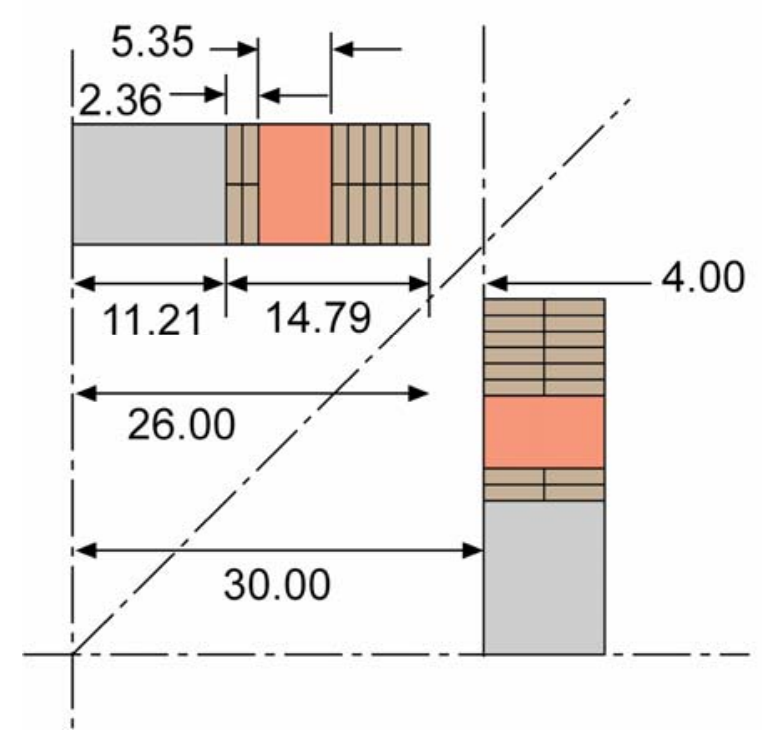

Figure 2. Interim reference design block dimensions (iron pole, 2 SC turns, wedge, 6 SC turns). The design requires additional optimization.

The following summarizes some of the results obtained from this study:

\subsection{Effect of varying the thickness of a uniform shield}

If the shield in Figure 1 is of uniform thickness ( $\mathrm{T}=\mathrm{t}$ and $\mathrm{d}=0$ ), the side cell and corner cell dipole components vary as shown in Figure 3. The sextupole component (B2) of the side cell is also shown. 


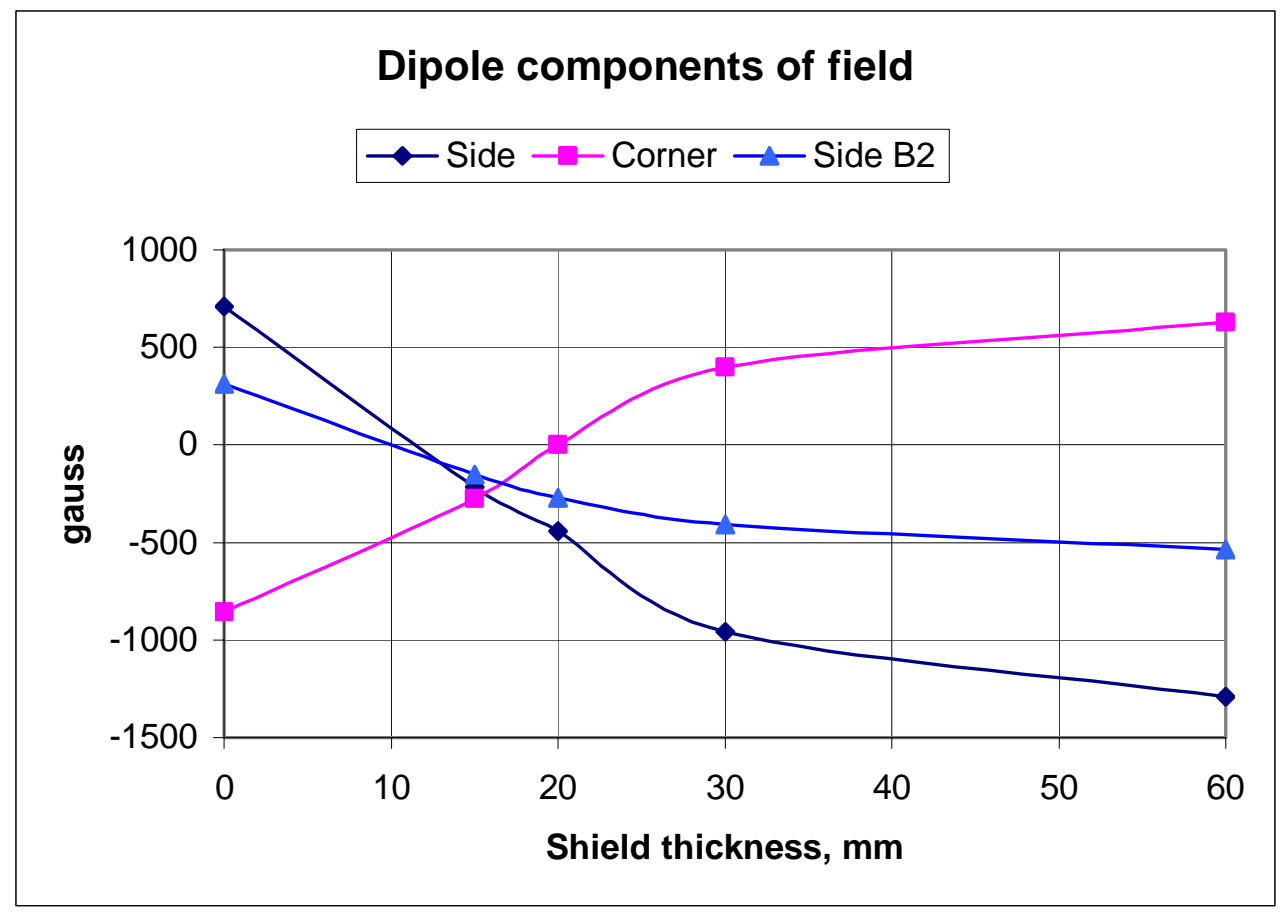

Figure 3. Effect of uniform shield thickness on dipole field components.

Thus, if the shield were $10 \mathrm{~mm}$ thick the side cell dipole and sextupole could be tuned out. However, the corner cell dipole requires a shield of $20 \mathrm{~mm}$ thickness to tune out its dipole component.

The question then arises: if the shield at the side cells were $10 \mathrm{~mm}$ thick and the shield at the corner cell was $20 \mathrm{~mm}$ thick (perhaps in a configuration as shown in Figure 1), can the dipole components in the side and corner cells be tuned out simultaneously?

In order to try to answer this question some additional studies were made using the basic configuration shown in Figure 1, a stepped shield in which the thickness at the periphery of the side cell is different than that for the corner cell.

The dipole components in the side cell can be tuned by varying the displacement of the portion of the shield on the periphery of the side cell. For example, if the displacement $d$ is varied for the case when $t=8$ and $T=13$, the dipole components vary as shown in Figure 4 . 


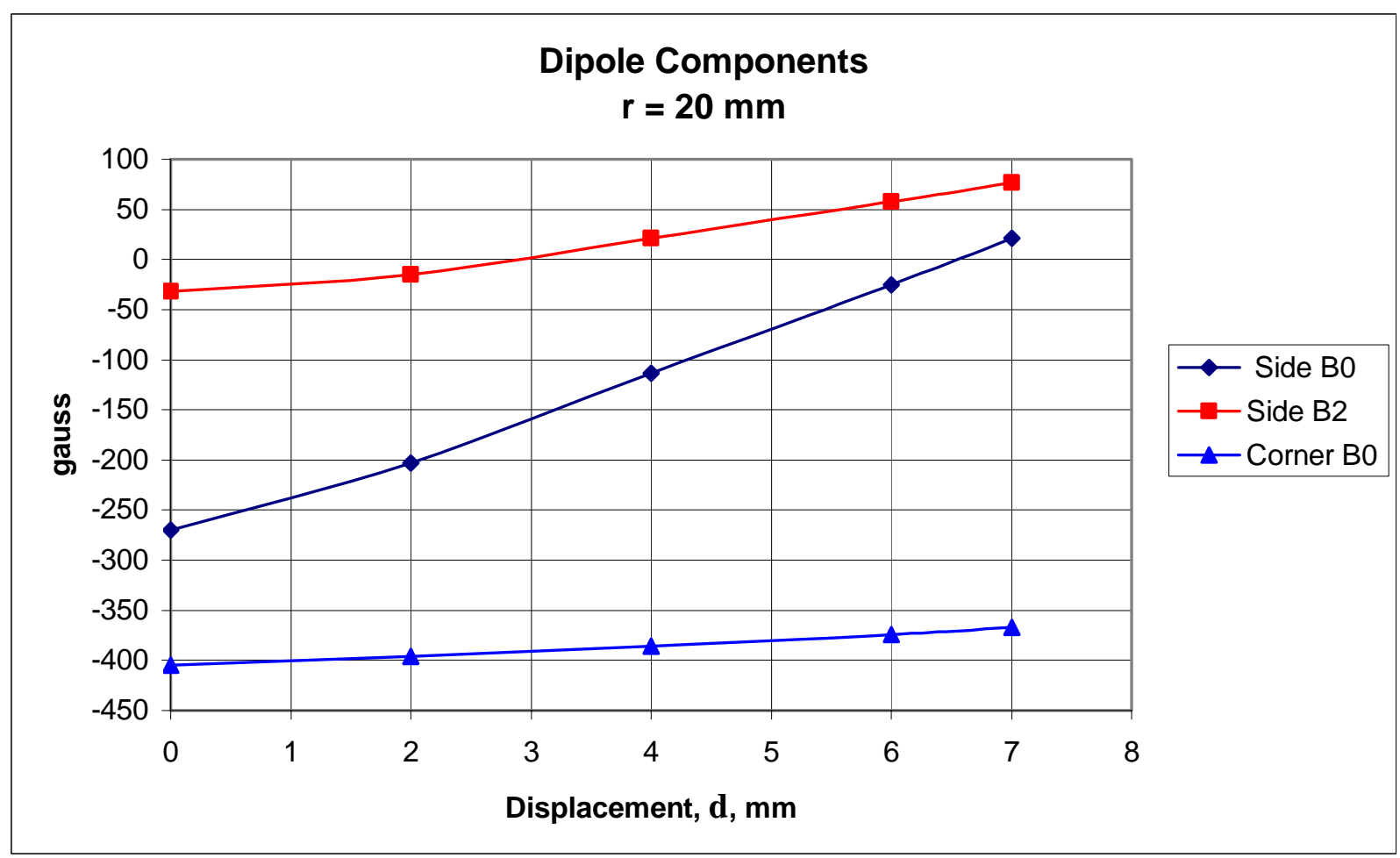

Figure 4. Effect of varying the displacement of the side cell shield (i.e. the shield portion of thickness $t$, adjacent to the side cell).

In this case the side cell dipole vanishes at $d=6.5 \mathrm{~mm}$. However, the sextupole is still present ( 65 gauss). Thus an optimization study could be done to determine if the sextupole can be offset by a feature in the shield geometry to make it vanish simultaneously with the dipole. This was done to some extent in the design of the SSC dipole by providing a notch in the pole of the yoke to offset the sextupole. It is also noted in Figure 4 that the dipole component in the corner cell is relatively unaffected by the displacement of the side cell shield. This indicates the possibility of being able to tune the corner dipole independently of the side cell dipole and thus achieve an optimization for the entire array.

\section{SUMMARY}

Some studies were done to determine if the dipole components of the corner and side cells of the $3 \times 3$ array could be tuned out by adjustments in the geometry of a rectangular iron shield surrounding the array as shown in Figure 1. Thus far the results show that this appears to be feasible. It is therefore expected that full optimization of the field uniformity in the side and corner cells can be obtained by shield geometry alone. If this turns out to be the case, then the array construction is simplified by the elimination of special edge termination coils that would be required on the periphery of the array to achieve the same result. However, additional studies are required in order to produce a fully optimized design that uses only the iron shield. Thus, this is one of the studies that would be performed in the next phase of this project.

1 R. Meinke, AML, “Field Uniformity Optimization of a 3x3 Quadrupole Array”, 2/28/05. 